Keywords: sealing, protecting, H-3X, C-14X, Slit Trench 9, special waste form

Retention: Permanent

\title{
Special Analysis for Slit Trench Disposal of the Reactor Process Heat Exchangers
}

\author{
L. L Hamm \\ L. B. Collard \\ S. E. Aleman \\ M. B. Gorensek \\ B. T. Butcher, Jr.
}

June 2012

Savannah River National Laboratory Savannah River Nuclear Solutions, LLC Aiken, SC 29808

Prepared for the U.S. Department of Energy under

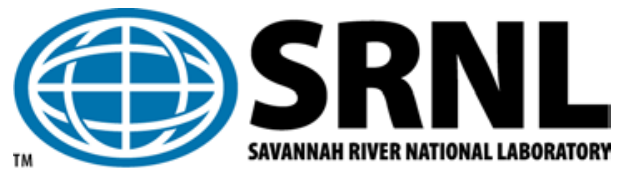
contract number DE-AC09-08SR22470. 
SRNL-STI-2012-00321

Revision 0

\section{DISCLAIMER}

This work was prepared under an agreement with and funded by the U.S. Government. Neither the U.S. Government or its employees, nor any of its contractors, subcontractors or their employees, makes any express or implied:

1. warranty or assumes any legal liability for the accuracy, completeness, or for the use or results of such use of any information, product, or process disclosed; or

2. representation that such use or results of such use would not infringe privately owned rights; or

3. endorsement or recommendation of any specifically identified commercial product, process, or service.

Any views and opinions of authors expressed in this work do not necessarily state or reflect those of the United States Government, or its contractors, or subcontractors.

Printed in the United States of America

Prepared for

U.S. Department of Energy 


\section{REVIEWS AND APPROVALS}

\section{AUTHORS:}

L.L. Hamm, Process Modeling \& Computational Chemistry

Date

L.B. Collard, Radiological Performance Assessment

Date

S.E. Aleman, Threat Assessments

Date

M.B. Gorensek, Process Modeling \& Computational Chemistry

Date

B.T. Butcher, Jr., Radiological Performance Assessment

Date

TECHNICAL REVIEW:

F.G. Smith, III, Process Modeling \& Computational Chemistry

Date

APPROVAL:

D.A. Crowley, Manager, Radiological Performance Assessment

Date

R.S. Aylward, Manager, Environmental Restoration Technology

Date

G.K. Humphries, Environmental Compliance

Date

M.G. Looper, Solid Waste Management Chief Engineer

Date

M.A. Kokovich, Solid Waste Facility Manager

Date 
SRNL-STI-2012-00321

Revision 0

\section{EXECUTIVE SUMMARY}

The Savannah River National Laboratory (SRNL), in response to a request from Solid Waste Management (SWM), conducted a Special Analysis (SA) to evaluate the performance of nineteen heat exchangers that are to be disposed in the E-Area low level waste facility Slit Trench \#9 (ST \#9). Although these nineteen heat exchangers were never decontaminated, the majority of the radionuclides in the heat exchanger inventory list were determined to be acceptable for burial because they are less than the "generic" waste form inventory limits given in the 2008 Performance Assessment (PA) (WSRC, 2008). However, as generic waste, the H-3 and C-14 inventories resulted in unacceptable sum-of-fractions (SOFs). Initial scoping analyses performed by SRNL indicated that if alterations were made to certain external nozzles to mitigate various potential leak paths, acceptable SOFs could be achieved through the use of a "Special" waste form. This SA provides the technical basis for this new "Special" waste form and provides the inventory limits for $\mathrm{H}-3$ and $\mathrm{C}-14$ for these nineteen heat exchangers such that the nineteen heat exchangers can be disposed in ST \#9. This "Special” waste form is limited to these nineteen heat exchangers in ST \#9 and applies for H-3 and C-14, which are designated as H-3X and C-14X, respectively.

The SA follows the same methodology used in the 2008 PA and the 2008 SA (Collard and Hamm, 2008) except for the modeling enhancements noted below. Infiltration rates above the heat exchangers are identical to those used in the 2008 PA; however, flow through the heat exchangers is unique. Because it is unknown exactly how sealed heat exchanger openings will perform and how surface and embedded contaminants will be released, multiple base cases or scenarios were established to investigate a set of performances. Each scenario consists of flow options (based on the performance of sealed openings) and a near-field release of contaminants (based on corrosion and diffusion performance). Two disposal configurations were analyzed where heat exchangers were assumed to be disposed four across and five lengthwise (the $4 \times 5$ configuration, with one empty) and three across and seven lengthwise (the 3x7 configuration, with two empty). A large range of conditions was considered. For example, peak well concentrations at the 100-m boundary for H-3 are shown in Figure ES-1 for a wide range of configurations (i.e. release mechanism and degree of sealing options). The maximum contaminant level (MCL) and a 10\% SOF goal for H-3 are also shown. The $10 \%$ goal was based on an estimated volume fraction that these nineteen heat exchangers would consume in ST \#9 and was solely used for scoping purposes to assess disposal feasibility and sealing requirements. Because various line breaks and poor sealing greatly exceeded that $10 \%$ goal, the determination was made that mitigating activities were needed, such as protection from line breaks and better sealing.

An initial set of scenarios was run to assess the requirements for sealing the heat exchanger openings and the need to ensure that the sealed heat exchangers stayed sealed during transit and disposal operations. After discovering that such mitigating activities were required, additional scenarios were run that included the mitigating activities. Scenarios deemed to have a very low probability of occurrence were excluded from consideration for calculating inventory limits (for example, those scenarios that assumed an instantaneous release of contaminants along with poor sealing). 


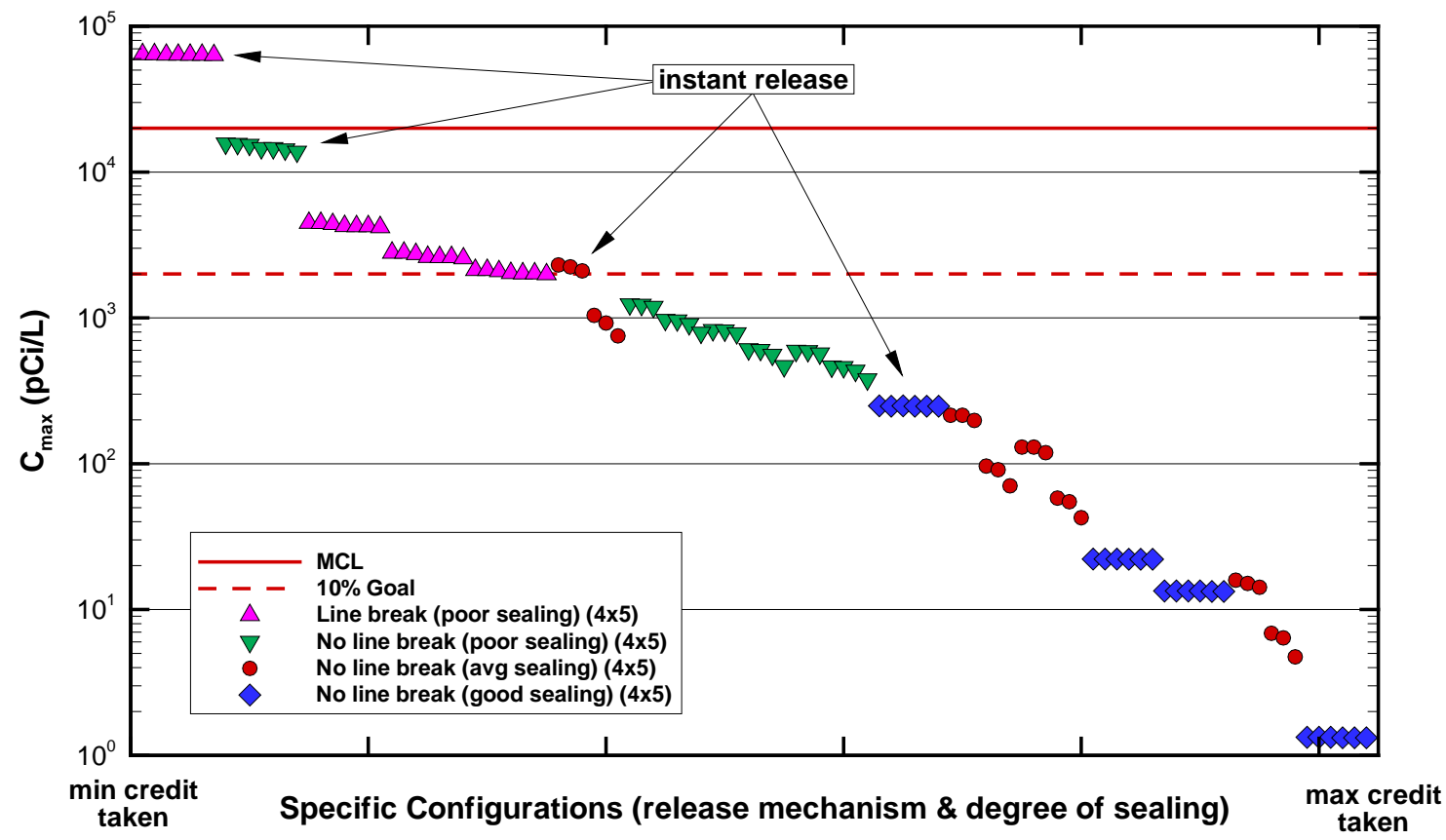

Figure ES-1 Summary of H-3 peak well concentrations in the aquifer for a broad range of release mechanisms and degree of sealing assumptions under the $4 \times 5$ configuration.

The SA used the most recent $K_{d}$ values for the C-14 analyses (Collard and Hamm, 2012) and the most recent Dose Conversion Factors (Collard and Hamm, 2012) for H-3 and C-14 which have been updated since the 2008 PA was issued. This SA took into account the location and the disposal timing of these heat exchangers. The disposal location is within a small area of the overall Slit Trench unit (about 6\% of the total) and is behind a line that is $200 \mathrm{ft}$ from the downgradient edge of ST \#9. The disposal timing is assumed to be after July 1, 2012 (because disposals cannot occur until this document is approved and mitigating activities are completed) which means that the disposal occurs after the first time period for the 2008 PA beta-gamma pathway (that time period is from December 1995 until December 2007), thus that pathway time period is not considered.

The SA was performed in the following manner:

1. Various vadose zone steady-state flow models were analyzed based on many potential pathway states (Chapter 3).

2. Transport through a nominal trench and vadose zone of a nominal one gram-mole of each parent radionuclide was calculated using the PORFLOW vadose zone model (Chapter 3). The vadose zone calculations considered both the case where all nineteen heat exchangers were non-crushable and the case where all nineteen heat exchangers were crushable. Vadose zone results for the two cases were also blended assuming five of the heat exchangers did not crush during dynamic compaction, but later collapsed accompanied by a cover that failed and subsided. The selection of five heat exchangers not crushing was based on the probabilities of collapse of multiple heat exchangers.

Vadose zone transport calculations produced contaminant fluxes to the water table for each radionuclide and each scenario evaluated. Those fluxes were scaled by the actual inventory of each parent to create sources for the PORFLOW aquifer transport model. 
3. The aquifer transport model (Chapter 4) was run and the maximum radionuclide concentrations at or beyond the 100-m point of assessment were saved as a function of time for subsequent dose and inventory limit calculations.

4. Well-concentration magnifiers (the inverse of the PA plume interaction factors) were calculated for ST \#9 (Chapter 5) following the 2008 PA approach, but eliminating nonparticipating disposal units. The disposal units considered as being capable of significantly interacting with ST \#9 were the Intermediate Level Vault (ILV) and the other disposal units in the SlitWest group (i.e. STs \#8 through \#13). The wellconcentration magnifier for $\mathrm{C}-14$ considered all of these disposal units. However, the well-concentration magnifier for H-3 excluded the ILV because the ILV significantly delays the release of all radionuclides; therefore, its plume overlap with ST \#9 is negligible.

5. For each groundwater pathway, doses and concentrations were calculated (Chapter 6) using the radionuclide concentrations obtained from the aquifer transport calculations and the well-concentration magnifiers. The "worst case" radionuclide concentration (the maximum value from any of the cases and scenarios analyzed at each time step) was used to make the dose and inventory limit calculations.

Table ES-1 provides new "Special” waste form groundwater pathway inventory limits for C-14X and $\mathrm{H}-3 \mathrm{X}$ in the heat exchangers. Inventory limits for generic C-14 and $\mathrm{H}-3$ in the West Slit Trenches are included for comparison. The lowest limit for generic C-14 is $1.9 \mathrm{E}-1 \mathrm{Ci}$, while for $\mathrm{C}-14 \mathrm{X}$ it is $2.7 \mathrm{E} 0$, an increase of more than 14 times. Because time windows are employed, at later times C-14X exhibits lower limits than those for generic C-14 because with its smaller $\mathrm{K}_{\mathrm{d}}$ the $\mathrm{C}-14$ moves much faster. The lowest limit for generic $\mathrm{H}-3$ is $3.6 \mathrm{E} 0 \mathrm{Ci}$, while for $\mathrm{H}-3 \mathrm{X}$ it is 1.7E3, an increase of almost 500 times. $\mathrm{H}-3 \mathrm{X}$ always exhibits limits larger than the generic $\mathrm{H}-3$ limits because they have the same $\mathrm{K}_{\mathrm{d}}$, so the heat exchanger always controls the limits by slowing down the release.

The heat exchanger special-waste-form inventories and their anticipated fraction of the inventory consumed for each pathway are presented in Table ES-2. No special waste form limits were calculated for the non-groundwater pathways because limits for generic waste are not challenged. 
Table ES-1. Inventory Limits (Ci) for Groundwater Pathways².

\begin{tabular}{|c|c|c|c|c|c|c|c|c|c|c|c|c|c|}
\hline & Beta & Beta & Beta & Alpha & Alpha & Alpha & Radium & Radium & Radium & Uranium & $\begin{array}{c}\text { All } \\
\text { Pathways }\end{array}$ & $\begin{array}{c}\text { All } \\
\text { Pathways }\end{array}$ & $\begin{array}{c}\text { All } \\
\text { Pathways }\end{array}$ \\
\hline Radionuclide & $\begin{array}{c}0 \text { to } \\
12 \\
\text { yr } \\
\end{array}$ & $\begin{array}{c}12 \text { to } \\
100 \\
\text { yr } \\
\end{array}$ & $\begin{array}{c}100 \text { to } \\
1130 \\
y r \\
\end{array}$ & $\begin{array}{c}0 \text { to } \\
1000 \text { yr }\end{array}$ & $\begin{array}{l}1000 \text { to } \\
1120 \mathrm{yr}\end{array}$ & $\begin{array}{l}1120 \text { to } \\
1130 \mathrm{yr}\end{array}$ & $\begin{array}{c}0 \text { to } \\
1000 \\
y r \\
\end{array}$ & $\begin{array}{c}1000 \text { to } \\
1120 \\
\text { yr } \\
\end{array}$ & $\begin{array}{c}1120 \text { to } \\
1130 \\
\text { yr } \\
\end{array}$ & $\begin{array}{c}0 \text { to } 1130 \\
\text { yr }\end{array}$ & $\begin{array}{c}130 \text { to } \\
200 \\
y r \\
\end{array}$ & $\begin{array}{c}200 \text { to } \\
1000 \\
\text { yr }\end{array}$ & $\begin{array}{c}1000 \text { to } \\
1130 \\
\text { yr } \\
\end{array}$ \\
\hline$C-14 X$ & --- & --- & $2.7 E+00$ & --- & --- & --- & --- & --- & --- & --- & 2.7E+00 & $5.7 E+00$ & $6.5 \mathrm{E}+00$ \\
\hline$H-3 X$ & --- & $1.7 \mathrm{E}+03$ & $1.0 \mathrm{E}+05$ & --- & --- & --- & --- & --- & --- & --- & $9.5 E+06$ & $9.6 \mathrm{E}+06$ & $1.2 \mathrm{E}+07$ \\
\hline $\begin{array}{c}\text { C-14 (West Slit } \\
\text { Trenches) }{ }^{1}\end{array}$ & $1.9 \mathrm{E}-01$ & $2.0 \mathrm{E}-01$ & $8.3 E+00$ & --- & --- & --- & --- & --- & --- & --- & $9.6 \mathrm{E}+00$ & $9.6 \mathrm{E}+00$ & $9.6 \mathrm{E}+00$ \\
\hline $\begin{array}{c}\text { H-3 (West Slit } \\
\text { Trenches) }\end{array}$ & $3.6 \mathrm{E}+00$ & $3.9 \mathrm{E}+00$ & $2.2 \mathrm{E}+04$ & --- & --- & --- & --- & --- & --- & --- & $3.5 E+06$ & $3.5 E+06$ & $3.5 E+06$ \\
\hline
\end{tabular}

${ }^{1}$ Generic limits from 2008 PA

${ }^{2}$ Limits reported as “----“ indicate that there is no limit or that the limit is greater than $1.0 \mathrm{E}+20$.

Table ES-2. Contribution to Sums-of-Fractions for Groundwater Pathways.

\begin{tabular}{|c|c|c|c|c|c|c|c|c|c|c|c|c|c|}
\hline \multirow[b]{2}{*}{ Radionuclide } & \multirow[b]{2}{*}{$\begin{array}{c}\text { Inventory }^{1} \\
\text { (Ci) }\end{array}$} & \multicolumn{2}{|c|}{ Beta } & \multicolumn{3}{|c|}{ Alpha } & \multicolumn{3}{|c|}{ Radium } & \multirow{2}{*}{$\begin{array}{c}\text { Uranium } \\
\begin{array}{c}\text { to } 1130 \\
\text { yr }\end{array}\end{array}$} & \multicolumn{3}{|c|}{ All Pathways } \\
\hline & & $\begin{array}{c}12 \text { to } \\
100 \\
y r\end{array}$ & $\begin{array}{c}100 \text { to } \\
1130 \\
\text { yr }\end{array}$ & $\begin{array}{c}0 \text { to } \\
1000 \\
y r\end{array}$ & $\begin{array}{c}1000 \\
\text { to } \\
1120 \\
\text { yr }\end{array}$ & $\begin{array}{c}1120 \\
\text { to } \\
1130 \\
\text { yr }\end{array}$ & $\begin{array}{c}0 \text { to } \\
1000 \\
y r\end{array}$ & $\begin{array}{c}1000 \\
\text { to } \\
1120 \\
\text { yr }\end{array}$ & $\begin{array}{c}1120 \\
\text { to } \\
1130 \\
\text { yr }\end{array}$ & & $\begin{array}{c}130 \text { to } \\
200 \\
y r\end{array}$ & $\begin{array}{c}200 \text { to } \\
1000 \\
y r\end{array}$ & $\begin{array}{c}1000 \text { to } \\
1130 \\
y r\end{array}$ \\
\hline$C-14 X$ & $8.62 \mathrm{E}-01$ & --- & 3.19E-01 & --- & --- & --- & --- & --- & -- & --- & 3.19E-01 & $1.51 \mathrm{E}-01$ & $1.33 \mathrm{E}-01$ \\
\hline$H-3 X$ & $1.85 \mathrm{E} 02$ & 1.09E-01 & $1.85 \mathrm{E}-03$ & --- & --- & --- & --- & --- & --- & --- & $1.95 \mathrm{E}-05$ & $1.93 \mathrm{E}-05$ & $1.54 \mathrm{E}-05$ \\
\hline Total & & $1.09 \mathrm{E}-01$ & 3.21E-01 & --- & --- & --- & --- & --- & --- & --- & 3.19E-01 & $1.51 \mathrm{E}-01$ & $1.33 \mathrm{E}-01$ \\
\hline
\end{tabular}

${ }^{1}$ Sum for 19 heat exchangers 


\section{TABLE OF CONTENTS}

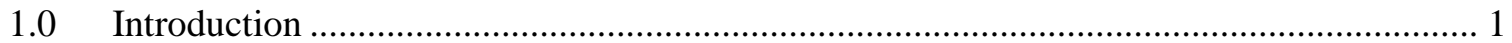

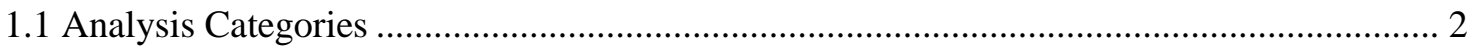

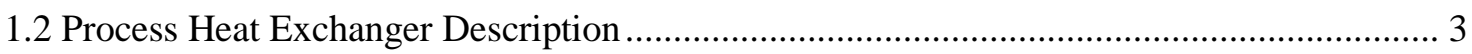

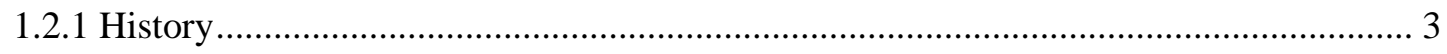

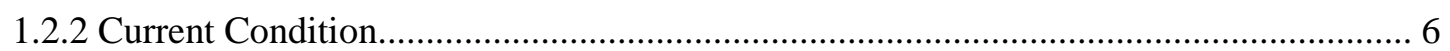

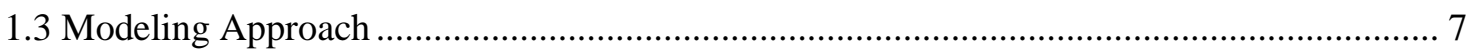

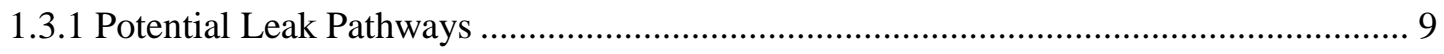

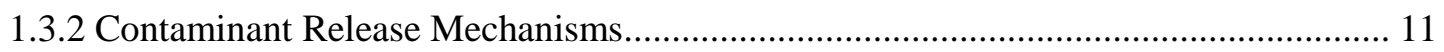

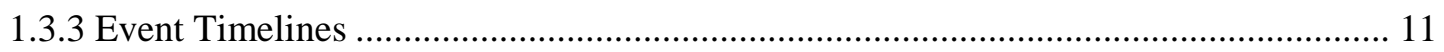

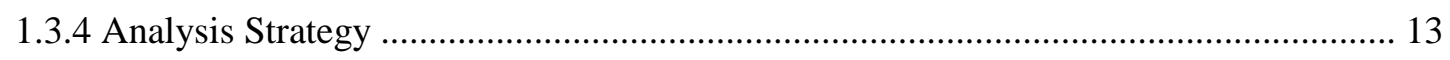

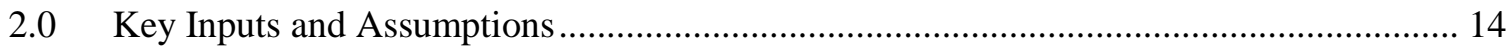

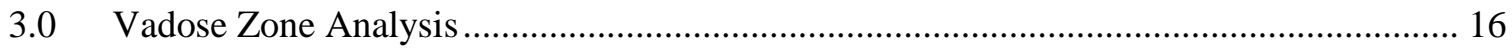

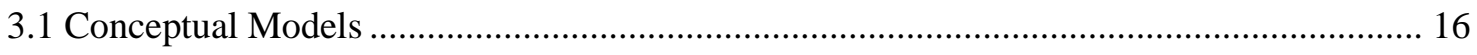

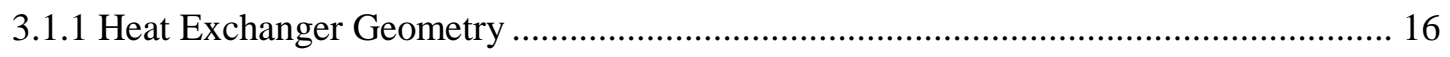

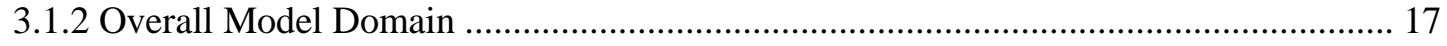

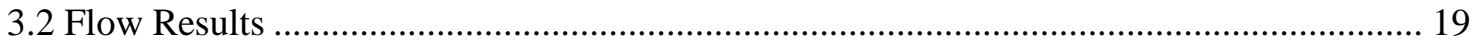

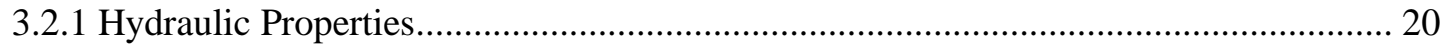

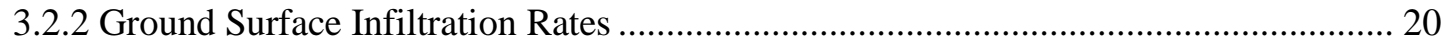

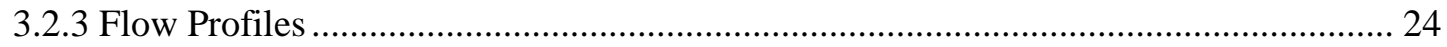

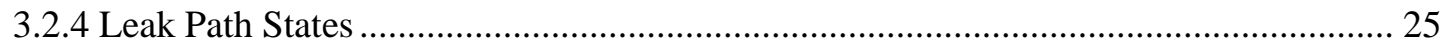

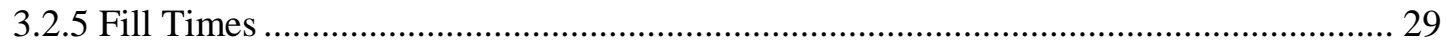

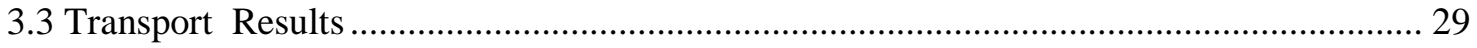

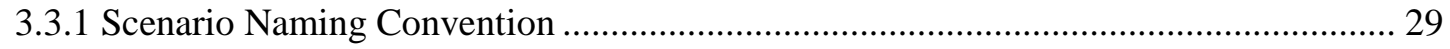

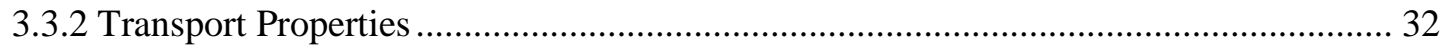

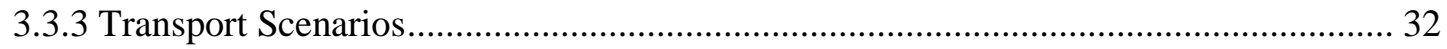

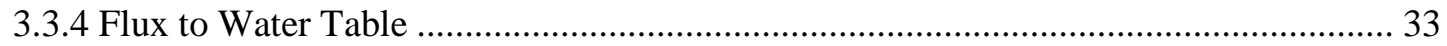

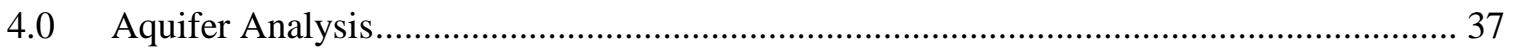

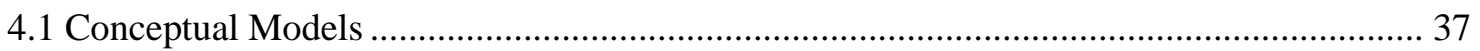

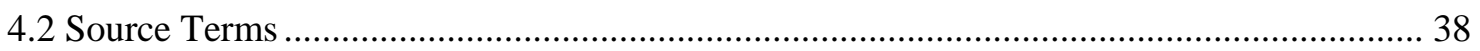

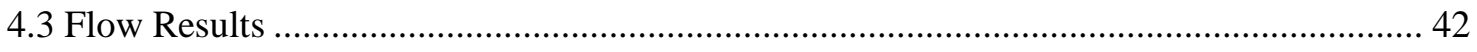

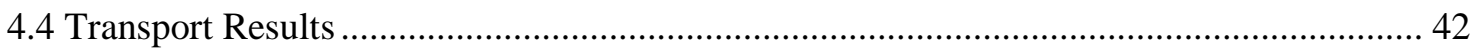

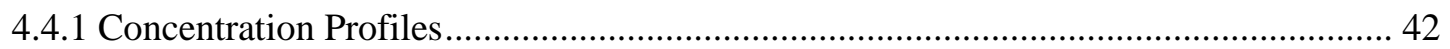


4.4.2 Concentration Histories for Concentration Profile Examples ..................................... 45

4.4.3 Concentration Histories over all Scenarios ................................................................. 46

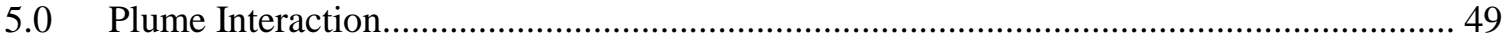

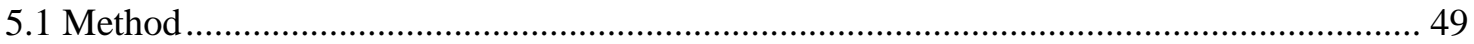

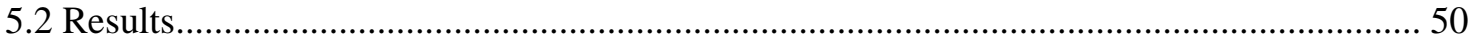

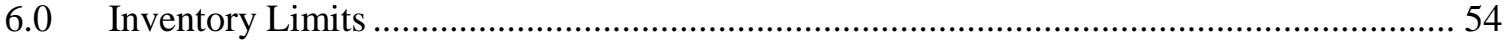

6.1 Groundwater Beta-Gamma Pathway Concentration Results ............................................. 54

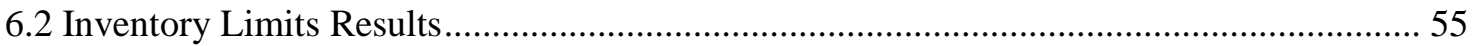

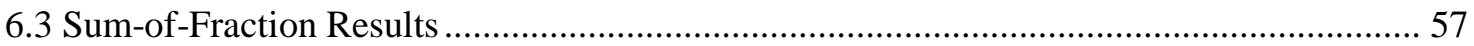

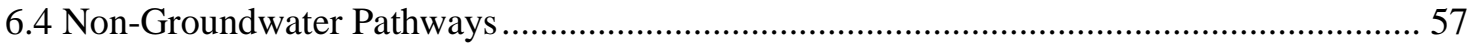

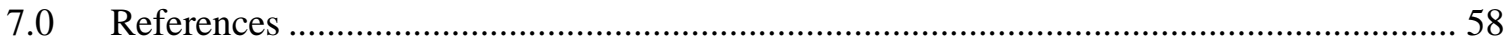

Appendix A. Heat Exchanger Diffusion Source Terms for H-3X and C-14X ....................... A-1

A.1 Diffusion Coefficients for Tritium in Type 304 Stainless Steel ...................................... A-1

Appendix B. Heat Exchanger Corrosion Source Term for H-3X and C-14X ........................ B-1

Appendix C. Sealing and protecting mitigation activities.................................................... C-1

Appendix D. Unreviewed Disposal Question Evaluation .................................................... D-1 


\section{LIST OF TABLES}

Table ES-1. Inventory Limits (Ci) for Groundwater Pathways....................................................

Table ES-2. Contribution to Sums-of-Fractions for Groundwater Pathways.............................ES-4

Table 1-1 Identifiers for a heat exchanger's potential leak paths (including its inlet and outlet connections along with its vent and drain ports).................................................................. 8

Table 1-2 Specific state of key components of heat exchangers based on survey performed in May 2012

Table 1-3 Event timeline (yr) employed in the 2D vadose zone transport simulations................. 12

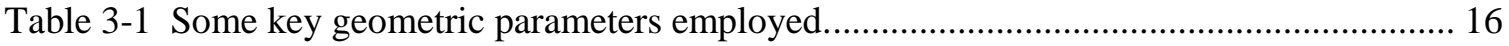

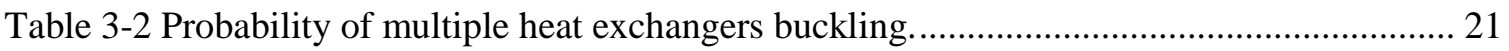

Table 3-3 Intact and subsided averaged surface infiltration rates............................................. 22

Table 3-4 Intact and subsided averaged source/sink strengths.................................................. 23

Table 3-5 Representative sample of the Flow Options ${ }^{\mathrm{a}}$ employed in vadose zone analyses........ 28

Table 3-6 Representative sample of the Flow Options ${ }^{\text {a }}$ employed beyond start of institutional

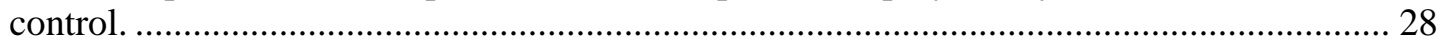

Table 3-7 Opening state identifiers and their descriptions...................................................... 30

Table 3-8 Leaker versus non-leaker heat exchanger type identifier.......................................... 30

Table 3-9 Leaker versus non-leaker heat exchanger type identifier........................................... 31

Table 3-10 Contaminant release mechanism identifier. ............................................................... 31

Table 3-11 Release option identifier indicating assumed oxide layer thickness, delay prior to vessel leakage, and minimum time required to fill vessel....................................................... 32

Table 3-12 $\mathrm{K}_{\mathrm{d}}$ values employed in transport analyses compared with prior values..................... 32

Table 3-13 Overall tally of scenarios considered in vadose zone transport analysis. .................. 33

Table 3-14 Example of vadose zone transport analysis scenarios ${ }^{\mathrm{a}}$ based on OptionT2_NL_NB3 and Optiont2_YL_NB3 (four scenarios for each would result when release models are added).

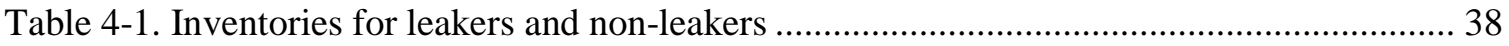

Table 4-2 Hypothetical example of heat exchanger assignment for the $4 x 5$ configuration ......... 41

Table 4-3 Example aquifer source cell inventories for C-14 Case 01 in $4 \times 5$ configuration ......... 42

Table 5-1. Plume interaction inventory source magnitudes (g-mol) and the concentration

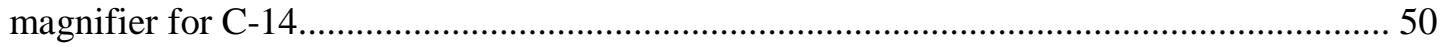


Table 5-2. Plume interaction inventory source magnitudes (g-mol) and the concentration magnifier for $\mathrm{H}-3$.

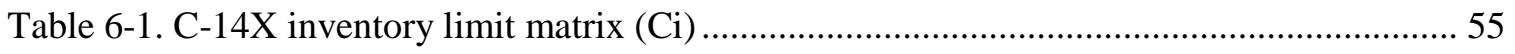

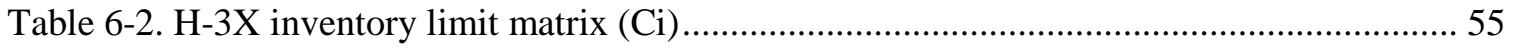

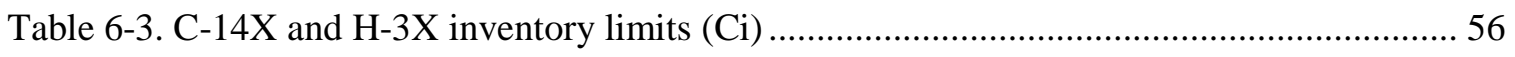

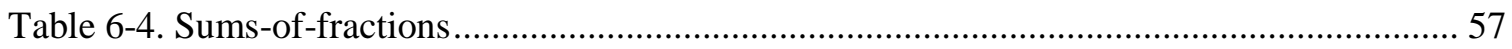

Table A-1 Diffusion coefficients for tritium in Type 304 stainless steel at temperatures needed

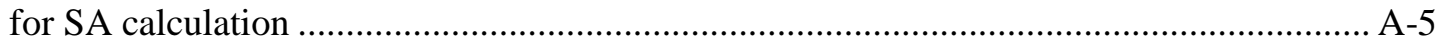

Table B-1. Best Estimate and Conservative Estimate Corrosion Scenarios............................... B-2

\section{LIST OF FIGURES}

Figure ES-1 Summary of H-3 peak well concentrations in the aquifer for a broad range of release mechanisms and degree of sealing assumptions under the $4 \times 5$ configuration. ES-2

Figure 1-1 Aerial view of Slit Trench 9 and its neighbors where the expected burial location of the nineteen Process Heat Exchangers is highlighted along with one of the two burial configurations modeled (i.e. 4x5 layout). .......................................................................... 3

Figure 1-2. Replacement Process Heat Exchanger being lowered into position............................ 4

Figure 1-3. Process Heat Exchanger on the concrete pad outside Building 690-N........................ 5

Figure 1-4. Engineering drawing of a Process Heat Exchanger.................................................. 6

Figure 1-5 Close-up view of the "Conceptual Model” of a Process Heat Exchanger showing the various key internal components and potential leak paths........................................................ 8

Figure 3-1 Close-up view of heat exchanger "Special” waste form model highlighting region

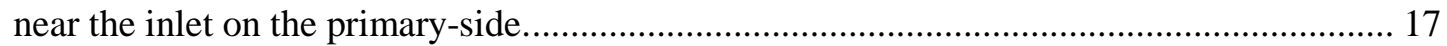

Figure 3-2 Estimated depth of the UVZ clayey region in the vicinity of ST \#9. ......................... 18

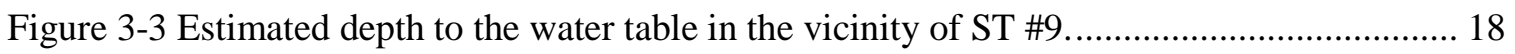

Figure 3-4 Overall layout of 2D vadose zone model showing key geometric elements. .............. 19

Figure 3-5 No Interim Cover condition showing streamlines around a heat exchanger that is in a fully sealed hydraulic state with 5-yr time markers.

Figure 3-6 No Interim Cover condition showing streamlines around a heat exchanger that is in a fully sealed hydraulic state with 5-yr groundwater flow time markers.................................. 24

Figure 3-7 Leaker type of heat exchanger under No Interim Cover conditions showing streamlines around the heat exchanger that is in a fully opened hydraulic state..................... 25 
Figure 3-8 Diagram illustrating the method employed to simulate the effective saturated hydraulic conductivity of a leak path.

Figure 3-9 Estimated minimum timing required to fill a heat exchanger versus the various Flow Options considered.

Figure 3-10 H-3 fractional flux to the water table for OptionT2_NL_NB3 and OptionT2_YL_NB3 specific transport scenarios (varying release model options) showing the intact results. 34

Figure 3-11 H-3 fractional flux to the water table for OptionT2 and release option DC_CE specific transport scenarios (varying the leakage set option) showing the intact results....... 35

Figure 3-12 H-3 fractional flux to the water table for OptionT3ab_YL_NB2 and each release mode specific transport scenarios (varying release model options) showing the intact results.

Figure 3-13 C-14 fractional flux to the water table for a specific transport scenario showing the intact, subsided (blended) results. Both leaker and non-leaker heat exchangers shown....... 36

Figure 4-1. Aerial footprint of Slit West Group and ILV with 3D streamtraces .......................... 37

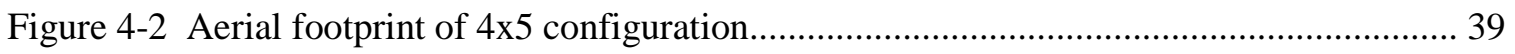

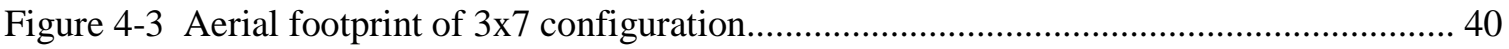

Figure 4-4. Aquifer concentration contours for H-3 on its key horizontal plane for Case01 near its time of peak maximum well concentration for the $4 \times 5$ configuration for scenario T3ab_YL_NB2_II

Figure 4-5. Aquifer concentration contours for C-14 on its key horizontal plane for Case01n11 near its time of peak maximum well concentration for the $4 \times 5$ configuration for scenario T3ab_YL_NB2_II.

Figure 4-6. Concentration histories (including the well-concentration magnifier) for H-3 for Case01 and the 4x5 configuration for scenario T3ab_YL_NB2_II and related scenarios..... 46

Figure 4-7. Concentration histories (including the well-concentration magnifier) for C-14 for Case01n11 and the 4x5 configuration for scenario T3ab_YL_NB2_II and related scenarios46

Figure 4-8. Summary of H-3 peak maximum well (Case01) concentrations in the aquifer for all scenarios in the $4 \times 5$ configuration.

Figure 4-9. Summary of C-14 peak maximum well (Case01 and Case01n11) concentrations in the aquifer for all scenarios in the $4 x 5$ configuration............................................................. 47

Figure 5-1. Plot of H-3 release from a Slit Trench vs. from the ILV ........................................ 50

Figure 5-2. Plume interaction for peak horizontal plane with ILV used to compute plume

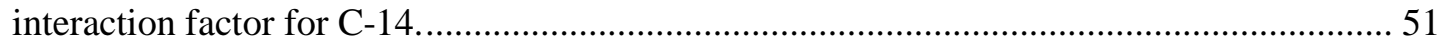

Figure 5-3. Plume interaction for peak horizontal plane without ILV used to compute plume interaction factor for $\mathrm{H}-3$. 52 
Figure 6-1. Selection of $\mathrm{H}-3$ scenarios (Case01) in the $4 \times 5$ configuration for limits calculations. 54

Figure 6-2. Comparison of PA well concentration for C-14 with a sample C-14X scenario....... 56

Figure A-1 Initial tritium concentration profile in Type 304 stainless steel and Zircaloy-2 (Elleman and Verghese, 1974).

Figure A-2 Tritium distributions after annealing in Type 304 stainless steel, Zircaloy-2, and niobium measured by Elleman and Verghese (1974).

Figure A-3 Surface layer and bulk diffusion coefficients for Type 304 stainless steel, niobium, and Zircaloy-2 measured by Elleman and Verghese (1974). .

Figure A-4 Comparison between Elleman and Verghese (1974) data (digitized) and Abraham et al. (1976) formulae for tritium diffusion coefficients in Type 304 stainless steel. .............. A-4

Figure A-5 Predicted tritium inventory in HX walls over time based on diffusion and decay. . A-6

Figure A-6 Predicted tritium fluxes from HX tube bundle and headers as functions of time for the first $200 \mathrm{yr}$ following burial...................................................................................... A-7

Figure B-1 H-3X Bundle Source Term Flux for Various Scenarios ………............................ B-3

Figure B-2 H-3X Header Source Term Flux for Various Scenarios …...................................... B-4

Figure B-3 C-14X Bundle Source Term Flux for Various Scenarios ……….......................... B-4

Figure B-4 C-14X Header Source Term Flux for Various Scenarios ……................................. B-5 


\section{LIST OF ACRONYMS}

$\begin{array}{ll}\text { ACP } & \text { Area Completion Projects } \\ \text { BE } & \text { Best Estimate } \\ \text { CDP } & \text { Cellulose Degradation Products } \\ \text { CE } & \text { Conservative Estimate } \\ \text { DOE } & \text { (U.S.) Department of Energy } \\ \text { EPA } & \text { (U.S.) Environmental Protection Agency } \\ \text { ERDA } & \text { (U.S.) Energy Research and Development Agency } \\ \text { ET } & \text { Engineered Trench } \\ \text { HWCTR } & \text { Heavy Water Component Test Reactor } \\ \text { HX } & \text { Heat Exchanger } \\ \text { ILV } & \text { Intermediate Level Vault } \\ \text { LVZ } & \text { Lower Vadose Zone } \\ \text { MCL } & \text { Maximum Contaminant Level } \\ \text { NR } & \text { Naval Reactor } \\ \text { PA } & \text { Performance Assessment } \\ \text { SA } & \text { Special Analysis } \\ \text { SOF } & \text { Sum-of-Fractions } \\ \text { SRNL } & \text { Savannah River National Laboratory } \\ \text { SRS } & \text { Savannah River Site } \\ \text { ST } & \text { Slit Trench } \\ \text { SWM } & \text { Solid Waste Management } \\ \text { UDQ } & \text { Unreviewed Disposal Question } \\ \text { UVZ } & \text { Upper Vadose Zone } \\ \text { WITS } & \text { Waste Information Tracking System } \\ & \end{array}$




\subsection{Introduction}

At the request of Solid Waste Management (SWM), this Special Analysis (SA) develops special waste form inventory limits for $\mathrm{H}-3$ and $\mathrm{C}-14$ in nineteen process heat exchangers that were not decontaminated and that are scheduled for disposal in Slit Trench 9 (ST \#9). For these two radionuclides, their special waste form identifiers are $\mathrm{H}-3 \mathrm{X}$ and $\mathrm{C}-14 \mathrm{X}$. A copy of the Unreviewed Disposal Question (UDQ) Screening that this SA is based on is attached as Appendix D.

The overall analysis approach in this SA is consistent with the approaches utilized in prior analyses. For example, many of the analysis steps performed for a "Generic" waste form still apply for this "Special” waste form. However, due to the unique and key aspects for these nineteen heat exchangers, special analysis steps were employed. Some of the more important analysis differences are:

- A finite release rate for H-3 was computed based on surface corrosion rates and embedded metal diffusion rates. The rates of corrosion for 304L stainless steel in contact with moist air and groundwater were explicitly considered. Process heat exchanger inventories were partitioned to the surface oxide layer and the embedded metal consistent with Area Completion Projects (ACP) inventory estimates (Walliser, 2012).

- A finite release rate for C-14 was computed based on surface corrosion rates. C-14 was assumed to be deposited within a thin surface oxide layer along the internal heat exchanger surfaces on the primary side. No embedded metal diffusion rates were considered for C-14.

- Hydraulic resistances to groundwater movement through the heat exchangers were explicitly considered by employing a geometric model of a heat exchanger that emulates the metal walls and void spaces.

- Line sinks were placed above and sources were placed below the 2D hydraulic model of the process heat exchanger to simulate groundwater flow around the sides of the heat exchanger. Otherwise, there would only be lateral flow across the top of the heat exchanger which is not representative of the actual 3D flow field.

- Leakage through various potential leak pathways was addressed explicitly within the geometry by analyzing a range of hydraulic states where varying degrees of hydraulic conductivity were employed.

- The degradation of vessel hydraulic integrity after disposal was addressed by analyzing various transport scenarios where the hydraulic state of a heat exchanger changed from a sealed state towards states of increasing leakage.

- Two approximately worst possible (yet credible) disposal configurations were considered based on the type of heat exchangers, inventories, and the imposed 200-ft distance from the ST \#9 down-gradient edge boundary constraint.

- The inventory limits and SOF contributions are based on a large set of scenarios where disposal configuration, release mechanisms, hydraulic states, and event timing were considered. This approach provides flexibility in the disposal process and confidence that exposures at the 100-meter boundary will remain within acceptable levels due to the disposal of these nineteen heat exchangers.

- A structural failure of five of the nineteen process heat exchangers (based on a probability analysis) with the associated subsidence of the soil is assumed for one case of the C-14 aquifer transport analyses; the other case is that no structural failures occur.

The inventory limits computed provide a high level of confidence that no single assumption with regard to disposal location, release mechanism, or degree of leakage will result in an exposure 
greater than the computed peak value. Some conservative assumptions are embedded in the inventory limits provided. For example, for those scenarios analyzed where a drain line break is assumed to occur before or during the burial process, the line break event is also assumed to occur in all nineteen heat exchangers. Addressing the entire range of potential leak path states on an individual heat exchanger basis was considered to be unnecessary, as well as computationally impractical.

An aerial view of the ST \#9 footprint and its nearest neighbors is shown in Figure 1-1. The six Slit Trenches, STs \#8 through \#13, constitute the West set of Slit Trenches per the 2008 PA. This region also includes the Intermediate Level Vault (ILV) and the 643-26E Naval Reactor Components Disposal Area (shown in Figure 1-1 as the NR pad). Just to the east of the West set of Slit Trenches resides the Center set of Slit Trenches where ST \#1 can be partially seen in Figure 1-1. The expected overall footprint where the nineteen heat exchangers are to be disposed is highlighted by a rectangular box (dashed magenta lines) with one of the two potential worst case disposal configurations (i.e. 4x5 layout) considered in this SA. The general direction of the local groundwater flow is also provided.

In establishing the two potentially worst case burial configurations (i.e. $4 \times 5$ and $3 \times 7$ layouts) it was assumed that the nineteen heat exchangers will not be closer than $200 \mathrm{ft}$ from the closest footprint edge to the 100-meter boundary. The blue line shown along one edge of the dashed magenta box in Figure 1-1 represents that 200-ft constraint. Chapter 4 contains additional discussion on these burial configurations.

The remainder of this chapter provides an overview of the analysis approach taken where the various aspects highlighted above are implemented. The key input and assumptions being made for this SA are discussed in Chapter 2. Details for the vadose zone, the aquifer, and plume interaction modeling and inventory limit calculations are addressed in Chapters 3, 4, 5, and 6, respectively, and several supporting appendices.

\subsection{Analysis Categories}

Analyses to satisfy DOE Order 435.1 (DOE 1999) included the following categories:

- Groundwater pathways

- Gross alpha

- Beta-gamma

- Radium

- Uranium

- Non-groundwater pathways

- Air

- Radon

- Inadvertent intruder, resident and post-drilling

- All-Pathways

Because it was assumed in the 2008 PA that air doses have no significant impact on the all-pathways analysis, the all-pathways reduced to a groundwater all-pathways. As was done in the 2008 PA and 2008 SA, the groundwater pathways were combined with the groundwater all-pathways analysis in this SA. Thus, only two categories were addressed within this report: (1) groundwater pathways and (2) non-groundwater pathways. 


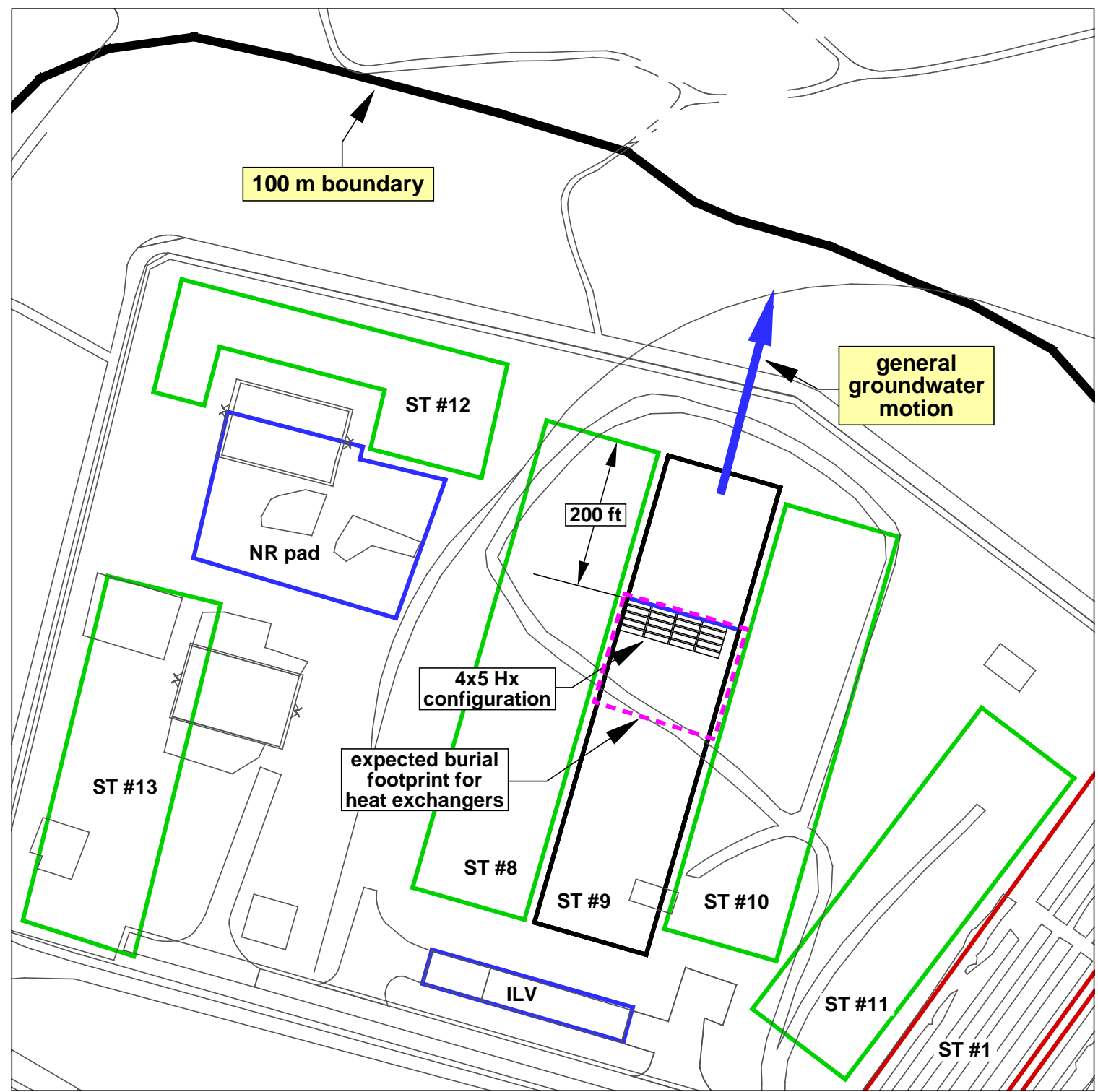

Figure 1-1 Aerial view of Slit Trench 9 and its neighbors where the expected burial location of the nineteen Process Heat Exchangers is highlighted along with one of the two burial configurations modeled (i.e. 4x5 layout).

\subsection{Process Heat Exchanger Description}

\subsubsection{History}

The process heat exchangers (HXs) that are the subject of this analysis were used to cool the heavy water moderator in the five production reactors at the Savannah River Site (SRS) beginning in the 1950s and continuing until all reactors were shut-down in the 1990s. Each reactor had six primary cooling loops, with two exchangers connected in parallel per loop, for a total of twelve HXs per reactor. Over time, HXs would fail and have to be replaced by spare units. (Figure 1-2 shows a spare HX being lowered into position through an access opening at an SRS Reactor.) Failed units would be removed from service, vacuum-dried to recover any remaining heavy water, flushed, and decontaminated. The heads would then be removed for inspection and a determination made as to whether repair was feasible. Most were repaired and held as spares. Those deemed to be beyond repair were stored at the Process Heat Exchanger 
Repair Facility (Building 690-N, also known as the Ford Building) for salvage or disposal. This facility remained active into the 1980s. Heat exchangers removed from service after the repair facility became inactive were stored there without drying or decontamination.

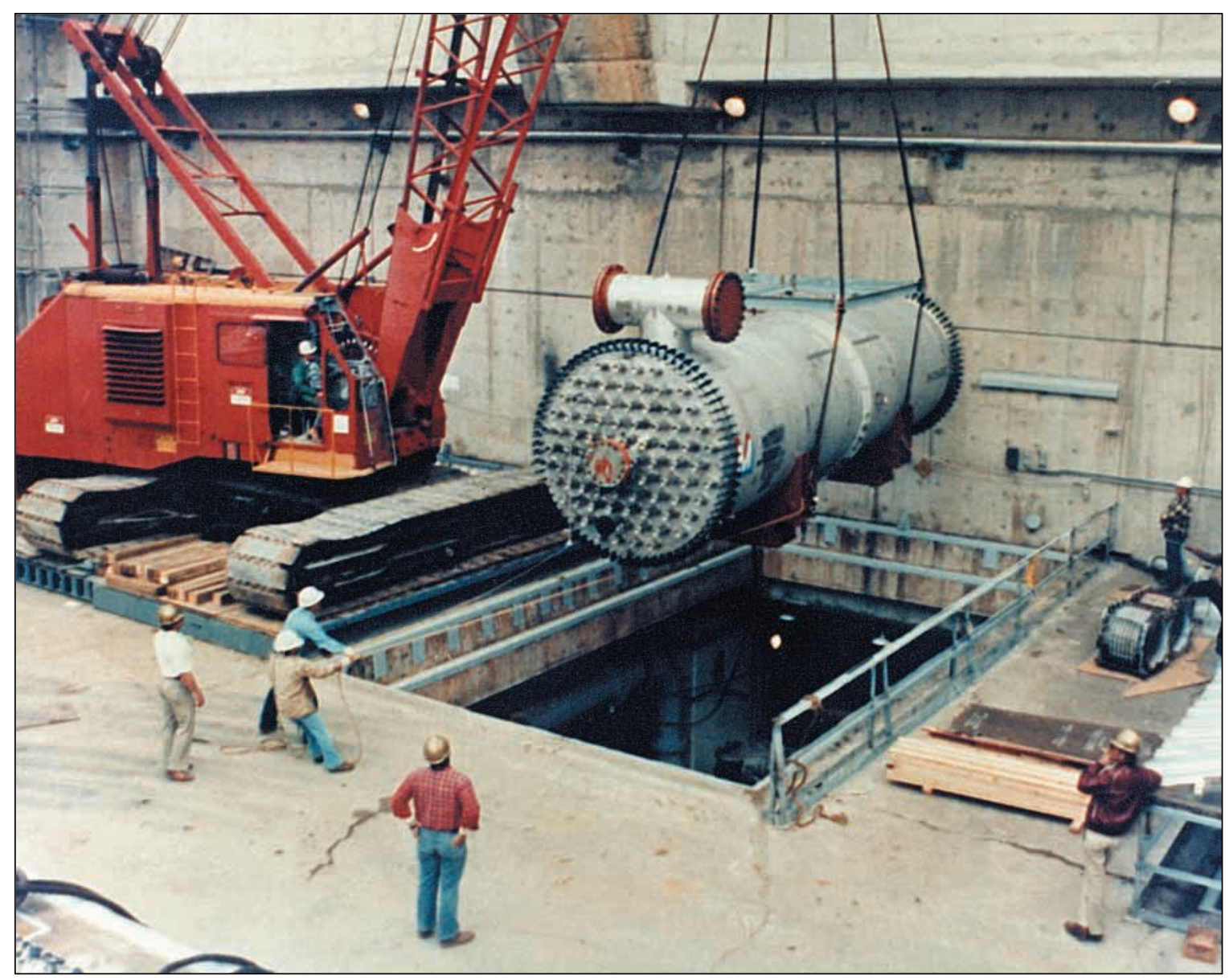

Figure 1-2. Replacement Process Heat Exchanger being lowered into position.

Ultimately, of the 94 HXs that were known to be at SRS in 1993 (Ketcham, 1993), 49 remained in storage at the closed repair facility as of January, 2012. Most had been decontaminated, but 19 were found to have residual contamination high enough to require an SA before they could be disposed as solid waste in E-Area. Figure 1-3 is a photograph of one of the contaminated HXs on the concrete pad outside Building 690-N taken January 25, 2012. 


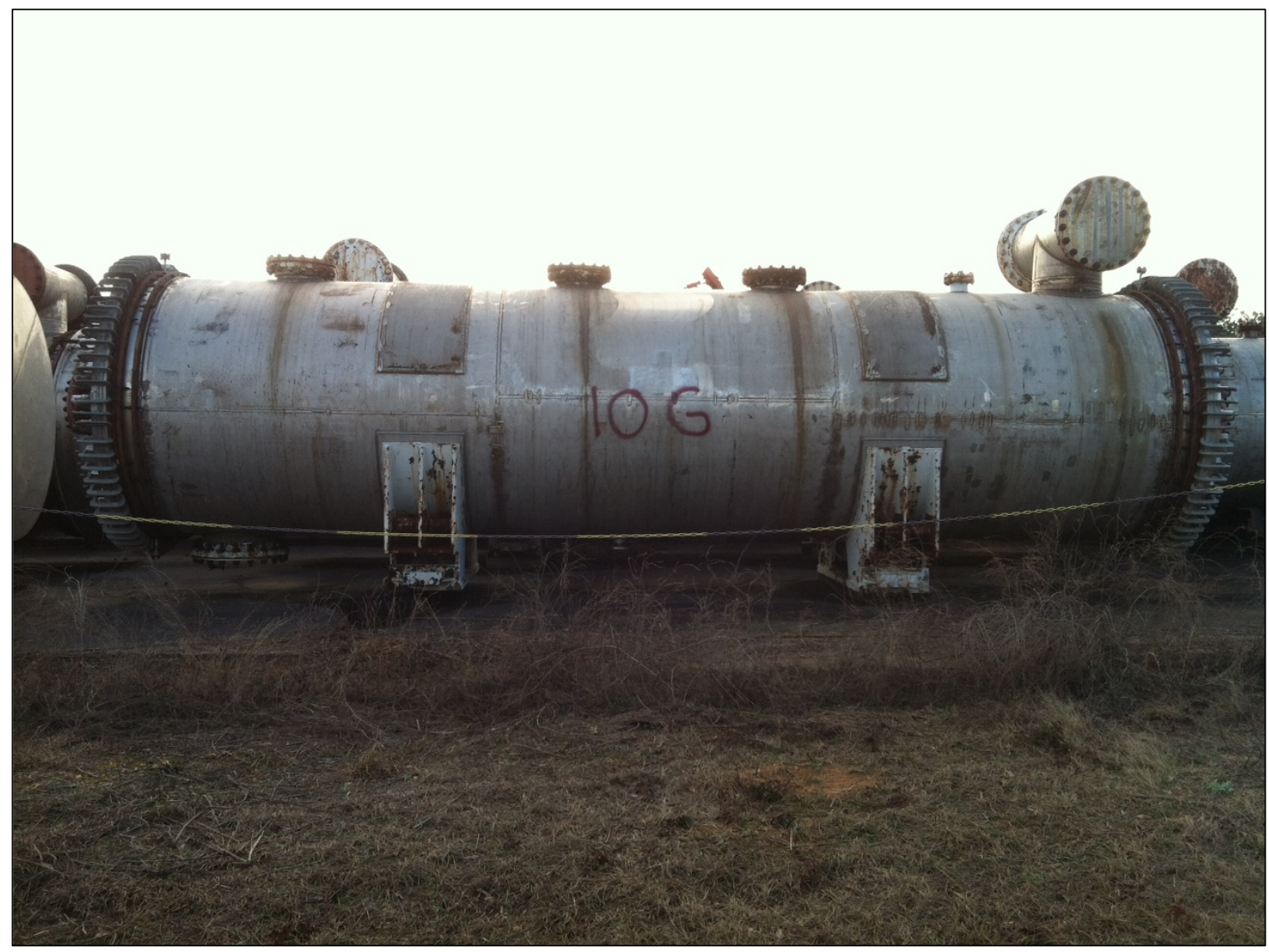

Figure 1-3. Process Heat Exchanger on the concrete pad outside Building 690-N.

An engineering drawing of a $\mathrm{HX}$ is shown in Figure 1-4. As can be seen there, when in operation, hot heavy water moderator from the reactor was fed to the tube side of the heat exchanger, entering on the left and exiting on the right. Cooling water was fed to the shell side, entering from the bottom on the right-hand side, and exiting out the top on the left-hand side. Therefore, contamination of a heat exchanger placed in service would begin on the tube side, which was in intimate contact with fluid that passed through the reactor core. Over time, tritium would diffuse from the tube side into the bulk metal of the heat exchanger tubes. The main groundwater pathway of concern within this SA is groundwater flowing through the tube side of contaminated HXs and picking up tritium and carbon-14 from the tube surfaces 
SRNL-STI-2012-00321

Revision 0

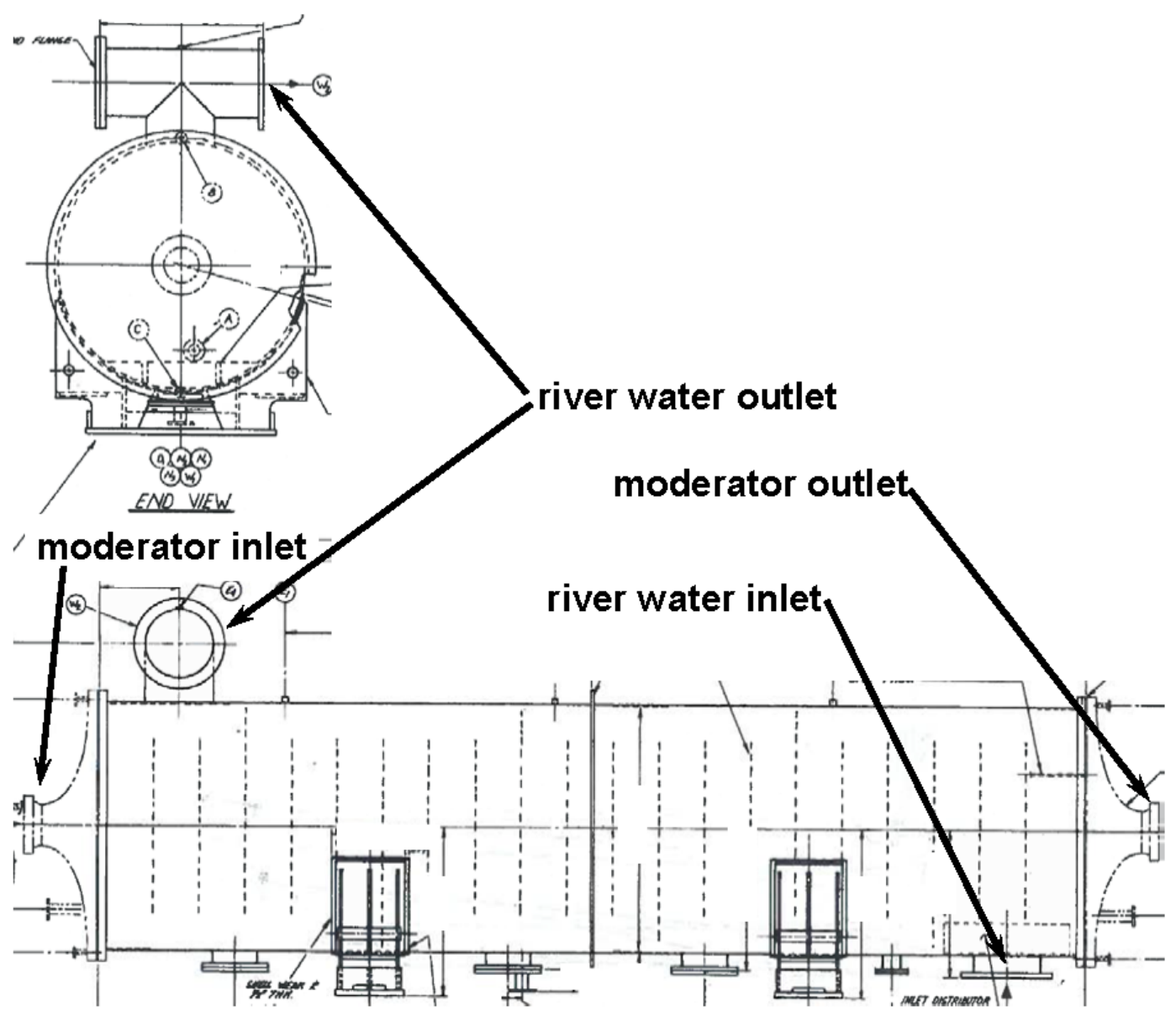

Figure 1-4. Engineering drawing of a Process Heat Exchanger.

\subsubsection{Current Condition}

Field inspection of the 19 HXs on the concrete pad outside Building 690-N revealed several issues that could affect tritium and carbon-14 release into groundwater. The most significant issue was that many of the plates used to seal the openings in the HXs were made from half-inch thick aluminum. Sitting on the pad, exposed to air, these plates provided sufficient sealing capability. However, upon burial in E-Area, contact with groundwater would create the possibility for galvanic corrosion of the aluminum, because the corrosion potential of aluminum is significantly greater than that of Type 304 stainless steel. This possibility would be further exacerbated by an unfavorable anode (aluminum)-to-cathode (stainless steel) surface area ratio [smaller anode-to-cathode surface ratio results in higher anodic current density (proportional to corrosion rate)]. A reliable estimate of the galvanic corrosion rate could not be obtained without a detailed model, but the upper bound could be high enough for the plate to be breached within a matter of years. Consequently, a recommendation was made to coat all of the aluminum seal plates with a durable, isolating material before burial.

While the application of a coating to the aluminum surface may seem simple enough, inspection of the plates showed that nearly all had some kind of plastic sheet attached with an adhesive that had weathered and deteriorated over time. This raised the concern that the deteriorated adhesive, 
if left in place, could prevent adequate bonding of the protective coating. Consequently, another recommendation was made to clean the aluminum seal plates before applying the coating to maximize the potential for good adhesion.

Many of the access ports also appeared to have small (roughly half-inch diameter) drain lines sealed with what appeared to be ball valves that could be broken off while manipulating the HX into position in the burial trench or from material falling on top of the heat exchanger in the trench. That would create an early breach of containment that could affect the release of tritium and carbon-14. Recommendations were made to protect these drain lines while maneuvering the HXs and while backfilling the trench during burial.

\subsection{Modeling Approach}

In the "Generic" waste form employed in the 2008 Performance Assessment (PA) the following two conservative assumptions were employed in its conceptual model for every contaminant:

- Each contaminant present is instantaneously available for transport by groundwater; and

- No subsurface hydraulic barriers (i.e. excluding covers) are considered that typically reduce the local motion of groundwater.

However, two engineering aspects associated with the migration of radionuclides from the HXs can significantly reduce groundwater doses at and beyond the 100 meter boundary; therefore, a Special Waste Form model was developed for the Vadose Zone. The "engineered" barriers considered are:

- The heat exchanger vessel walls (both the secondary-side shell walls and the primary-side header walls) are made of 0.5 in thick (or thicker) 304L stainless steel. Internal 304L stainless steel tube walls isolate the primary and secondary-sides hydraulically. At various external locations, metal flanges or plates have been placed to isolate the internal regions of the heat exchangers from its surroundings.

- The finite release rate of activation and depositional products into the internal regions of the heat exchanger (corrosion and diffusion) occurs after final shutdown (during storage and after burial). These activation and depositional products are embedded within various heat exchanger internal surfaces and only become mobile after the steel matrix locally corrodes away or contaminants diffuse out (i.e. generally slow processes).

In order to model the hydraulically reduced groundwater movement through the internal structure of the heat exchangers, numerous potential leak paths for each individual heat exchanger were taken into consideration. This multitude of possibilities suggested that the conceptual model for a "Special" waste form should be capable of systematically addressing a broad range of potential leak path conditions.

It was assumed that each original penetration into a heat exchanger could become a potential leak path sometime after burial and would require consideration in the determination of inventory limits. The various penetrations into a heat exchanger are listed in Table 1-1. The symbols chosen for the various leak paths within the conceptual model were made relatively consistent with those labels marked in the engineering drawings (except for the septifoils and process lines). Figure 1-5 provides a clearer image to see these labels and the locations they refer to. 
Table 1-1 Identifiers for a heat exchanger's potential leak paths (including its inlet and outlet connections along with its vent and drain ports).

\begin{tabular}{|c|c|c|c|c|c|c|}
\hline $\begin{array}{l}\text { Figure 1-7 } \\
\text { Leak path } \\
\text { Identifier }\end{array}$ & $\begin{array}{c}\text { Drawing } \\
\text { Letter } \\
\text { Mark }\end{array}$ & Purpose & Side & $\begin{array}{c}\text { Sch } 40 \text { Pipe } \\
\text { (in) }\end{array}$ & $\begin{array}{l}\text { Pipe OD } \\
\text { (in) }\end{array}$ & $\begin{array}{l}\text { Pipe ID } \\
\text { (in) }\end{array}$ \\
\hline E1 to E4 & $\mathrm{E} 1$ to $\mathrm{E} 4$ & vent & secondary & 1.0 & 1.315 & 1.049 \\
\hline W1 & W1 & river water in & & 24.0 & 24.000 & 22.626 \\
\hline W2 & W2 (2) & river water out & & 24.0 & 24.000 & 22.626 \\
\hline $\mathrm{N} 1$ to $\mathrm{N} 3$ & $\mathrm{~N} 1$ to $\mathrm{N} 3$ & clean out & & 16.0 & 16.000 & 15.000 \\
\hline Not modeled & D1 & Drain & & 4.0 & 4.500 & 4.026 \\
\hline D4 & D4 & Drain & & 6.0 & 6.625 & 6.065 \\
\hline L1 \& L2 & - & Tube wall leak & Tube bundle & - & 0.50 & 0.402 \\
\hline S1 \& S2 & $A(2)$ & Septifoil & primary & 3.0 & 3.500 & 3.068 \\
\hline B1 \& B2 & $B(2)$ & top drain port & & 1.0 & 1.315 & 1.049 \\
\hline $\mathrm{C} 1 \& \mathrm{C} 2$ & $C(2)$ & bottom drain port & & 1.0 & 1.315 & 1.049 \\
\hline P1 & - & process water in & & 12.0 & 12.750 & 11.938 \\
\hline $\mathrm{P} 2$ & - & process water out & & 12.0 & 12.750 & 11.938 \\
\hline
\end{tabular}

From this information (and other supporting data sources associated with heat exchanger geometry and operational experience) the heat exchangers were grouped into two categories whose definitions are:

- Leakers - Heat exchangers (11 in total, Butcher, 2012a) that were classified as having internal leaks between the primary and secondary sides when removed from service. The leak paths are internal to the vessel and occur between the tube bundle and the shell side.

- Non-Leakers - Heat exchangers (8 in total) that were classified as being functional without internal leaks between the primary and secondary sides when removed from service.

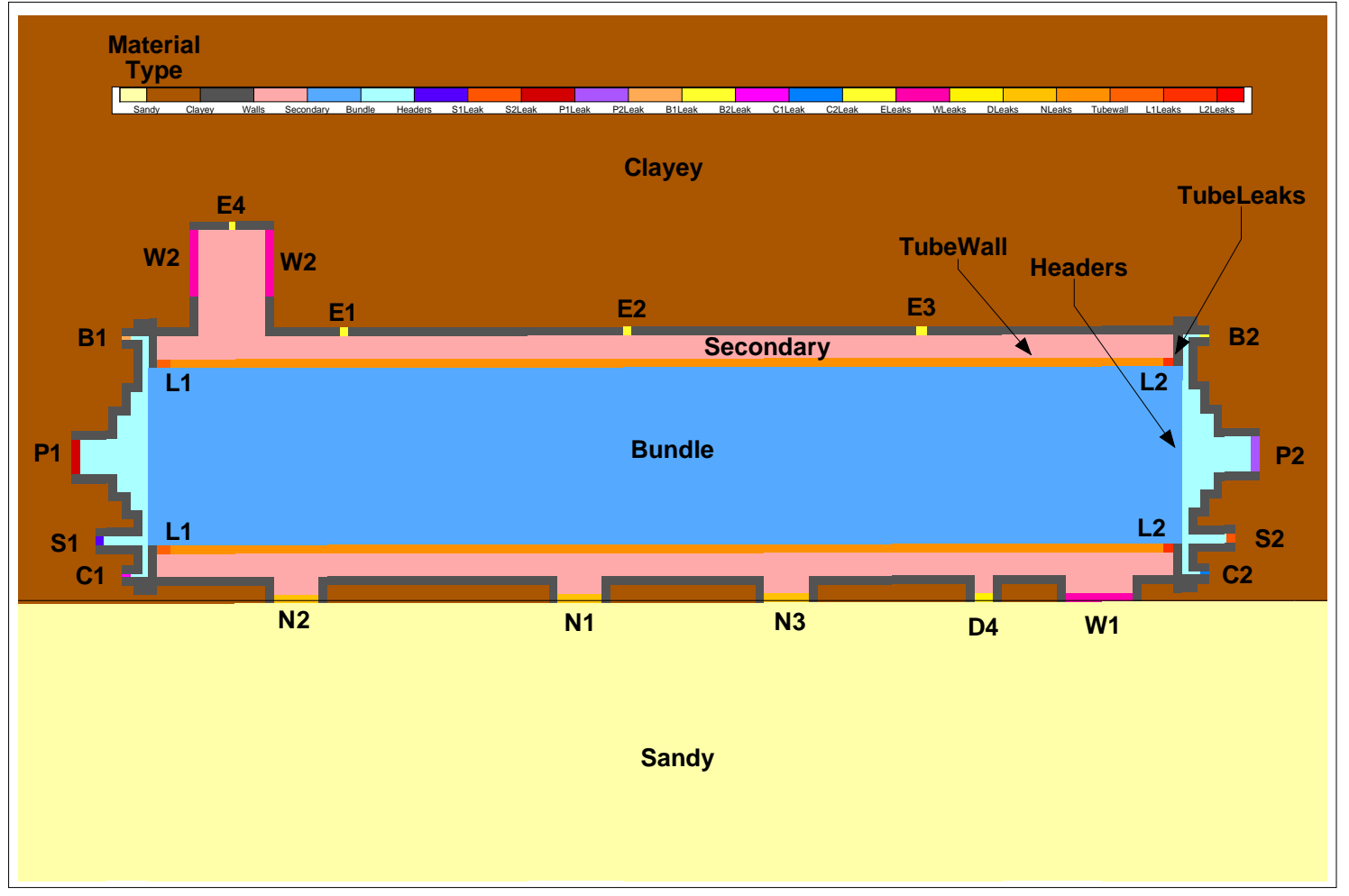

Figure 1-5 Close-up view of the "Conceptual Model” of a Process Heat Exchanger showing the various key internal components and potential leak paths. 


\subsubsection{Potential Leak Pathways}

Each heat exchanger has approximately twenty different possible leak paths between its internal regions and its surroundings (as shown in Figure 1-5 and listed in Table 1-1). Given the two categories of heat exchangers (i.e. leakers and non-leakers) these possible leak paths can also be grouped into three classes:

- Primary-side external leak paths - These are potential external leak paths between the internal regions on the primary-side of a heat exchanger and its surroundings.

- Secondary-side external leak paths - These are potential external leak paths between the internal regions on the secondary-side of a heat exchanger and its surroundings.

- Primary-side to Secondary-side internal leak paths - These are potential internal leak paths between the primary and secondary sides.

From the conceptual modeling approach, two separate sets of similar flow and transport analyses were required to address both leakers and non-leakers. A variety of varying leak path states were considered within each set of analyses. Here, we define a unique leak path state by specifying the hydraulic conductivity state of each potential pathway for the heat exchanger vessel. The various potential pathways within the model are:

Primary-side leak paths

- B1 - upper drain port on left (inlet) header

- B2 - upper drain port on right (outlet) header

- $\mathrm{C} 1$ - lower drain port on left (inlet) header

- $\quad$ C2 - lower drain port on right (outlet) header

- $\quad$ S1 - septifoil line on left (inlet) header

- $\quad$ S2 - septifoil line on right (outlet) header

- $\quad$ P1 - process water line on left (inlet) header

- $\quad$ P2 - process water line on right (outlet) header

Secondary-side leak paths

- E - upper vent ports (E1-4 combined) on shell

- D4 - lower drain port near right (inlet) shell

- $\quad \mathrm{N}$ - lower clean-out ports (N1-3 combined) on shell

- W - inlet/outlet cooling water lines (W1-2 combined) on shell

Primary-side to secondary-side leak paths

- L1 - tube walls of bundle near left (inlet) header

- L2 - tube walls of bundle near right (outlet) header

These various leak pathways can be seen in Figure 1-5 where each pathway is labeled consistently with the available engineering drawings. The orientation shown represents the original orientation of a heat exchanger upon being put into service for the first time. Some of the nineteen heat exchangers were removed from service, repaired, and then placed back into service. The in-service orientation of these reused heat exchangers was in some cases:

- Shells rotated 180 degrees (flipped) vertically and then rotated 180 degrees (flipped) horizontally. Note that line connections for the primary and secondary piping remained fixed within each operating reactor facility.

- Inlet and outlet headers retained their original orientations.

- The above geometric rotations would cause the E vents, $\mathrm{N}$ clean-out ports, $\mathrm{B}$ and $\mathrm{C}$ drain ports and the septifoils to swap their vertical positions.

From the modeling perspective the orientation shown in Figure 1-5 was used because the orientation was not considered to be very significant. 
To better establish the current and future hydraulic state of a potential leak path, SRNL requested ACP to perform a walk-down of the process heat exchangers in early May, 2012 to verify the specifics associated with materials in place covering the various connection ports. A summary of that walk-down is provided in Table 1-2. As Table 1-2 indicates, three different material type flanges (or plates) were employed in addressing the various potential leak paths:

- Carbon steel

- Stainless steel

- Aluminum

Table 1-2 Specific state of key components of heat exchangers based on survey performed in May 2012.

\begin{tabular}{|c|c|c|c|c|c|c|c|c|}
\hline $\begin{array}{l}\text { Location of } \\
\text { Flange }\end{array}$ & Flange Size & Nozzle & $\begin{array}{c}\text { Flange } \\
\text { Thickness }\end{array}$ & Flange & Bolt / Stud & $\begin{array}{c}\begin{array}{c}\text { Size of Studs } \\
\text { and Bolts }\end{array} \\
\end{array}$ & Size of Nuts & Nut \\
\hline \multirow[t]{4}{*}{ Secondary } & $24^{\prime \prime}$ & River Water & $1 / 2 "$ & Aluminum & $\begin{array}{c}\text { B } 7 \text { Carbon } \\
\text { Steel }\end{array}$ & $11 / 4 "$ & $11_{4}^{\prime \prime}$ & $\begin{array}{c}\text { H } 2 \text { Carbon } \\
\text { Steel }\end{array}$ \\
\hline & $16^{\prime \prime}$ & Clean out & $17 / 16^{\prime \prime}$ & $\begin{array}{c}\text { Forged } \\
\text { Steel } \\
\end{array}$ & $\begin{array}{c}\text { B } 7 \text { Carbon } \\
\text { Steel }\end{array}$ & 1" & $1^{\prime \prime}$ & $\begin{array}{c}\text { H } 2 \text { Carbon } \\
\text { Steel }\end{array}$ \\
\hline & $6^{\prime \prime}$ & Drain Port & $1^{\prime \prime}$ & $\begin{array}{c}\text { Forged } \\
\text { Steel }\end{array}$ & $\begin{array}{c}\text { B } 7 \text { Carbon } \\
\text { Steel }\end{array}$ & $3 / 4 "$ & $3 / 4 "$ & $\begin{array}{c}\text { H } 2 \text { Carbon } \\
\text { Steel }\end{array}$ \\
\hline & $4^{\prime \prime}$ & Drain Port & $1 / 2 "$ & Aluminum & $\begin{array}{c}\text { B } 7 \text { Carbon } \\
\text { Steel }\end{array}$ & $5 / 8^{\prime \prime}$ & $5 / 8^{\prime \prime}$ & $\begin{array}{c}\text { H } 2 \text { Carbon } \\
\text { Steel }\end{array}$ \\
\hline \multirow[t]{3}{*}{ Primary } & $12^{\prime \prime}$ & Process Water & $1 / 2 "$ & Aluminum & $\begin{array}{c}\text { B } 7 \text { Carbon } \\
\text { Steel }\end{array}$ & $11 / 8^{\prime \prime}$ & $11 / 8^{\prime \prime}$ & $\begin{array}{c}\text { H } 2 \text { Carbon } \\
\text { Steel }\end{array}$ \\
\hline & $3^{\prime \prime}$ & Septifoil & $1 / 2 "$ & $\begin{array}{l}\text { Aluminum } \\
\text { Plate }\end{array}$ & $\begin{array}{c}\text { B } 7 \text { Carbon } \\
\text { Steel }\end{array}$ & $3 / 4$ & $3 / 4^{\prime \prime}$ & $\begin{array}{c}\text { H } 2 \text { Carbon } \\
\text { Steel }\end{array}$ \\
\hline & $1 / 2 "$ & Drain Port & $9 / 16^{\prime \prime}$ & $\begin{array}{c}\text { Stainless } \\
\text { Steel }\end{array}$ & $\begin{array}{c}\text { B } 7 \text { Carbon } \\
\text { Steel }\end{array}$ & $1 / 2 "$ & $1 / 2 "$ & $\begin{array}{c}\text { H2 Carbon } \\
\text { Steel }\end{array}$ \\
\hline
\end{tabular}

SRNL performed scoping calculations to estimate inventory limits for $\mathrm{H}-3$ and C-14 over a range of assumed leak path states (i.e. varying the degree of leakage through a leak path). The timing after burial when certain pathways changed from being completely sealed to a state of partial leakage was estimated based on corrosion rate analyses. For aluminum plates in direct contact with stainless steel flanges (that are attached to a relatively large vessel) the conservative throughwall pitting times were as low as $2-5 \mathrm{yr}$ in duration. A set of varying contaminant release rates was also considered.

Based on these scoping analyses, ACP was requested to provide coatings over these plates to ensure that a minimum of five years of service after burial could be assumed. Guidance on the type of coatings and methods of application were provided to ACP by SRNL (Butcher, 2012b).

In follow-up walk-downs of the process heat exchangers performed by SRNL and ACP, the following items were identified as potential leak path mechanisms needing more consideration:

- The 7/16-in gaskets residing between the carbon steel blind-flanges and vessel faces for secondary-side drains ports (D4) and clean-out ports (N1, N2, N3);

- The $\sim 0.5$-in drain lines extending out on typically two locations on 18 of the 19 heat exchangers (B1, D4, and/or W2);

- The valves at the ends of each of the 0.5 -in drain lines.

To address all of these potential leak paths, SRNL proposed available off-the-shelf coatings and wrap/tape products that could be applied to serve as moisture barriers during the first few years following disposal (Butcher, 2012b). Based on proper surface preparation (residue removal, cleaning and texturing) and application of these products, SRNL determined that these hydraulic barriers can be considered in calculating the actual finite release rate of $\mathrm{H}-3$ and C-14 inventories. Thus, changing the configuration of the heat exchangers to match the modeled conditions is necessary to achieve acceptable disposal limits. Guidance on the type of coatings and methods of 
application provided to ACP by SRNL was captured by ACP in a summary level work process description (Appendix C).

\subsubsection{Contaminant Release Mechanisms}

As mention above, a range of potential release mechanisms was considered. The results (shown later) indicate that the assumed release mechanism employed can have a large impact on 100 -meter boundary exposures for $\mathrm{H}-3$, but for C-14 the impact is very small. $\mathrm{H}-3$ is a very mobile contaminant $\left(\mathrm{K}_{\mathrm{d}}=0 \mathrm{~mL} / \mathrm{g}\right.$ in sand or clay) while for $\mathrm{C}-14$ it is only slightly mobile $\left(\mathrm{K}_{\mathrm{d}}=1 \mathrm{~mL} / \mathrm{g}\right.$ in sand and $30 \mathrm{~mL} / \mathrm{g}$ in clay). Also, for C-14 the inventory is primarily of a depositional nature where it is to a large extent limited to the surface oxide layer. In contrast, $\mathrm{H}-3$ is a sufficiently mobile species such that significant amounts of the inventory can diffuse atomically into the stainless steel matrix directly. This diffusion potential for $\mathrm{H}-3$ was accounted for by ACP through an application of a factor of two increase in estimated $\mathrm{H}-3$ inventories per each heat exchanger (see Appendix C; ACP referred to this multiplier as a "safety factor"). The source term model employed within this SA distributes the H-3 inventory consistent with ACP's inventory evaluations. The various source term modeling details are provided in Appendices A and B.

The source term models employed in this SA can be classified by the following:

- Instant/Instant (II) - The contaminant is released instantaneously for potential groundwater transport from both the oxide layer and stainless steel metal. However, transport occurs only after actual groundwater motion exists locally. This option applies for $\mathrm{H}-3$ and C-14.

- Diffusion/Corrosion Conservative Estimate (DC_CE) - Finite release mechanisms are employed for both the release of contaminant from the surface oxide layer and release from the stainless steel metal through diffusion. There is no storage of contaminant assumed in stagnant regions within the tube bundle or header. Conservative oxide layer thickness $(3 \mu \mathrm{m})$ and vessel fill time is assumed (for a moist air or water corrosion environment). This option applies for H-3 where half of the inventory is placed into each region (i.e. half embedded in the stainless steel and half contained in the surface oxide layer). For C-14 all inventory is placed in the oxide layer.

- Diffusion/Corrosion Best Estimate (DC_BE) - Same model as for Diffusion/Corrosion Conservative Estimate but best estimate values for oxide layer thickness $(5 \mu \mathrm{m})$.

- Diffusion/Corrosion Conservative Estimate with Storage (DC_CE_Storage) - Same model as for Diffusion/Corrosion Conservative Estimate with storage of contaminant in stagnant regions within the tube bundle and header while the vessel filling process is underway. If the contamination was at a high elevation it could be released early, but it would not be available for transport via groundwater until the heat exchanger filled with water that reached that elevation.

For H-3 the most limiting source term model above is the II model and, depending upon the various leak path conditions considered, the other release models stack up differently. For C-14, no one source term option is the most limiting, because all performed relatively similarly.

\subsubsection{Event Timelines}

Event timelines were developed for the source term analyses and for the transport analyses. The event below defines timelines that were directly employed in the separate source term analyses.

- Timing associated with the filling of a heat exchanger for rate of corrosion and contaminant availability employed in the source term release modeling. This aspect was separated out from the timeline used in the vadose zone transport analyses in a conservative manner. 
A host of items were addressed in order to establish event timelines for the transient transport analyses that provide contaminant fluxes to the water table that were employed in subsequent aquifer transport analyses. The following is a list of those items:

- Changes in the hydraulic states of the various potential leak pathways (i.e. B1, B2, C1, C2, S1, S2, P1, P2, E, D, N, and W). For example, complete sealing (isolation) of the heat exchangers from their surroundings depends upon a variety of aspects and leakage ultimately results sometime after burial (integrity of coatings over the aluminum plates, corrosion rates of these aluminum plates once coating integrity is lost, integrity of the gaskets seals at the carbon steel flanges, etc.)

- Infiltration rates at the ground surface are time-varying due to the application of the interim ground-surface cover (assumed to occur at the end of December in 2025), the final cover (assumed to occur 100 yr later), degradation of the final cover after its initial placement, and the possibility of local subsidence.

Table 1-3 provides the basic overall timeline employed for the various $2 \mathrm{D}$ vadose zone transport analyses. At each of the 19 time periods listed, multiple steady-state 2D vadose zone flow solutions were generated due to the variety of leak path states considered, whether or not subsidence or intact conditions existed, and for leaker versus non-leaker heat exchangers being considered.

Table 1-3 Event timeline (yr) employed in the 2D vadose zone transport simulations.

\begin{tabular}{|c|c|c|c|c|c|}
\hline $\begin{array}{l}\text { Time } \\
\text { Period } \\
\text { index }\end{array}$ & $\begin{array}{l}\text { Relative } \\
\text { Start } \\
\text { Time }\end{array}$ & $\begin{array}{l}\text { Relative } \\
\text { End } \\
\text { Time }\end{array}$ & $\begin{array}{l}\text { Time } \\
\text { Duration }\end{array}$ & $\begin{array}{l}\text { Absolute } \\
\text { End } \\
\text { Time }\end{array}$ & Description of Time Period \\
\hline- & - & - & - & 2012.5 & Time of heat exchanger burials (7/1/2012) \\
\hline T00 & 0.0 & 5.0 & 5 & 2017.5 & Hydraulic state of pathways are possibly redefined \\
\hline- & - & - & - & 2017.5 & Transition of leak path states \\
\hline T01a & 5.0 & 8.5 & 3.5 & 2021.0 & Hydraulic state of pathways are possibly redefined \\
\hline- & - & - & - & 2017.5 & Transition of leak path states \\
\hline T01b & 8.5 & 10 & 1.5 & 2022.5 & Hydraulic state of pathways are possibly redefined \\
\hline- & - & - & - & 2022.5 & Transition of leak path states \\
\hline T01c & 10.0 & 13.5 & 3.5 & 2026.0 & Hydraulic state of pathways are possibly redefined \\
\hline- & - & - & - & 2026.0 & $\begin{array}{l}\text { Interim cover placed (start of institutional control) } \\
\text { and transition of leak path states to fully opened }\end{array}$ \\
\hline T02 & 13.5 & 113.5 & 100 & 2126.0 & Interim cover performance maintained \\
\hline- & - & - & - & 2126.0 & $\begin{array}{c}\text { Final cover placement at end of institutional controls, } \\
\text { either intact or subsided conditions set, last set of } \\
\text { hydraulic state of pathways redefined }\end{array}$ \\
\hline T03 & 113.5 & 163.5 & 50 & 2176.0 & $\begin{array}{c}\text { Degradation of intact cover (Case01) or impact of } \\
\text { subsidence reduced (Case11) }\end{array}$ \\
\hline T04 & 163.5 & 213.5 & 50 & 2226.0 & \\
\hline T05 & 213.5 & 263.5 & 50 & 2276.0 & \\
\hline T06 & 263.5 & 313.5 & 50 & 2326.0 & \\
\hline T07 & 313.5 & 363.5 & 50 & 2376.0 & \\
\hline T08 & 363.5 & 413.5 & 50 & 2426.0 & \\
\hline T09 & 413.5 & 463.5 & 50 & 2476.0 & \\
\hline T10 & 463.5 & 513.5 & 50 & 2526.0 & \\
\hline T11 & 513.5 & 563.5 & 50 & 2576.0 & \\
\hline T12 & 563.5 & 613.5 & 50 & 2626.0 & \\
\hline T13 & 613.5 & 663.5 & 50 & 2676.0 & \\
\hline T14 & 663.5 & 713.5 & 50 & 2726.0 & \\
\hline T15 & 713.5 & 813.5 & 100 & 2826.0 & \\
\hline T16 & 813.5 & 913.5 & 100 & 2926.0 & \\
\hline T17 & 913.5 & 1013.5 & 100 & 3026.0 & \\
\hline T18 & 1013.5 & 1113.5 & 100 & 3126.0 & \\
\hline
\end{tabular}

Details with regard to the specific times in the above timelines are discussed in Chapter 3. 


\subsubsection{Analysis Strategy}

For "Generic" and "Special" waste forms in the 2008 PA, a single conceptual model was employed which implies:

- One source term release mechanism; and

- One set of hydraulic engineered barriers where these barriers could change over time but only under one set of conditions.

In the 2008 PA, ST inventory limits were computed based on a "worst" case scenario. This "worst" case scenario was determined from four different cases (i.e. intact versus subsided conditions under cellulose degradation products (CDP) versus no CDP being present). For certain nuclides and/or waste forms only a subset of these four cases was required.

The analysis strategy taken in this SA differs from the standard 2008 PA approach employed for "Special" waste forms in that no single conceptual model is relied upon exclusively. Instead, a multitude of conceptual models were considered where:

- A variety of hydraulic engineered barrier behaviors (e.g. a specified set of leak path states defined for all potential leak pathways) were employed where the evolution of these barriers could be different over time,

- Four possible release mechanisms were considered,

- Two potentially worst case burial configurations for the nineteen heat exchangers were considered,

- Two types of heat exchangers were considered (i.e. leakers and non-leakers),

- Only the no CDP present case was required because the heat exchanger waste form is void of CDP, and

- Even though the heat exchangers probably are structurally sound over the entire performance period, no structural analyses were performed. Therefore, buckling and partial collapse were assumed to occur at the end of institutional control and both intact and subsided cases were considered (note that because of H-3's short half-life it was not necessary to evaluate the subsided case).

As discussed in Chapter 3, in principle, a large number of leak path states could be envisioned for a single heat exchanger which would then become a very large number if nineteen separate heat exchangers were addressed. To reduce the number of analysis simulations performed, only four sets of "hydraulic" options were considered where for each set the hydraulic state of each potential leak path was specified over key time periods and was applied to all 19 heat exchangers. These four "hydraulic" options are referred to, based on their degree of sealing (i.e. their hydraulic integrity), as:

- Poor sealing (and a line break occurring during burial),

- Poor sealing (and no line break),

- Average sealing (and no line break), and

- Good sealing (and no line break).

The terms poor, average, and good reflects the degree of sealing assumed at the various potential leak path locations. During the transport and burial process a potential for a line break in the short 0.5-in drain lines is also addressed by analyses with and without a line break at burial.

In summary, for each burial configuration (i.e. $4 \times 5$ and $3 \times 7$ layouts) the following numbers of aquifer transport analyses were performed:

- 104 intact cases for H-3 and

- 208 intact and subsided cases for C-14.

From this broad range of aquifer transport analyses, inventory limits for H-3 and C-14 were determined (see Chapter 6). 
SRNL-STI-2012-00321

Revision 0

\subsection{Key Inputs and Assumptions}

1. Assumption: Heat exchangers are sealed and protective mitigation activities are implemented (see Appendix C).

It was assumed that the sealing and protective mitigation activities described in Appendix $\mathrm{C}$ were properly performed. Furthermore, the sealing and protective activities apply for the entire burial process, up to and including backfilling.

2. Assumption: The heat exchangers are not buried before July 1, 2012.

Performance calculations were based on burial on July 1, 2012 (heat exchangers may be placed in the Slit Trench before then, but should not be covered with soil). Earlier burial would increase the short-term $\mathrm{H}-3$ peak concentrations.

3. Assumption: The heat exchangers are not buried closer than $200 \mathrm{ft}$ from the ST \#9 edge that is closest to the hypothetical well.

Performance calculations were based on heat exchanger burial being no closer than $200 \mathrm{ft}$ from the ST \#9 edge that is closest to the hypothetical well. Two configurations were analyzed to determine the sensitivity of heat exchanger disposal geometries. The analyses were conducted with arrangements of heat exchangers that were selected to try to produce the highest well concentrations such that Solid Waste would not be restricted in the order in which the heat exchangers were arranged.

4. Assumption: The heat exchangers are placed horizontally within ST \#9 and at its bottom.

It was assumed that each heat exchanger was disposed such that its longitudinal axis was approximately horizontal. A slight tilt to the upper surface infiltration boundary condition was imposed for the vadose zone model to accommodate a slight potential tilt in the heat exchanger. The heat exchangers cannot be disposed on any significant slope, such as a side slope. Each heat exchanger should be placed at the bottom of the trench.

\section{Assumption: No waste placed beneath the heat exchangers.}

No waste should be placed beneath a heat exchanger. Each heat exchanger should be placed at the bottom of the trench without any other waste being present beneath it. A heat exchanger presents a large flow obstruction with a converging flow field underneath, which would significantly impact the behavior of waste placed beneath it.

\section{Assumption: No non-crushable containers placed over heat exchanger footprints.}

No non-crushable containers should be placed directly over the footprint of each heat exchanger. Non-crushable containers have the potential to subside after the end of institutional controls and could potentially increase the assumed maximum level of subsidence and infiltration rates employed in these analyses.

7. Assumption: No cement-based materials placed within $10 \mathrm{ft}$ of heat exchanger footprints.

Cement-based materials result in caustic plumes and caustic attack of the aluminum plates should be avoided. The protective coatings over the aluminum plates should 
greatly reduce this risk; however, as a defense-in-depth measure no cement-based materials should be placed within $10 \mathrm{ft}$ of the aerial footprint of a heat exchanger.

8. Assumption: Each heat exchanger has the potential to buckle independently of any of the other heat exchangers

9. Assumption Over the 1,000-yr performance period (after end of institutional control) the likelihood of at least one heat exchanger buckling is $50 \%$. Restated, there is a $50 \%$ chance no heat exchanger experiences buckling over the $1,000-y r$ period. 


\subsection{Vadose Zone Analysis}

Vadose zone analyses were performed using a "special waste form" for H-3 and C-14. For each radionuclide, PORFLOW flow and transport vadose zone analyses were performed for a range of scenarios as discussed in Chapter 1 and further discussed below. The fractional contaminant fluxes to the water table computed from the transport simulations were then used in the aquifer analyses described in Chapter 4.

\subsection{Conceptual Models}

The overall basis for the vadose zone conceptual models is described in Chapter 1 . In this chapter, the implementation of the flow and transport results is presented. First, details with regard to the geometric aspects of the model are discussed.

\subsubsection{Heat Exchanger Geometry}

Table 3-1 contains some of the key geometric parameters employed in the development of the vadose zone model. The majority of the geometric aspects of the nineteen individual heat exchangers are almost identical. However, differences do exist in terms of number of tubes within the tube bundle and whether or not the core rods are present.

Table 3-1 Some key geometric parameters employed.

\begin{tabular}{|l|}
\hline Parameter description \\
\hline \hline Quantity of tubes \\
Length of tubes \\
Tube outer diameter \\
Tube wall thickness \\
Tube inner diameter \\
Rod outer diameter \\
Internal surface area (single tube) \\
Internal surface area (single tube) \\
Total bundle internal surface area \\
Rod outer surface area (single tube) \\
Rod outer surface area (single tube) \\
Total rod outer surface area \\
Total surface area of tube sheets \\
Total surface area of both headers \\
Total surface area header + tubes + rod \\
Fraction of surface on tubes and rods \\
Face-to-Face tube sheet length \\
Face-to-Face Hx overall length \\
OD of Hx shell \\
Flange face to tube sheet \\
Hx centerline to centerline of RW outlet \\
Hx centerline to top of RW outlet \\
Hx centerline to bottom of RW outlet \\
\hline
\end{tabular}

The depositional and diffusion process for loading contaminants within a heat exchanger is a surface phenomenon. Therefore, allocation of contaminants within a heat exchanger is done based on the internal surface fractions on primary-side surfaces. The breakdown is between the surfaces within the bundle and those within the headers:

- Bundle - internal surface of tubes and outer surface of rod if present; and

- Headers - internal surface of headers and internal surface of tube sheets.

Because the majority of surface area is within the bundle (regardless of the presence of the rods), only one surface fraction between headers and bundle is used. 
From a geometric and numerical perspective, a heat exchanger has too many internal and external structures to attempt modeling at a finer level. However, certain internal and external structures play key roles in the migration path of groundwater into and through its primary and secondarysides. Therefore, based on prior engineering experience and judgment, a compromise was reached.

Figure 1-5 presented in Chapter 1 illustrates the compromise reached in this SA for modeling a heat exchanger as a "Special” waste form buried in ST \#9. The majority of a contaminant resides on the surface of (and embedded in metal for H-3) the primary-side walls. A close-up view is provided in Figure 3-1 below. The external walls of the heat exchangers are shown shaded in gray. The tube bundle has been reduced down to a single porous media region shaded in cyan. The "tube bundle" represents the primary-side and is separated from the secondary-side by the tube wall shaded in light orange.

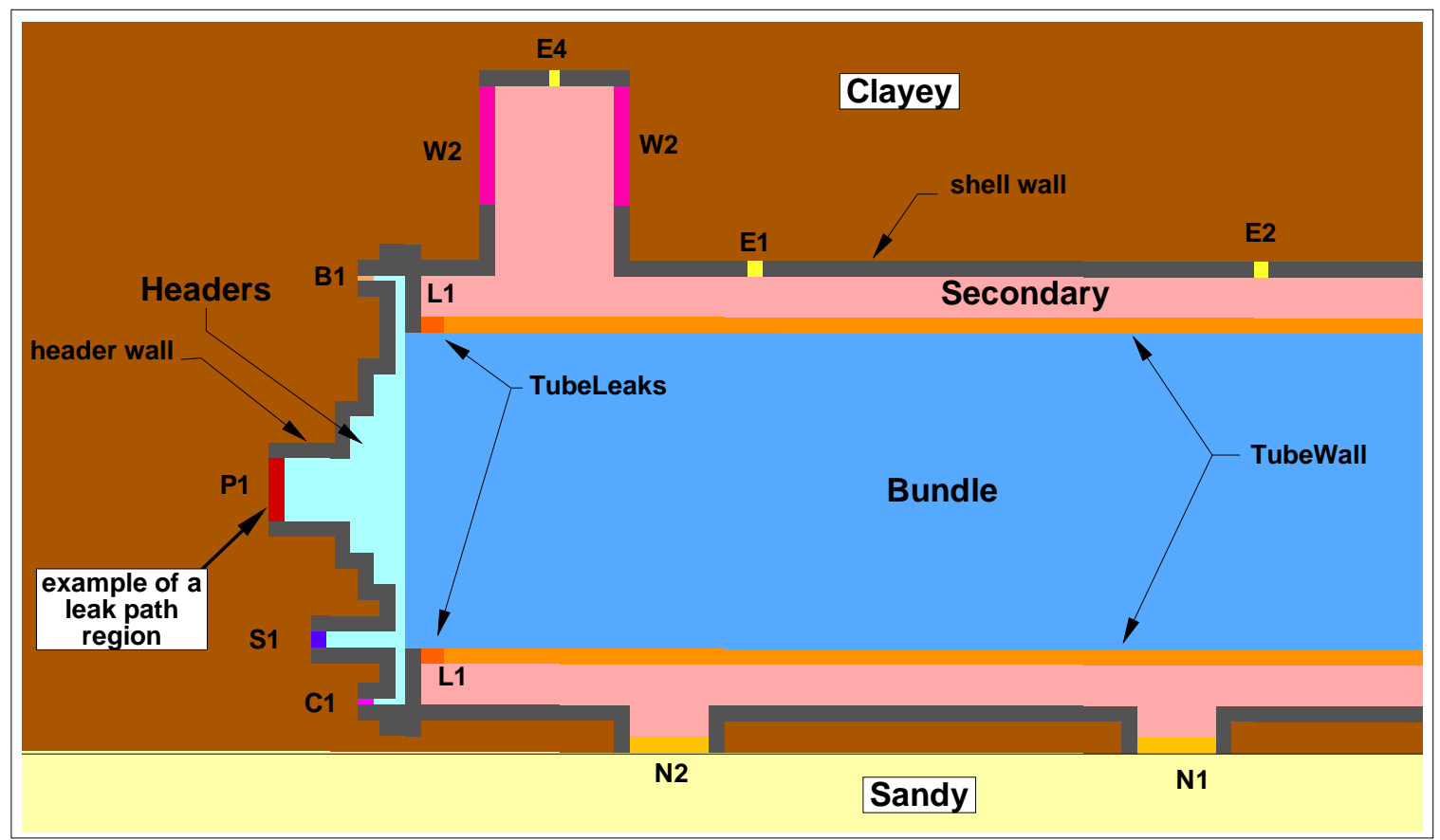

Figure 3-1 Close-up view of heat exchanger "Special” waste form model highlighting region near the inlet on the primary-side.

For groundwater modeling purposes, the opened area regions within the heat exchanger are represented as gravel regions (i.e. hydraulic and water retention properties for gravel employed). The regions consisting of wall materials are represented by pseudo-metallic properties with extremely low hydraulic conductivity.

At the mouths of each penetration point, (e.g. nozzles B1, C1, and S1) small rectangular regions are shown shaded with different colors. Special leak path properties are employed as discussed in detail below. Individual leak paths are explicitly modeled to allow the flexibility to address a variety of potential leakage conditions (i.e. states).

\subsubsection{Overall Model Domain}

In developing the 2D vadose zone model, the following vertical depths must be defined:

- Depth (thickness) of the "Upper Vadose Zone” (UVZ) clayey layer; and

- Depth to the water table. 
The same data and approach employed in the Engineered Trench \#3 (ET \#3) down-select analysis effort (Collard and Hamm, 2012) was used in this effort. Figure 3-2 shows the depth (thickness) of the UVZ in the vicinity of ST \#9. An average value of $20.0 \mathrm{ft}$ is used in this SA.

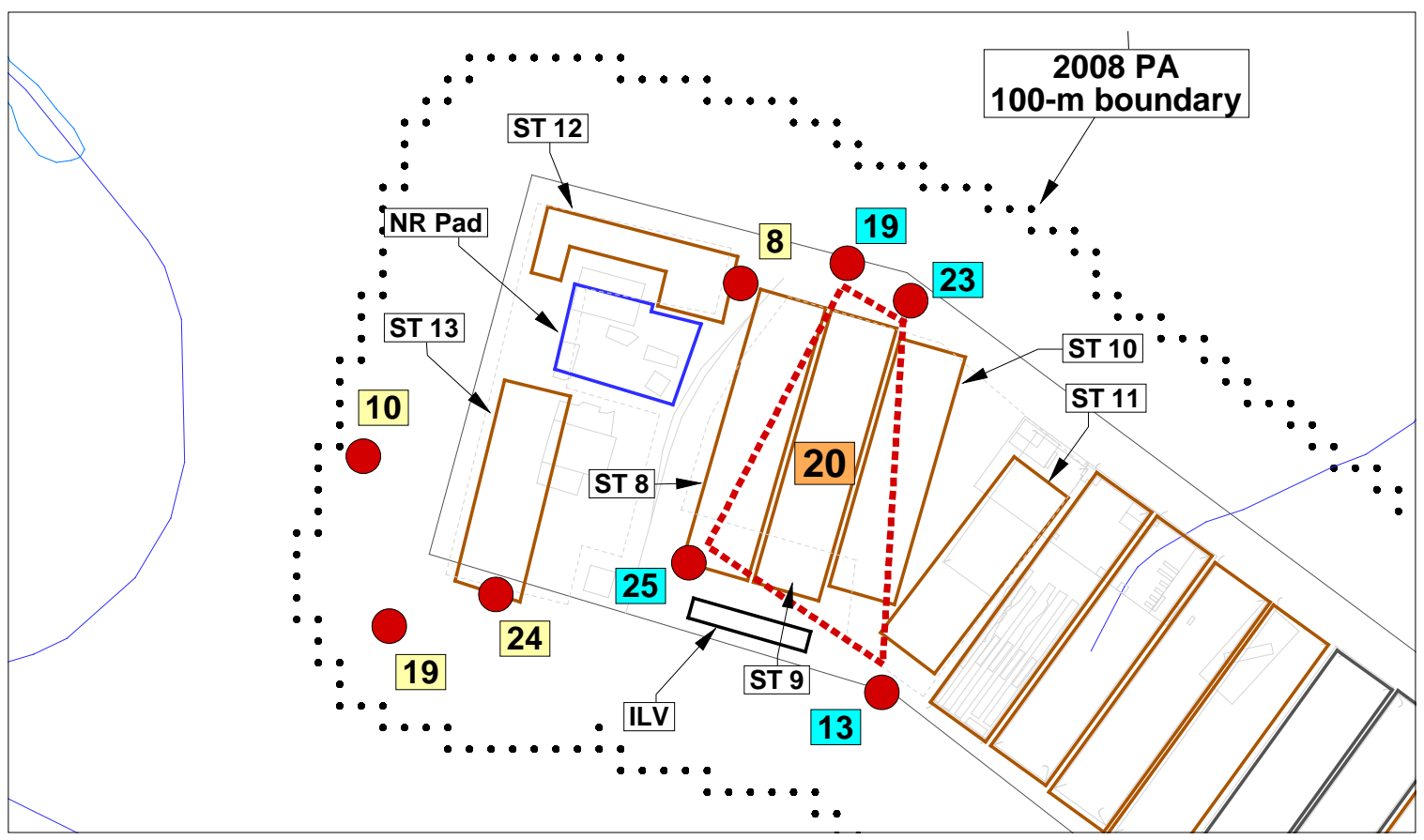

Figure 3-2 Estimated depth of the UVZ clayey region in the vicinity of ST \#9.

Figure 3-3 shows the depth to the water table in the vicinity of ST \#9. An average value of 66.0 $\mathrm{ft}$ is used in this SA.

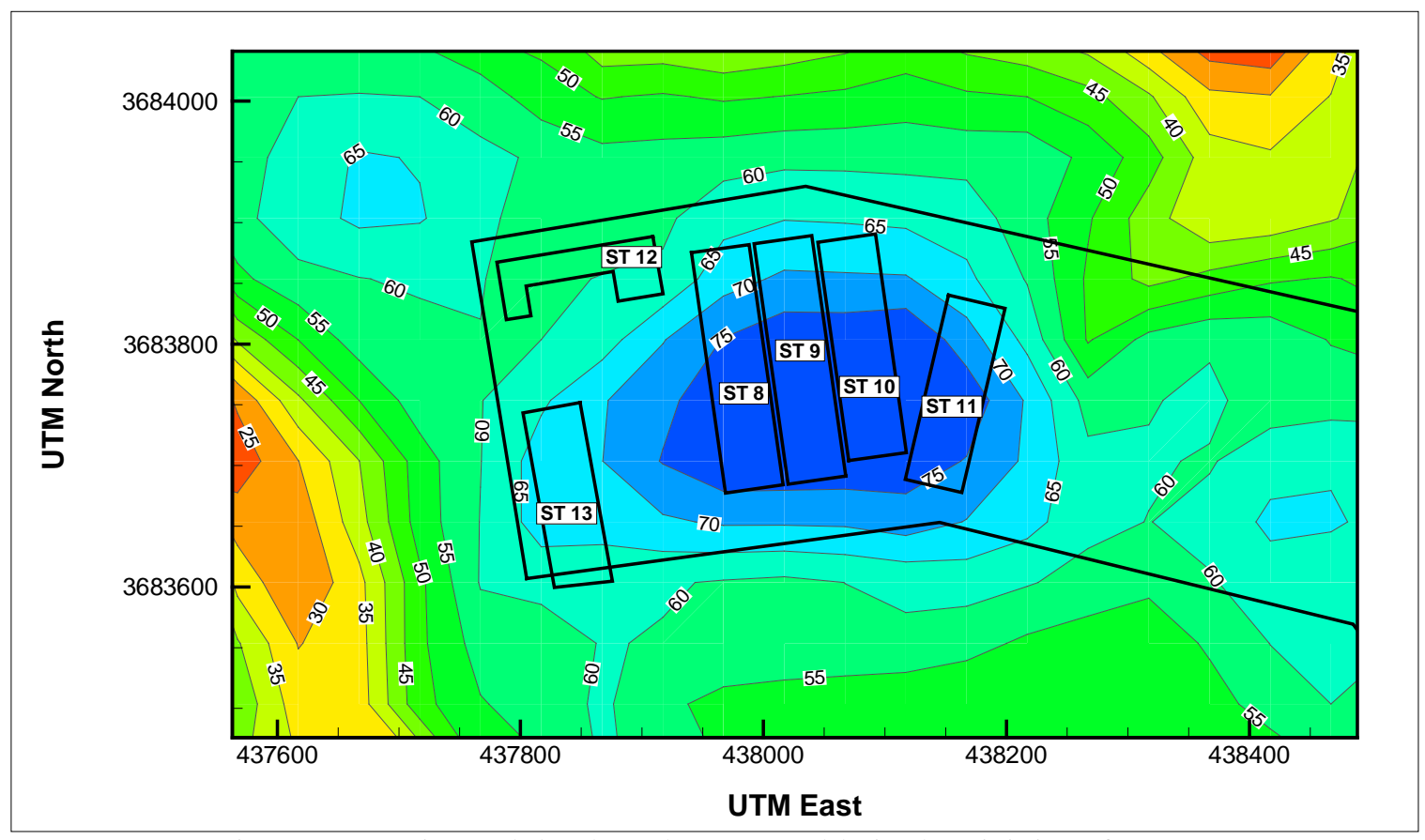

Figure 3-3 Estimated depth to the water table in the vicinity of ST \#9. 
Based on the estimated depths to the water table and UVZ thickness the overall 2D vadose model was constructed. The extent of the horizontal domain was determined based on overall water balance considerations. Assuming that individual heat exchangers would be placed in a rectangular array with two-foot spacing between neighbors, the net amount of horizontal domain required on each side of an individual heat exchanger's footprint was calculated to be $21.2 \mathrm{ft}$. Given the overall length of a heat exchanger from process inlet face to process outlet face of 35.5 $\mathrm{ft}$, the overall vadose zone model is $76.0 \mathrm{ft}$ wide. The overall $2 \mathrm{D}$ vadose zone model is shown in Figure 3-4. The heat exchanger is centered horizontally and has been located where its lowermost metal structures (i.e. $\mathrm{N}$ cleanouts and $\mathrm{W}$ inlet cooling line) are touching the top of the "Lower Vadose Zone” (LVZ) sandy region. This upper face of the LVZ is located $20 \mathrm{ft}$ below the ground surface.

Only one isolated heat exchanger is being modeled within the vadose zone. As stated above, additional room has been added to maintain the appropriate overall water balance at the ground surface. This approximates a repeating pattern of heat exchangers within a rectangular array.

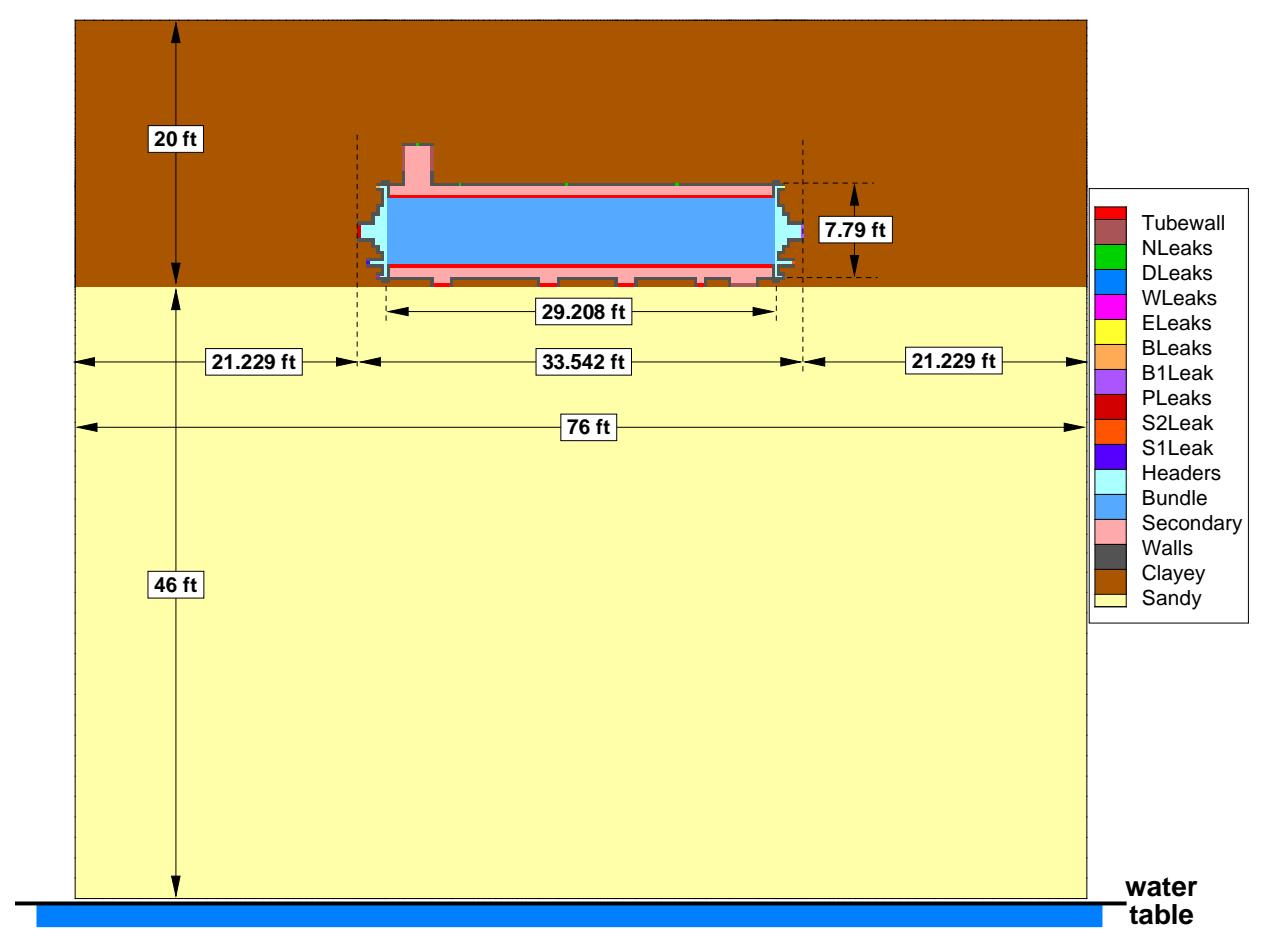

Figure 3-4 Overall layout of 2D vadose zone model showing key geometric elements.

\subsection{Flow Results}

A series of steady-state flow solutions was generated using the geometric model presented above. In this section a description of the boundary conditions and material properties is provided. Relevant information from previous PAs and SAs is used on a case-by-case basis. Those areas where unique aspects of the heat exchanger "Special" waste form exist will be discussed in more detail. 


\subsubsection{Hydraulic Properties}

The hydraulic properties employed were taken from prior PA and SA reports. For soil materials, the properties were taken from the 2008 PA. The properties for the structural components of a heat exchanger, as well as the leakage modeling techniques, were taken from the analysis for the burial of the HWCTR in ST \#14 (Hamm, L. L. and F. G. Smith, III, 2010).

\subsubsection{Ground Surface Infiltration Rates}

Surface infiltration rates were taken from the 2008 PA report for the intact case (i.e. Case01). For the subsidence case (i.e. Case11) the Slit Trench values from the 2008 PA are inappropriate because they were obtained through an averaging method unique to the geometry of five parallel Slit Trenches. The 2008 PA averaging method considered the scenario of one of the five Slit Trenches subsiding while the others remained intact, along with the constraint that only up to $10 \%$ of the waste could be non-crushable containers.

For the burial layout configurations of the nineteen heat exchangers, a different averaging scheme has been employed. It is assumed that the structural integrity of the heat exchangers would make their likelihood of buckling during the $1,000 \mathrm{yr}$ performance period unlikely. Each heat exchanger is made from 304L stainless steel where:

- the headers at end of the heat exchanger are very stiff components with a 0.5 in thick shell;

- $\quad$ the tube bundles with rods inside each tube are densely packed;

- the shell has numerous support structures including several baffle plates; and

- 304L stainless steel has a low corrosion rate.

No structural analysis was performed to confirm the above assumption; therefore, for this SA it is assumed that partial buckling of a heat exchanger is possible. Given the material bundle densities within the heat exchanger, this buckling event can only collapse the regions between the outer diameter of the tube bundle and the heat exchanger shell (i.e. less than one foot of collapse). For a one-foot drop in the ground surface, it is also assumed that sufficient subsidence has occurred to warrant an increase in infiltration rates as shown in the 2008 PA values originally generated by Phifer et al. (2006).

To assist in establishing average infiltration rates under subsidence, the following conservative approach was adopted. The following is a list of assumptions made in obtaining the estimated average infiltration rates:

- Each heat exchanger has the potential to buckle independently of any of the other heat exchangers; and

- Over the 1,000-yr performance period (after end of institutional control) the likelihood of at least one heat exchanger buckling is $50 \%$. Restated, there is a $50 \%$ chance no heat exchanger experiences buckling over the 1,000-yr period.

To estimate the probabilities of occurrence of multiple heat exchangers experiencing buckling during this 1,000-yr period, the binomial distribution function can be employed:

$$
\mathrm{b}(\mathrm{x} ; \mathrm{n}, \theta)=\left(\begin{array}{l}
\mathrm{n} \\
\mathrm{x}
\end{array}\right) \theta^{\mathrm{x}}(1-\theta)^{\mathrm{n}-\mathrm{x}}
$$

where,

n - $\quad$ total number of heat exchangers (19),

$\mathrm{x}$ - $\quad$ number of heat exchangers that buckle (0 to 19),

$\theta$ - probability that one heat exchanger buckle over time period, and 
b - probability that $\mathrm{x}$ heat exchangers buckle over time period.

The leading term in Eq. (3-1) is the binomial coefficient. From the above assumption that there is a $50 \%$ chance of no buckled heat exchangers, the probability of just one buckling, $\theta$, can be computed from Eq. (3-1) to be:

$$
\mathrm{b}(1 ; 19, \theta)=\left(\begin{array}{c}
19 \\
1
\end{array}\right) \theta^{1}(1-\theta)^{19-1}=0.50
$$

The solution using an Excel spreadsheet function is

$$
\theta=0.035824
$$

The probability of more than one heat exchanger buckling can be computed from Eq. (3-1) and the results are listed in Table 3-2.

Table 3-2 Probability of multiple heat exchangers buckling.

\begin{tabular}{|l|c|c|}
\hline \multicolumn{1}{|c|}{ Case } & $\mathbf{X}$ & $\mathbf{b}(\mathbf{x})$ \\
\hline \hline Intact case & 0 & 0.50000 \\
\hline Subsided case & 1 & 0.35297 \\
\hline Subsided case & 2 & 0.11803 \\
\hline Subsided case & 3 & 0.02485 \\
\hline Subsided case & 4 & 0.00369 \\
\hline Subsided case & 5 & 0.00041 \\
\hline Subsided case & 6 & 0.00004 \\
\hline Subsided case & 7 & 0.00000 \\
\hline Subsided case & 8 & 0.00000 \\
\hline Subsided case & 9 & 0.00000 \\
\hline Subsided case & 10 & $2.3159 \mathrm{E}-10$ \\
\hline Subsided case & 11 & $7.0402 \mathrm{E}-12$ \\
\hline Subsided case & 12 & $1.7439 \mathrm{E}-13$ \\
\hline Subsided case & 13 & $3.4889 \mathrm{E}-15$ \\
\hline Subsided case & 14 & $5.5555 \mathrm{E}-17$ \\
\hline Subsided case & 15 & $6.8805 \mathrm{E}-19$ \\
\hline Subsided case & 16 & $6.3911 \mathrm{E}-21$ \\
\hline Subsided case & 17 & $4.1905 \mathrm{E}-23$ \\
\hline Subsided case & 18 & $1.73 \mathrm{E}-25$ \\
\hline Subsided case & 19 & $3.383 \mathrm{E}-28$ \\
\hline & Sum $=$ & 1.00000 \\
\hline
\end{tabular}

As Table 3-2 indicates, the likelihood of more than four to five heat exchangers buckling is vanishingly small. When looking at the various subsidence configurations analyzed in the 2008 PA for the five Slit Trench geometries, we can see that the worst configuration for subsidence was when an end trench subsides. When looking at possible heat exchanger burial footprint layouts, we can see a situation where five or more heat exchangers can reside within the region of an end Slit Trench. Therefore, for this SA the infiltration rate results for an end Slit Trench subsiding only (i.e. middle and center Slit Trenches remaining intact) is employed.

The 2008 PA considered two cases - an intact cap (Case01) and a subsided cap (Case11). In the former case all containers were assumed to crush in 2026 during dynamic compaction and the cap remained intact for all times. In the latter case some containers were assumed not to crush in 2026 during dynamic compaction. Instead, they were assumed to collapse later which would cause the cap to subside locally leading to much higher local infiltration rates.

Values for intact (Case01) and subsided (Case11) conditions were taken and then time-averaged over the 19 different time periods as defined in the event timeline presented in Chapter 1 . The infiltration rates in time and their time-averaged values are listed in Table 3-3 for each of the 19 selected time periods. 
Table 3-3 Intact and subsided averaged surface infiltration rates.

\begin{tabular}{|c|c|c|c|c|c|c|}
\hline & $\begin{array}{c}\text { Relative start } \\
\text { time }\end{array}$ & $\begin{array}{c}\text { Relative end } \\
\text { time }\end{array}$ & $\begin{array}{c}\text { Intact } \\
\text { Case01 } \\
\text { point value }\end{array}$ & $\begin{array}{c}\text { Subsided } \\
\text { Case11 } \\
\text { point value }\end{array}$ & $\begin{array}{c}\text { Intact } \\
\text { Case01 } \\
\text { avg. value }\end{array}$ & $\begin{array}{c}\text { Subsided } \\
\text { Case11 } \\
\text { avg. value }\end{array}$ \\
\hline $\begin{array}{c}\text { Time } \\
\text { index }\end{array}$ & (yr) & (yr) & (cm/yr) & (cm/yr) & (cm/yr) & (cm/yr) \\
\hline \hline T00 & 0.0 & 5.0 & 40.000 & - & 40.000 & - \\
\hline T01 & 5.0 & 13.5 & 40.000 & - & 40.000 & - \\
\hline T02 & 13.5 & 113.5 & 0.914 & - & 0.9144 & - \\
\hline T03 & 113.5 & 163.5 & 0.248 & 123.414 & 0.2541 & 123.4010 \\
\hline T04 & 163.5 & 213.5 & 0.260 & 123.388 & 0.2666 & 123.3755 \\
\hline T05 & 213.5 & 263.5 & 0.273 & 123.363 & 0.6407 & 122.4467 \\
\hline T06 & 263.5 & 313.5 & 1.009 & 121.531 & 1.3765 & 120.6145 \\
\hline T07 & 313.5 & 363.5 & 1.744 & 119.698 & 2.1122 & 118.7823 \\
\hline T08 & 363.5 & 413.5 & 2.480 & 117.866 & 2.8480 & 116.9501 \\
\hline T09 & 413.5 & 463.5 & 3.216 & 116.034 & 3.6868 & 114.8591 \\
\hline T10 & 463.5 & 513.5 & 4.158 & 113.684 & 4.6287 & 112.5093 \\
\hline T11 & 513.5 & 563.5 & 5.100 & 111.334 & 5.5706 & 110.1594 \\
\hline T12 & 563.5 & 613.5 & 6.042 & 108.984 & 6.5125 & 107.8096 \\
\hline T13 & 613.5 & 663.5 & 6.983 & 106.635 & 7.4544 & 105.4597 \\
\hline T14 & 663.5 & 713.5 & 7.925 & 104.285 & 8.5126 & 102.8330 \\
\hline T15 & 713.5 & 813.5 & 9.100 & 101.381 & 10.2743 & 98.4776 \\
\hline T16 & 813.5 & 913.5 & 11.449 & 95.574 & 12.6233 & 92.6705 \\
\hline T17 & 913.5 & 1013.5 & 13.798 & 89.767 & 14.9723 & 86.8634 \\
\hline T18 & 1013.5 & 1113.5 & 16.147 & 83.960 & 17.3213 & 81.0562 \\
\hline
\end{tabular}

To simulate the flow field around a heat exchanger, line sources and line sinks were placed directly above and below the central section of a heat exchanger. These features are highlighted in Figure 3-5. Because a heat exchanger is a three-dimensional cylindrical object and the leak path of most importance resides within its end headers, the best 2D slice was through its axial plane versus a 2D slice through its cross-section. Unfortunately, a significant amount of groundwater flows around its perimeter (i.e. the secondary-side shell) and without accommodating for this net flow, transport time at the water table would be shifted. To correct for this, an appropriate amount of source and sink strengths was added to each simulation. These line strengths were computed based on the infiltration rates being applied at the ground surface for each time period of interest and cover condition being considered. The time-averaged source and sink strengths are given in Table 3-4. 


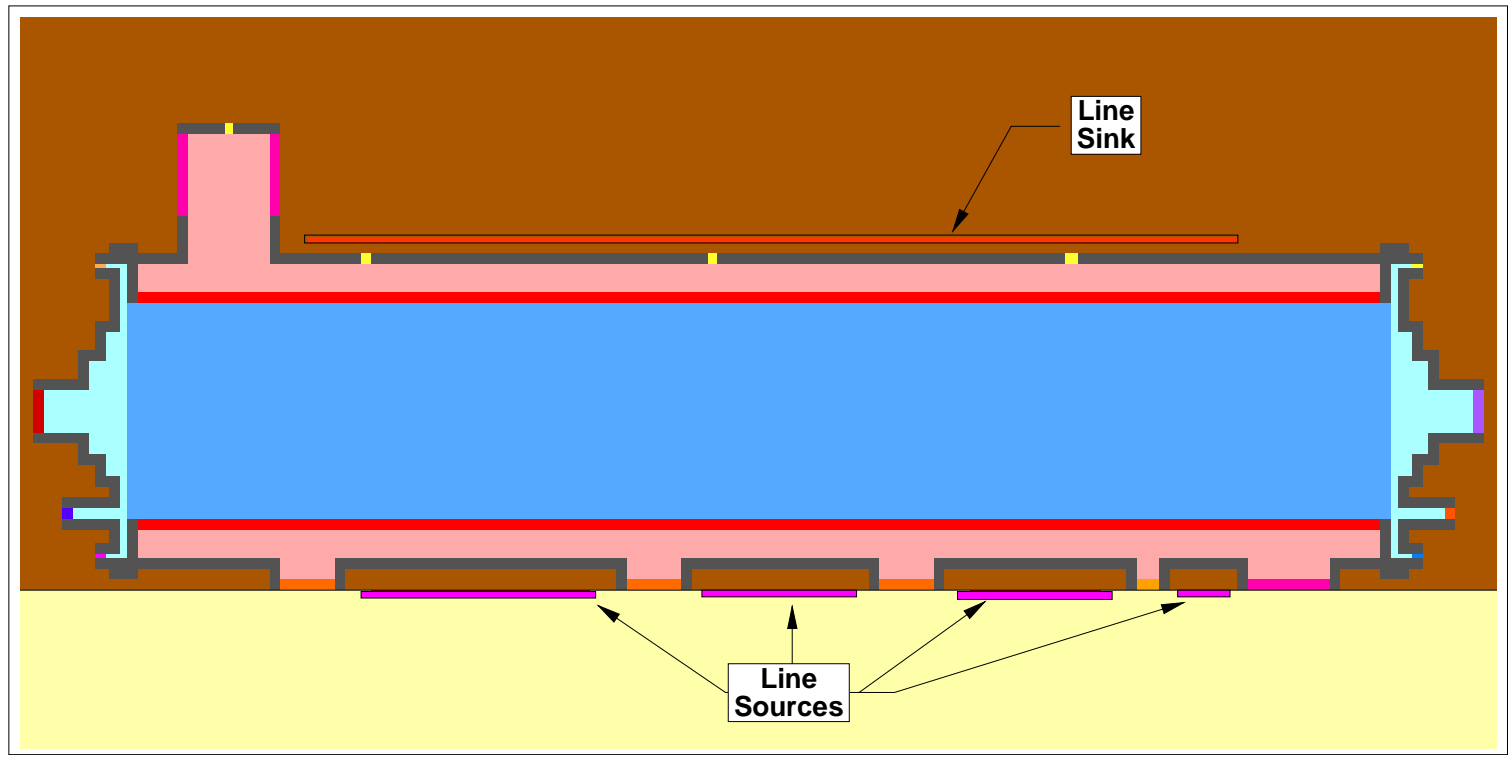

Figure 3-5 No Interim Cover condition showing streamlines around a heat exchanger that is in a fully sealed hydraulic state with 5-yr time markers.

Table 3-4 Intact and subsided averaged source/sink strengths.

\begin{tabular}{|c|c|c|c|c|c|c|}
\hline & $\begin{array}{c}\text { Relative start } \\
\text { time }\end{array}$ & $\begin{array}{c}\text { Relative end } \\
\text { time }\end{array}$ & $\begin{array}{c}\text { Intact } \\
\text { Case01 } \\
\text { sink value }\end{array}$ & $\begin{array}{c}\text { Intact } \\
\text { Case01 } \\
\text { source value }\end{array}$ & $\begin{array}{c}\text { Subsided } \\
\text { Case11 } \\
\text { sink value }\end{array}$ & $\begin{array}{c}\text { Subsided } \\
\text { Case11 } \\
\text { source value }\end{array}$ \\
\hline $\begin{array}{c}\text { Time } \\
\text { index }\end{array}$ & (yr) & (yr) & (cm/yr) & (cm/yr) & (cm/yr) & (cm/yr) \\
\hline \hline T00 & 0.0 & 5.0 & -40.000 & 74.5321 & -40.000 & 74.5321 \\
\hline T01 & 5.0 & 13.5 & -40.000 & 74.5321 & -40.000 & 74.5321 \\
\hline T02 & 13.5 & 113.5 & -0.9144 & 1.7038 & -0.9144 & 1.7038 \\
\hline T03 & 163.5 & 163.5 & -0.2541 & 0.4736 & -123.4010 & 229.9337 \\
\hline T04 & 163.5 & 213.5 & -0.2666 & 0.4967 & -123.3755 & 229.8863 \\
\hline T05 & 213.5 & 263.5 & -0.6407 & 1.1938 & -122.4467 & 228.1556 \\
\hline T06 & 263.5 & 313.5 & -1.3765 & 2.5648 & -120.6145 & 224.7417 \\
\hline T07 & 313.5 & 363.5 & -2.1122 & 3.9357 & -118.7823 & 221.3277 \\
\hline T08 & 363.5 & 413.5 & -2.8480 & 5.3067 & -116.9501 & 217.9138 \\
\hline T09 & 413.5 & 463.5 & -3.6868 & 6.8697 & -114.8591 & 214.0176 \\
\hline T10 & 463.5 & 513.5 & -4.6287 & 8.6247 & -112.5093 & 209.6391 \\
\hline T11 & 513.5 & 563.5 & -5.5706 & 10.3797 & -110.1594 & 205.2606 \\
\hline T12 & 563.5 & 613.5 & -6.5125 & 12.1347 & -107.8096 & 200.8821 \\
\hline T13 & 613.5 & 663.5 & -7.4544 & 13.8898 & -105.4597 & 196.5036 \\
\hline T14 & 663.5 & 713.5 & -8.5126 & 15.8615 & -102.8330 & 191.6093 \\
\hline T15 & 713.5 & 813.5 & -10.2743 & 19.1442 & -98.4776 & 183.4939 \\
\hline T16 & 813.5 & 913.5 & -12.6233 & 23.5211 & -92.6705 & 172.6735 \\
\hline T17 & 913.5 & 1013.5 & -14.9723 & 27.8980 & -86.8634 & 161.8530 \\
\hline T18 & 1013.5 & 1113.5 & -17.3213 & 32.2749 & -81.0562 & 151.0325 \\
\hline
\end{tabular}

To account for the potential slope of a heat exchanger resting at its burial location, a 1\% variation in the ground surface infiltration rates was employed rather than developing a geometrically sloped vadose zone mesh. For example, three ground surface boundary regions exist within the PORFLOW mode:

- $\quad$ RECH1 - surface boundary to the right of the heat exchange burial footprint;

- $\quad$ RECH2 - surface boundary directly over the heat exchange burial footprint; and

- RECH3 - surface boundary to the left of the heat exchange burial footprint;

Under No Interim Cover conditions (i.e. only four feet of soil backfill is present over top the waste) the overall infiltration rate is $40.0 \mathrm{~cm} / \mathrm{yr}$ (i.e. $15.748 \mathrm{in} / \mathrm{yr}$ ). To simulate a slight slope of a heat exchanger the following surface infiltration rates were applied: 
- $\quad$ RECH1 = $39.6 \mathrm{~cm} / \mathrm{yr}$;

- $\quad$ RECH2 $=40.0 \mathrm{~cm} / \mathrm{yr}$; and

- $\quad \mathrm{RECH3}=40.4 \mathrm{~cm} / \mathrm{yr}$;

Overall water budget remains constant with the above infiltration variations.

\subsubsection{Flow Profiles}

In order to perform transient vadose zone transport simulations, a series of steady-state flow profiles were required over the 19 time periods as shown by the time-dependent infiltration rates listed in Table 3-4. In principle, a flow solution at every time period for both leaker and nonleaker heat exchangers would be required covering all possible leak path options and intact as well as subsided conditions. To reduce the large number of flow simulations, once a cover was placed over the Slit Trench, all leak pathways were set fully opened. This greatly reduced the number of flow runs and was shown to only marginally impact inventory limits (i.e. a slight builtin conservatism).

Figure 3-6 shows the flow profile within the vadose zone for a heat exchanger in a fully sealed hydraulic state prior to placement of a cover. Five-year groundwater flow time markers are also shown.

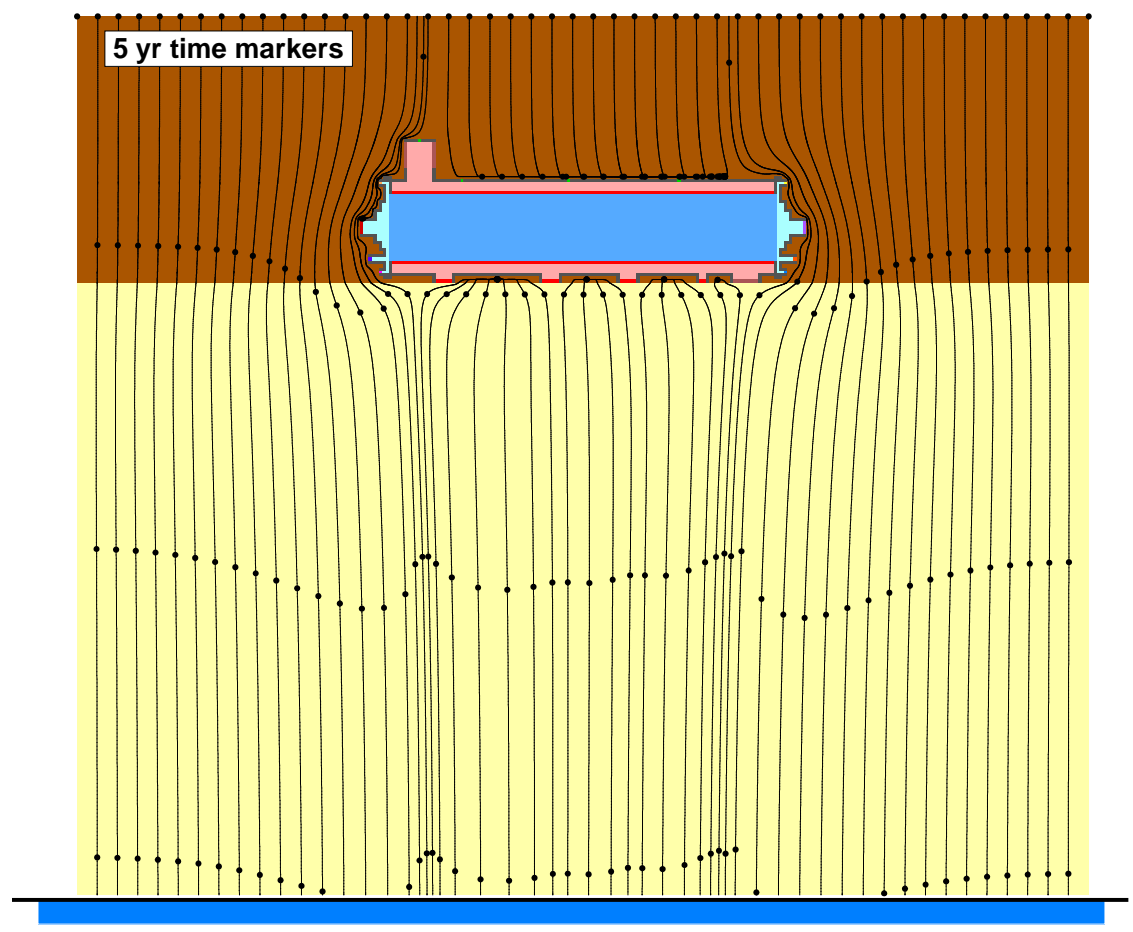

Figure 3-6 No Interim Cover condition showing streamlines around a heat exchanger that is in a fully sealed hydraulic state with 5-yr groundwater flow time markers.

To illustrate the flow profile up close to the heat exchanger and typical flow paths through a heat exchanger, results are shown in Figure 3-7. Here a Leaker type of heat exchanger is shown where all potential leak paths have been set to fully open. The case shown also has no interim cover at the ground surface. This particular case is being shown to illustrate flow fields and does not represent any one of the actual Flow Options employed within this SA. 


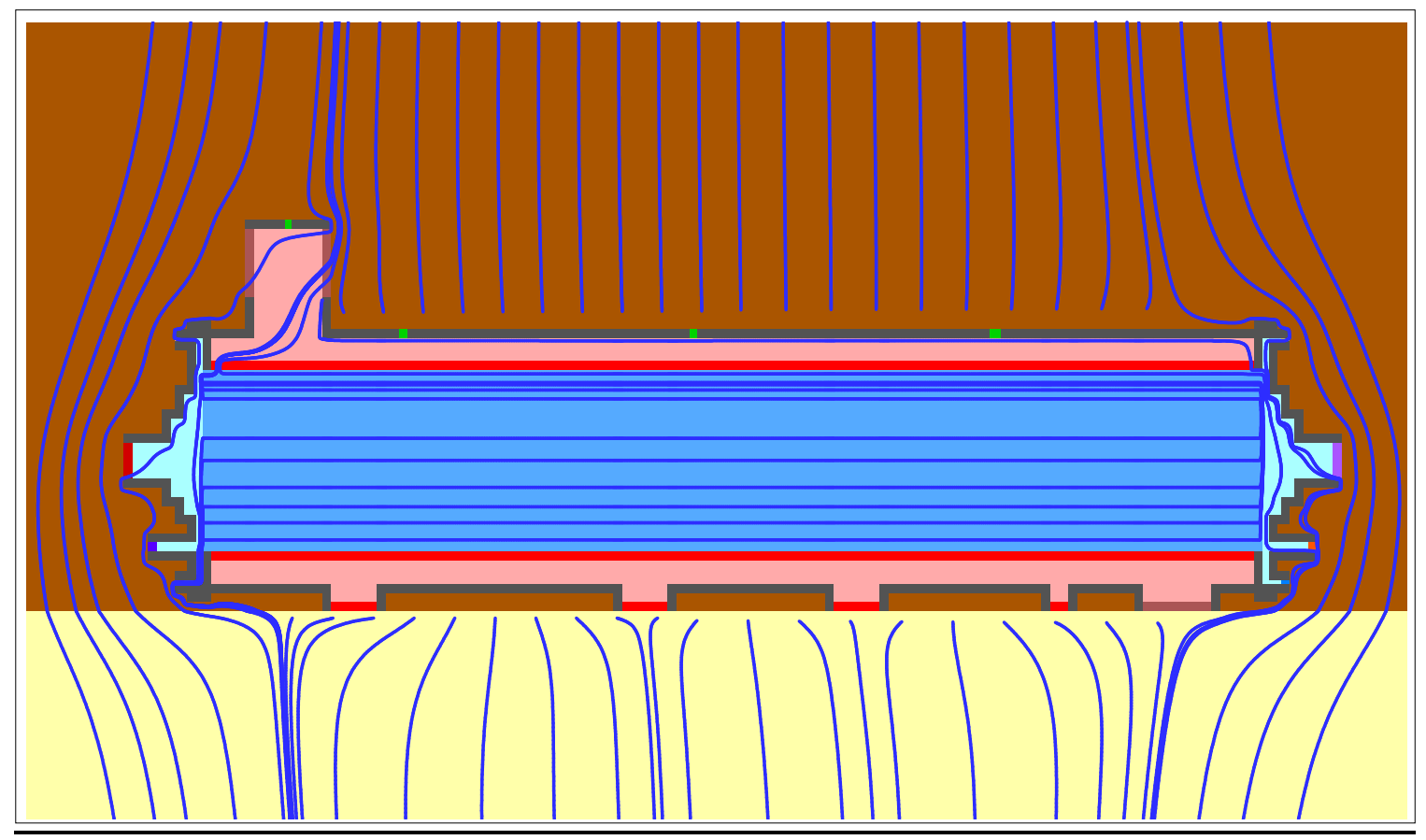

Figure 3-7 Leaker type of heat exchanger under No Interim Cover conditions showing streamlines around the heat exchanger that is in a fully opened hydraulic state.

\subsubsection{Leak Path States}

As mentioned in Chapter 1, nineteen potential leak pathways were explicitly built into the 2D vadose zone model and can be seen in Figure 1-6. For analysis purposes, several of the potential leak paths were grouped together. The primary-side leak paths were left ungrouped due to their importance. The secondary-side leak paths were grouped based on their pathway type (e.g. the $\mathrm{N} 1, \mathrm{~N} 2$, and N3 clean-out ports were grouped into a single N leak path option). The following is a listing of the various leak path options available for flow and transport simulations:

Primary side Leak Paths (Leak paths thru the various primary header nozzles)

- S1Leak: left-side septifoil leak path at primary nozzle

- S2Leak: right-side septifoil leak path at primary nozzle

- P1Leak: left-side process line leak path at primary nozzles

- P2Leak: right-side process line leak path at primary nozzles

- B1Leak: upper left-side drain port line leak path at primary nozzles

- B2Leak: upper right-side drain port line leak path at primary nozzles

- C1Leak: lower left-side drain port line leak path at primary nozzles

- C2Leak: lower right-side drain port line leak path at primary nozzles

Secondary side Leak Paths (Leak paths thru the various secondary shell nozzles)

- ELeaks: vent leak paths on secondary shell (set to metal properties)

- WLeaks: river water line leak paths on secondary shell

- DLeaks: drain port line leak path on secondary shell

- NLeaks: clean out line leak paths on secondary shell

Tube bundle walls separating primary and secondary (Leak paths through Tubewall)

- L1Leaks: leak paths for left-side leaks thru tube bundle walls

- L2Leaks: leak path for right-side leaks thru tube bundle walls 
The last two leak paths (i.e. L1 and L2) are unique in that they establish the type of heat exchanger being considered (i.e. a leaker or non-leaker).

Each type of external leak path is associated with a penetration into the heat exchanger (i.e. nozzle) whose fully opened condition is represented by the cross sectional area of that nozzle. Nozzle diameters are listed in Table 1-1. The hydraulic state of an external leak path (here a specific nozzle location) was established by varying the local hydraulic conductivity at the nozzle mouth. Hydraulic conductivities are computed from water retention properties for unsaturated conditions and the saturated hydraulic conductivity. The two end-state conditions are:

- The fully opened state where the flange or plate material is completely removed and only local hydraulic properties apply. The water retention properties of gravel were assumed. For example, a gravel-saturated hydraulic conductivity of $0.15 \mathrm{~cm} / \mathrm{s}$ applies.

- The fully sealed state where the flange, plate, and gasket material are completely present and functioning. The properties of metal were assumed. The saturated hydraulic conductivity was dropped to the value $5 \times 10^{-15} \mathrm{~cm} / \mathrm{s}$. This value was found to provide adequate flow blockage without excessive numerical demands.

The "effective" saturated hydraulic conductivity for a leak path at a specified nozzle location was computed assuming a parallel flow resistance approximation. Figure 3-8 illustrates the basic approach taken in estimating this effective conductivity value. The effective saturated hydraulic conductivity is computed by:

$$
\mathrm{K}_{\mathrm{eff}}^{\mathrm{sat}}=\eta \mathrm{K}_{\text {gravel }}^{\mathrm{sat}}+(1-\eta) \mathrm{K}_{\text {metal }}^{\mathrm{sat}}
$$

and

$$
\eta=\frac{A_{\text {gap }}}{A_{\text {nozzle }}}=\frac{(\pi \mathrm{Dw})}{\left(\frac{\pi \mathrm{D}^{2}}{4}\right)}=\frac{4 w}{D}
$$

where,

$$
\begin{array}{ll}
\mathrm{D} & \text { inside diameter of specific nozzle, } \\
\mathrm{w} & \text { gap size used as a parameter for varying leakiness, } \\
\mathrm{K}_{\mathrm{eff}}^{\text {sat }} & \text { effective saturated hydraulic conductivity, } \\
\mathrm{K}_{\text {gravel }}^{\text {sat }} & \text { gravel saturated hydraulic conductivity, and } \\
\mathrm{K}_{\text {metal }}^{\text {sat }} & \text { metal saturated hydraulic conductivity. }
\end{array}
$$

The gap size $(\mathrm{w})$ was employed as a parameter to vary the degree of leakage at a specified nozzle. The same approach was employed in determining effective properties for porosity, particle density, and saturated diffusion coefficient values. 


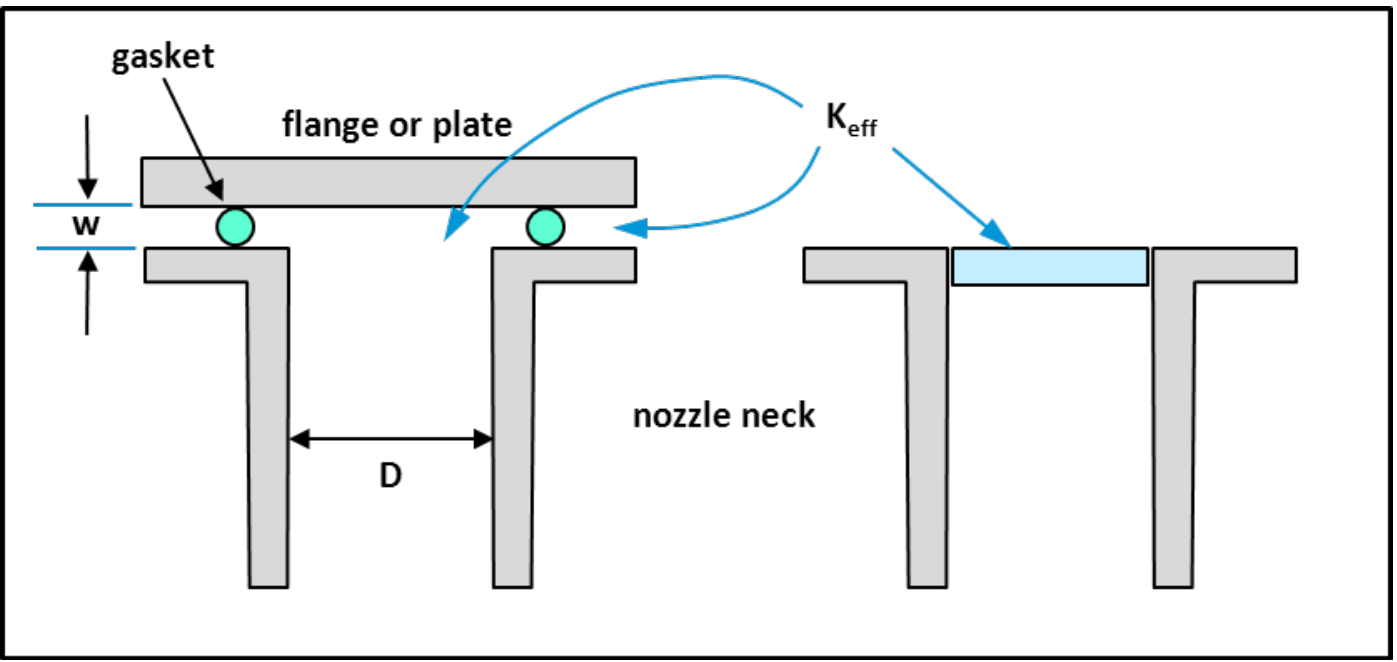

Figure 3-8 Diagram illustrating the method employed to simulate the effective saturated hydraulic conductivity of a leak path.

The following four states were considered for each leak path:

- Fully opened (max. leakage) $-w$ is set to a value where $\eta=1$ resulting in the local region at the mouth of the nozzle with gravel properties.

- Fully closed (no leakage) $-\mathrm{w}$ is set to zero, $\eta=0$, resulting in the local region at the mouth of the nozzle with metal properties.

- Partially opened (min. leakage) $-\mathrm{w}=1 / 64$ in resulting in the local region at the mouth of the nozzle with a mixture of gravel and metal properties. The specific value of $\eta$ varies for each nozzle type by Eq. (3-4).

- Partially opened (avg. leakage) $-w=1 / 16$ in resulting in the local region at the mouth of the nozzle with a mixture of gravel and metal properties. The specific value of $\eta$ varies for each nozzle type by Eq. (3-4).

A unique "Flow Option" is defined by:

- Selecting either a Leaker or Non-leaker heat exchanger by setting the L1 and L2 leak paths to one of the above leakage states;

- Selecting each external leak path, one of the four leakage states above (B1, B2, C1, C2, S1, S2, P1 and P2 for the primary-side and E, D, N, and W for the secondary-side); and

- Selecting either an intact or subsidence condition for the time period of interest.

The third item above only occurs once a cover is placed (i.e. post end of institutional control). As mentioned earlier, to reduce the total number of Flow Options considered, the first two items are set to fully open beyond the start of institutional control.

For book keeping purposes (and automation of analyses) each unique Flow Option was given an option number. Table 3-5 provides a representative sampling of the various Flow Options considered. 
Table 3-5 Representative sample of the Flow Options ${ }^{\mathrm{a}}$ employed in vadose zone analyses.

\begin{tabular}{|c|c|c|c|c|c|c|c|c|c|c|c|c|c|c|c|}
\hline $\begin{array}{l}\text { Option } \\
\text { ID }\end{array}$ & $\begin{array}{l}\text { Time } \\
\text { period }\end{array}$ & B1 & B2 & C1 & C2 & S1 & S2 & P1 & P2 & L1 & L2 & E & D & $\mathbf{N}$ & w \\
\hline 1 & \multirow[t]{27}{*}{$0-13.5$} & 1 & 1 & 1 & 1 & 1 & 1 & 1 & 1 & 1 & 1 & 0 & 1 & 1 & 1 \\
\hline 2 & & $1 / 64$ & $1 / 64$ & $1 / 64$ & $1 / 64$ & $1 / 64$ & $1 / 64$ & $1 / 64$ & $1 / 64$ & $1 / 64$ & $1 / 64$ & 0 & $1 / 64$ & $1 / 64$ & $1 / 64$ \\
\hline 3 & & $1 / 16$ & $1 / 16$ & $1 / 16$ & $1 / 16$ & $1 / 16$ & $1 / 16$ & $1 / 16$ & $1 / 16$ & $1 / 16$ & $1 / 16$ & 0 & $1 / 16$ & $1 / 16$ & $1 / 16$ \\
\hline 5 & & $1 / 16$ & $1 / 16$ & $1 / 16$ & $1 / 16$ & $1 / 64$ & $1 / 64$ & 0 & 0 & $1 / 16$ & 0 & 0 & 0 & 0 & 0 \\
\hline 6 & & $1 / 16$ & $1 / 16$ & $1 / 16$ & $1 / 16$ & $1 / 64$ & $1 / 64$ & $1 / 64$ & $1 / 64$ & $1 / 16$ & 0 & 0 & 0 & 0 & 0 \\
\hline 7 & & $1 / 16$ & $1 / 16$ & $1 / 16$ & $1 / 16$ & $1 / 64$ & $1 / 64$ & 0 & 0 & $1 / 16$ & $1 / 64$ & 0 & $1 / 64$ & $1 / 64$ & $1 / 64$ \\
\hline 8 & & $1 / 16$ & $1 / 16$ & $1 / 16$ & $1 / 16$ & $1 / 64$ & $1 / 64$ & $1 / 64$ & $1 / 64$ & $1 / 16$ & $1 / 64$ & 0 & $1 / 64$ & $1 / 64$ & $1 / 64$ \\
\hline 9 & & $1 / 64$ & $1 / 64$ & $1 / 64$ & $1 / 64$ & $1 / 64$ & $1 / 64$ & 0 & 0 & $1 / 64$ & 0 & 0 & 0 & 0 & 0 \\
\hline 10 & & $1 / 64$ & $1 / 64$ & $1 / 64$ & $1 / 64$ & $1 / 64$ & $1 / 64$ & $1 / 64$ & $1 / 64$ & $1 / 64$ & 0 & 0 & 0 & 0 & 0 \\
\hline 11 & & $1 / 64$ & $1 / 64$ & $1 / 64$ & $1 / 64$ & $1 / 64$ & $1 / 64$ & 0 & 0 & $1 / 64$ & $1 / 64$ & 0 & $1 / 64$ & $1 / 64$ & $1 / 64$ \\
\hline 12 & & $1 / 64$ & $1 / 64$ & $1 / 64$ & $1 / 64$ & $1 / 64$ & $1 / 64$ & $1 / 64$ & $1 / 64$ & $1 / 64$ & $1 / 64$ & 0 & $1 / 64$ & $1 / 64$ & $1 / 64$ \\
\hline 13 & & $1 / 16$ & $1 / 16$ & $1 / 16$ & $1 / 16$ & 1 & 1 & 1 & 1 & $1 / 16$ & 0 & 0 & 0 & 0 & 1 \\
\hline 14 & & $1 / 16$ & $1 / 16$ & $1 / 16$ & $1 / 16$ & 1 & 1 & 1 & 1 & $1 / 16$ & $1 / 64$ & 0 & 0 & 0 & 1 \\
\hline 15 & & $1 / 16$ & $1 / 16$ & $1 / 16$ & $1 / 16$ & $1 / 16$ & $1 / 16$ & $1 / 16$ & $1 / 16$ & $1 / 16$ & 0 & 0 & 0 & 0 & $1 / 16$ \\
\hline 16 & & $1 / 16$ & $1 / 16$ & $1 / 16$ & $1 / 16$ & $1 / 16$ & $1 / 16$ & $1 / 16$ & $1 / 16$ & $1 / 16$ & $1 / 64$ & 0 & 0 & 0 & $1 / 16$ \\
\hline 17 & & $1 / 16$ & $1 / 16$ & $1 / 16$ & $1 / 16$ & 0 & 0 & 0 & 0 & $1 / 16$ & 0 & 0 & $1 / 64$ & 0 & 0 \\
\hline 18 & & $1 / 16$ & $1 / 16$ & $1 / 16$ & $1 / 16$ & 0 & 0 & 0 & 0 & $1 / 16$ & $1 / 64$ & 0 & 0 & 0 & 0 \\
\hline 19 & & $1 / 64$ & $1 / 64$ & 0 & 0 & 0 & 0 & $1 / 64$ & $1 / 64$ & $1 / 64$ & 0 & 0 & 0 & 0 & $1 / 64$ \\
\hline 20 & & $1 / 64$ & $1 / 64$ & 0 & 0 & $1 / 64$ & $1 / 64$ & $1 / 64$ & $1 / 64$ & $1 / 64$ & 0 & 0 & 0 & 0 & $1 / 64$ \\
\hline 21 & & $1 / 64$ & $1 / 64$ & 0 & 0 & 0 & 0 & $1 / 64$ & $1 / 64$ & $1 / 64$ & $1 / 64$ & 0 & 0 & 0 & $1 / 64$ \\
\hline 22 & & 0 & 0 & 0 & 0 & 0 & 0 & 0 & 0 & 0 & $1 / 64$ & 0 & 0 & 0 & $1 / 64$ \\
\hline 23 & & 0 & 0 & 0 & 0 & 0 & 0 & 0 & 0 & 0 & $1 / 64$ & 0 & $1 / 64$ & $1 / 64$ & $1 / 64$ \\
\hline 24 & & $1 / 16$ & $1 / 16$ & $1 / 16$ & $1 / 16$ & 0 & 0 & 0 & 0 & $1 / 16$ & $1 / 64$ & 0 & 0 & 0 & $1 / 64$ \\
\hline 25 & & $1 / 16$ & $1 / 16$ & $1 / 16$ & $1 / 16$ & 0 & 0 & 0 & 0 & $1 / 16$ & $1 / 64$ & 0 & $1 / 64$ & $1 / 64$ & $1 / 64$ \\
\hline 26 & & $1 / 64$ & 0 & $1 / 64$ & 0 & $1 / 64$ & 0 & $1 / 64$ & 0 & $1 / 64$ & $1 / 64$ & 0 & 0 & 0 & $1 / 64$ \\
\hline 27 & & 0 & $1 / 64$ & 0 & $1 / 64$ & 0 & $1 / 64$ & 0 & $1 / 64$ & 0 & $1 / 64$ & 0 & 0 & 0 & $1 / 64$ \\
\hline 28 & & $1 / 64$ & 0 & $1 / 64$ & 0 & $1 / 64$ & 0 & $1 / 64$ & 0 & $1 / 64$ & $1 / 64$ & 0 & 0 & $1 / 64$ & 0 \\
\hline
\end{tabular}

a - (1) for max leakage; (1/16) for avg. leakage; (1/64) for min leakage; (0) for no leakage [sealed].

Only 28 out of the 98 Flow Options for the time periods prior to start of institutional control (i.e. 0 to $13.5 \mathrm{yr}$ ) are listed in Table 3-5. Beyond the start of institutional control (i.e. beyond $13.5 \mathrm{yr}$ ) an additional 32 Flow Options were employed. Table 3-6 provides a small sample of these Flow Options. The completely opened heat exchanger leakage state (i.e. leakage states from Flow Option 1 above) was assumed and only the infiltration rates changed with time period. The E vents are very small potential leak paths and were left closed in this set of analyses to better address flow diversion around the shell of the heat exchangers.

Table 3-6 Representative sample of the Flow Options ${ }^{\mathrm{a}}$ employed beyond start of institutional control.

\begin{tabular}{|c|c|c|c|c|c|c|c|c|c|c|c|c|c|c|c|}
\hline $\begin{array}{c}\text { Option } \\
\text { ID }\end{array}$ & $\begin{array}{c}\text { Time } \\
\text { period }\end{array}$ & B1 & B2 & C1 & C2 & S1 & S2 & P1 & P2 & L1 & L2 & E & D & N & W \\
\hline 52_T03 & T03 & 1 & 1 & 1 & 1 & 1 & 1 & 1 & 1 & 1 & 1 & 0 & 1 & 1 & 1 \\
\hline 52_T04 & T04 & 1 & 1 & 1 & 1 & 1 & 1 & 1 & 1 & 1 & 1 & 0 & 1 & 1 & 1 \\
\hline 52_T05 & T05 & 1 & 1 & 1 & 1 & 1 & 1 & 1 & 1 & 1 & 1 & 0 & 1 & 1 & 1 \\
\hline 52_T06 & T06 & 1 & 1 & 1 & 1 & 1 & 1 & 1 & 1 & 1 & 1 & 0 & 1 & 1 & 1 \\
\hline
\end{tabular}

a - (1) for max leakage; (1/16) for avg. leakage; (1/64) for min leakage; (0) for no leakage [sealed].

Flow solutions for each Flow Option were created. Each flow solution was processed to determine its level of accuracy with respect to mass balance errors. For each Flow Option, solutions were created where local mass balance errors (indicated by local mass residuals) were maintained below $1 \times 10^{-5}$. Prior experience has indicated that this mass residual tolerance provides adequate vadose zone flow fields acceptable for subsequent vadose zone transport simulations. 


\subsubsection{Fill Times}

Because corrosion rates are dependent upon the environmental conditions, such as 304L stainless steel in contact with either moist air or groundwater, an estimate of the timing required to fill a heat exchanger was made. A minimum bound estimate was computed for each of the Flow Options mentioned above. A minimum value was computed for the tube bundle region where for each steady-state flow solution the inlet flow rates were used while the outlet flow rates were set to zero. The results of these analyses are summarized in Figure 3-9. The following estimates were employed in corrosion-based source term release calculations:

- Best estimate value - set to $20.0 \mathrm{yr}$ and represents a best estimate of the lower bound time to fill; and

- Conservative estimate value - set to $10.0 \mathrm{yr}$ and represents an absolute lower bound time to fill.

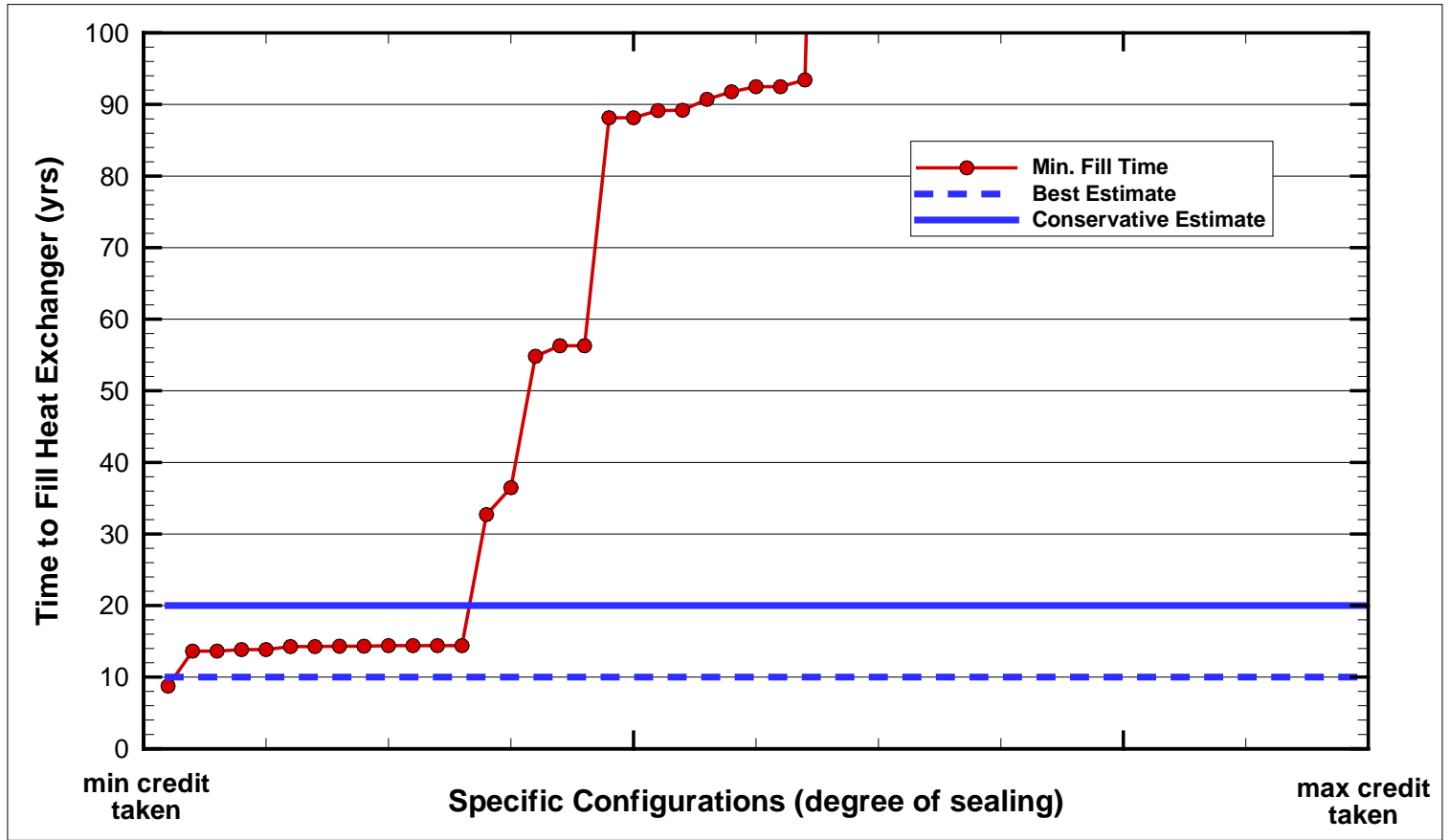

Figure 3-9 Estimated minimum timing required to fill a heat exchanger versus the various Flow Options considered.

\subsection{Transport Results}

The vadose zone transport results show that the H-3 flux to the water table is very sensitive with respect to the integrity of the heat exchanger and the type of release mechanism assumed. However, for C-14, this sensitivity is greatly reduced and its behavior is more dominated by the infiltration rate after subsidence.

\subsubsection{Scenario Naming Convention}

The composite leak path state of a buried heat exchanger can:

- initially vary subject to uncertainties associated with each heat exchanger's actual physical condition and variations in the application of requested sealing techniques; and

- change over time (e.g. degradation of gaskets, coatings, wrappings, or bonnets) due to its continual contact with slightly acidic groundwater.

At each point in time, a specific composite leak path state exists and the steady-state flow field is taken from the list of possible composite states provided in the "Flow Options" discussed in the 
previous sections (e.g. see Tables 3-5 and 3-6). To account for these two items, a host of vadose zone transport analyses was performed and the naming convention employed is discussed.

In addition to the time variation of a heat exchanger's composite leak path state, uncertainties exist pertaining to the degree of contaminant release per unit time. As discussed in Chapter 1, four different release rate models were considered. Based on these various aspects, a scenario naming convention was established to better organize the multitude of analyses required.

The scenario naming convention consists of combining individual states or conditions to form unique scenarios. An example of a convention name is as follows:

\section{- OptionT1_YL_NB_DC_BE}

The various states/options are separated by underscores as follows:

\section{- OpeningState_LeakerState_LineBkSetState_ReleaseMechanism_ReleaseOption}

Leak path states are defined for given time periods (see Flow Option in earlier section) while the progression through multiple leak path states is represented by a time series of these leak path states. The complete definition of a series of leak path states is achieved by specifying both the OpeningState and LineBkSetState options are shown in Table 3-7 and discussed below. Note that the Al flanges have no gaskets.

Table 3-7 Opening state identifiers and their descriptions.

\begin{tabular}{|c|c|c|c|c|c|}
\hline \multicolumn{6}{|c|}{ Opening State (applied to flow and transport) } \\
\hline LineBkSetState & Identifier & Gaskets & Al plates & Valves & Comments \\
\hline \multirow[t]{7}{*}{ NB \& YB sets } & OptionT1 & closed & $1 / 64$ open & closed & \multirow{7}{*}{$\begin{array}{c}0-5 \mathrm{yr} \text { at the } \mathrm{T} 1 \text { state, } \\
\text { then } 5-13.5 \mathrm{yr} \text { remaining states }\end{array}$} \\
\hline & OptionT2 & closed & 1/16 open & closed & \\
\hline & OptionT2b & closed & Full open & closed & \\
\hline & OptionT3a & $1 / 64$ open & $1 / 16$ open & $1 / 64$ open & \\
\hline & OptionT3b & 1/64 open & $1 / 16$ open & $1 / 64$ open & \\
\hline & OptionT3ab & $1 / 64$ open & Full open & $1 / 64$ open & \\
\hline & OptionT3bb & 1/64 open & Full open & 1/64 open & \\
\hline \multirow[t]{6}{*}{ NB2 set } & OptionT2 & closed & 1/16 open & closed & \multirow{6}{*}{$\begin{array}{c}0-5 \mathrm{yr} \text { sealed state, } \\
\text { then } 5-13.5 \mathrm{yr} \text { at these states }\end{array}$} \\
\hline & OptionT2b & closed & Full open & closed & \\
\hline & OptionT3a & $1 / 64$ open & $1 / 16$ open & $1 / 64$ open & \\
\hline & OptionT3b & $1 / 64$ open & $1 / 16$ open & 1/64 open & \\
\hline & OptionT3ab & $1 / 64$ open & Full open & $1 / 64$ open & \\
\hline & OptionT3bb & $1 / 64$ open & Full open & $1 / 64$ open & \\
\hline \multirow[t]{6}{*}{ NB3 set } & OptionT2 & closed & $1 / 16$ open & closed & \multirow{6}{*}{$\begin{array}{c}0-5 \mathrm{yr} \text { sealed state, } \\
\text { then } 5-8.5 \mathrm{yr} \text { T1 state, } \\
\text { then } 8.5-13.5 \mathrm{yr} \text { at these states }\end{array}$} \\
\hline & OptionT2b & closed & Full open & closed & \\
\hline & OptionT3a & $1 / 64$ open & $1 / 16$ open & $1 / 64$ open & \\
\hline & OptionT3b & $1 / 64$ open & $1 / 16$ open & $1 / 64$ open & \\
\hline & OptionT3ab & $1 / 64$ open & Full open & $1 / 64$ open & \\
\hline & OptionT3bb & 1/64 open & Full open & $1 / 64$ open & \\
\hline
\end{tabular}

Vadose zone transport simulations were performed for both the leaker and non-leaker heat exchanger types. Table 3-8 provides the identifier employed.

Table 3-8 Leaker versus non-leaker heat exchanger type identifier.

\begin{tabular}{|c|c|}
\hline \multicolumn{2}{|c|}{ LeakerState (applied to flow and transport) } \\
\hline Identifier & $\begin{array}{c}\text { Internal leaker state } \\
\text { YL } \\
\text { throughout entire simulation period. }\end{array}$ \\
\hline NL & $\begin{array}{c}\text { No bundle tube wall leakage (L1, L2) } \\
\text { prior to cover placement (0-13.5 } \mathrm{yr} \text { ) and } \\
\text { then tube wall leakage for the } \\
\text { remainder of the simulation period. }\end{array}$ \\
\hline
\end{tabular}

A line break option was included in the list of analyses considered. Table 3-9 provides the identifier employed to indicate the state of the 0.5-in lines. Included within this identifier is the 
degree of sealing achieved by the various activities performed to reduce change of external leakage.

Table 3-9 Leaker versus non-leaker heat exchanger type identifier.

\begin{tabular}{|c|c|c|}
\hline \multicolumn{3}{|c|}{ LineBreakSetState (applied to flow and transport) } \\
\hline Identifier & Line break & Sealing state \\
\hline NB & No & $\begin{array}{c}\text { Poor - varying degree of leakage occurring from } \\
\text { initial burial on (0-13.5 yr) }\end{array}$ \\
\hline NB2 & & $\begin{array}{l}\text { Average - No leakage occurs during first } 5 \mathrm{yr}(0-5 \\
\mathrm{yr}) \text {, then modest leakage for next } 8.5 \mathrm{yr}(5-13.5 \mathrm{yr})\end{array}$ \\
\hline NB3 & & $\begin{array}{l}\text { Good - No leakage occurs during first } 5 \mathrm{yr}(0-5 \mathrm{yr}) \text {, } \\
\text { then slight leakage for next } 5 \mathrm{yr}(5-10 \mathrm{yr}) \text {, followed } \\
\text { by modest leakage for next } 3.5 \mathrm{yr}(10-13.5 \mathrm{yr})\end{array}$ \\
\hline YB & Yes & $\begin{array}{c}\text { Poor - varying degree of leakage occurring from } \\
\text { initial burial on ( } 0-13.5 \mathrm{yr}) \text { in addition to the line } \\
\text { break leakage impact. }\end{array}$ \\
\hline
\end{tabular}

A range of contaminant release rates was considered. Both the traditional instant release mode employed for "Generic" waste forms and a finite release mode were considered. The modeling details for these different source terms are discussed in Appendices A and B. The finite release rate mode employed was based on surface corrosion rates and diffusion through metal. Table 310 lists the release mechanism mode identifier for these two options. Under the finite release mechanism mode, C-14 is handled only by surface corrosion since C-14 does not atomically diffuse into the metal matrix appreciably.

Table 3-10 Contaminant release mechanism identifier.

\begin{tabular}{|c|c|}
\hline \multicolumn{2}{|c|}{ ReleaseMechanism (applied only to transport) } \\
\hline Identifier & Condition \\
\hline II & $\begin{array}{r}\text { Instantaneous release from oxide surface (for H-3 and C-14) and from inside metal (for } \\
\mathrm{H}-3 \text { only) }\end{array}$ \\
\hline DC & $\begin{array}{r}\text { Diffusion from inside metal (for H-3 only) and surface corrosion of oxide layer } \\
\text { (for H-3 and C-14) [C-14 only is present in oxide layer] }\end{array}$ \\
\hline
\end{tabular}

The finite release rate computed under the surface corrosion mechanism required specification of the following three factors (see Appendix B for details):

- The initial thickness of the surface oxide layer (a best estimate value of $5 \mu \mathrm{m}$ and a conservative estimate value of $3 \mu \mathrm{m}$ was employed);

- The delay time prior to the start of leakage into the primary-side of the heat exchanger vessel (since surface contamination is limited to primary-side surfaces only). To be consistent with the assumed degree of sealing, a 5-yr delay was employed here.

- The minimum time required to fill the primary-side of the heat exchanger. Minimum values are being employed to ensure a degree of conservatism where the best estimate of this min. value was set to $10 \mathrm{yr}$ and a conservative estimate of this min, value was set to $20 \mathrm{yr}$.

Because corrosion rates depend upon whether the surfaces are being exposed to moist air or groundwater, local release rates are different for tube surfaces above and below the water level during the fill process. Migration of the contaminant depends upon mobile groundwater being present. Given these two aspects, an effective storage of released contaminant exists in those tube bundle and header regions that are in contact with moist air only. The option to utilize this storage mechanism was also considered. Table 3-11 lists the three options considered in the analyses (note that all combinations were not addressed, because the line break would be prevented by some of the ACP mitigating activities). 
Table 3-11 Release option identifier indicating assumed oxide layer thickness, delay prior to vessel leakage, and minimum time required to fill vessel.

\begin{tabular}{|c|c|c|c|c|c|c|}
\hline Identifier & Line State & $\begin{array}{l}\text { Degree of } \\
\text { Sealing }\end{array}$ & $\begin{array}{c}\text { Oxide layer } \\
\text { thickness } \\
(\mu \mathrm{m})\end{array}$ & $\begin{array}{c}\text { Delay of } \\
\text { Leakage } \\
\text { (yr) }\end{array}$ & $\begin{array}{l}\text { Min. Time } \\
\text { to Fill (yr) }\end{array}$ & Storage \\
\hline \multirow[t]{4}{*}{ BE } & Line Break & poor & \multirow[t]{4}{*}{5} & \multirow[t]{2}{*}{0} & \multirow[t]{4}{*}{20} & \multirow[t]{4}{*}{ None } \\
\hline & \multirow[t]{3}{*}{$\begin{array}{c}\text { No Line } \\
\text { Break }\end{array}$} & poor & & & & \\
\hline & & average & & 5 & & \\
\hline & & good & & & & \\
\hline \multirow[t]{4}{*}{ CE } & Line Break & poor & \multirow[t]{4}{*}{3} & \multirow[t]{2}{*}{0} & \multirow[t]{4}{*}{10} & \multirow[t]{4}{*}{ None } \\
\hline & \multirow[t]{3}{*}{$\begin{array}{c}\text { No Line } \\
\text { Break }\end{array}$} & poor & & & & \\
\hline & & average & & 5 & & \\
\hline & & good & & & & \\
\hline \multirow[t]{4}{*}{ CE_Storage } & Line Break & poor & \multirow[t]{4}{*}{3} & \multirow[t]{2}{*}{0} & \multirow[t]{4}{*}{10} & \multirow[t]{4}{*}{ Yes } \\
\hline & \multirow[t]{3}{*}{$\begin{array}{c}\text { No Line } \\
\text { Break }\end{array}$} & poor & & & & \\
\hline & & average & & \multirow[t]{2}{*}{5} & & \\
\hline & & good & & & & \\
\hline
\end{tabular}

\subsubsection{Transport Properties}

The transport properties employed were taken from prior SA reports. Because the heat exchangers do not have CDP present only non-CDP values are addressed. The main item that has changed since the 2008 PA is the $K_{d}$ values for C-14 in soil. A listing of these values is provided in Table 3-12.

Table 3-12 $K_{d}$ values employed in transport analyses compared with prior values.

\begin{tabular}{|c|c|c|c|c|c|c|}
\hline Element & $\begin{array}{l}\text { PA2008 } \\
\text { Sand } K_{d} \\
(\mathrm{ml} / \mathrm{g})\end{array}$ & $\begin{array}{c}\text { PA2008 } \\
\text { Sand K } \\
(\mathrm{ml} / \mathrm{g})\end{array}$ & $\begin{array}{c}\text { Kaplan } \\
2010 \\
\text { Sand K } \\
(\mathrm{ml} / \mathrm{g})\end{array}$ & $\begin{array}{c}\text { Kaplan } \\
2010 \\
\text { Clay K } \\
(\mathrm{ml} / \mathrm{g})\end{array}$ & $\begin{array}{c}\text { ET \#3 Down- } \\
\text { select } \\
\text { Sand } K_{d} \\
(\mathrm{ml} / \mathrm{g})\end{array}$ & $\begin{array}{c}\text { ET \#3 Down- } \\
\text { select } \\
\text { Clay K } \\
(\mathrm{ml} / \mathrm{g})\end{array}$ \\
\hline \multirow{2}{*}{$\begin{array}{l}\mathrm{C} \\
\mathrm{H}\end{array}$} & 0 & 0 & 10 & 400 & 1 & 30 \\
\hline & 0 & 0 & 0 & 0 & 0 & 0 \\
\hline
\end{tabular}

Database $K_{d}$ values (Kaplan 2010) for $C$ are 10 and $400 \mathrm{ml} / \mathrm{g}$ for sand and clay, respectively. However, about six months of contact time is needed to achieve equilibrium (Roberts and Kaplan 2008), and groundwater moves much faster so local equilibrium would never be achieved. Therefore $K_{d}$ values after one or two days of contact time were selected as effective modeling values (as shown in Table 3-12), i.e. $1 \mathrm{ml} / \mathrm{g}$ and $30 \mathrm{ml} / \mathrm{g}$. These values were also used in Collard and Hamm (2012).

The $K_{d}$ values for H-3 and C-14 were set to zero for all regions representing metal walls, internal regions of the heat exchanger, and leakage path regions (i.e. specifically for the materials metal and gravel).

\subsubsection{Transport Scenarios}

There were a total of 208 (for $\mathrm{H}-3$ ) and 416 (for C-14) vadose zone transport scenarios considered and deduced from Table 3-13. 
Table 3-13 Overall tally of scenarios considered in vadose zone transport analysis.

\begin{tabular}{|c|c|c|c|c|c|c|}
\hline Nuclide & Case & Open State & $\begin{array}{c}\text { Heat } \\
\text { Exchanger } \\
\text { Type }\end{array}$ & $\begin{array}{l}\text { Leakage } \\
\text { Set } \\
\text { (includes } \\
\text { line break) }\end{array}$ & $\begin{array}{c}\text { Release } \\
\text { Model }\end{array}$ & Comment \\
\hline \multirow[t]{2}{*}{ C-14 } & \multirow{2}{*}{$\begin{array}{c}\text { (Intact) } \\
\text { or } \\
\text { Case11 } \\
\text { (subsided) }\end{array}$} & OptionT1 & $\begin{array}{l}\mathrm{NL} \\
\mathrm{YL}\end{array}$ & $\begin{array}{l}\mathrm{YB} \\
\mathrm{NB}\end{array}$ & $\begin{array}{c}\text { II } \\
\text { BE } \\
\text { CE } \\
\text { CE_Storage }\end{array}$ & $\begin{array}{l}\text { Total of } 16 \text { scenarios per } \\
\text { case (intact only for } \mathrm{H}-3 \\
\text { and both for } \mathrm{C}-14 \text { ). }\end{array}$ \\
\hline & & $\begin{array}{c}\text { OptionT2 } \\
\text { OptionT2b } \\
\text { OptionT3a } \\
\text { OptionT3ab } \\
\text { OptionT3b } \\
\text { OptionT3bb }\end{array}$ & $\begin{array}{l}\mathrm{NL} \\
\mathrm{YL}\end{array}$ & $\begin{array}{c}\text { YB } \\
\\
\text { NB } \\
\text { NB2 } \\
\text { NB3 }\end{array}$ & $\begin{array}{c}\text { II } \\
\text { BE } \\
\text { CE } \\
\text { CE_Storage }\end{array}$ & $\begin{array}{l}\text { Total of } 192 \text { scenarios per } \\
\text { case (intact only for H-3 } \\
\text { and both for C-14). }\end{array}$ \\
\hline
\end{tabular}

Table 3-13 entries are:

- 2 radionuclides considered ( $\mathrm{H}-3$ and $\mathrm{C}-14)$;

- $1 \mathrm{x}$ [Case01] - (intact) case only considered since H-3 significantly decayed by the end of institutional control (113.5 yr after burial) while 2x for C-14 [Case01 and Case11];

- $7 \mathrm{x}$ [open states] - a range of leakage state strategies considered to assess impact of leakage on inventory limits;

- 2x [heat exchanger type] - leaker and non-leaker heat exchangers (i.e. YL and NL);

- $2 x$ or $4 x$ [leakage state sets] - timing of changes in leakage states that includes initial line break option;

- $4 x$ [release model] - four release models considered (i.e. II, BE, CE, CE_Storage);

To provide as examples of particular vadose zone transport scenarios, Table 3-14 lists the following two scenarios (same basic scenario for a leaker and a non-leaker heat exchanger):

- OptionT2_NL_NB3 - Non-leaker with four scenarios (II, BE, CE, CE_Storage); and

- OptionT2_YL_NB3 - Leaker with four scenarios (II, BE, CE, CE_Storage).

Table 3-14 Example of vadose zone transport analysis scenarios ${ }^{\mathrm{a}}$ based on OptionT2_NL_NB3 and Optiont2_YL_NB3 (four scenarios for each would result when release models are added).

\begin{tabular}{|c|c|c|c|c|c|c|c|c|c|c|c|c|c|c|c|}
\hline $\begin{array}{c}\text { Option } \\
\text { ID }\end{array}$ & $\begin{array}{c}\text { Time } \\
\text { period }\end{array}$ & B1 & B2 & C1 & C2 & S1 & S2 & P1 & P2 & L1 & L2 & E & D & N & W \\
\hline Leaker & & & & & & & & & & & & & & & \\
\hline $\mathbf{8 3}$ & $0-5$ & 0 & 0 & 0 & 0 & 0 & 0 & 0 & 0 & 0 & 0 & 0 & 0 & 0 & 0 \\
\hline $\mathbf{5 3}$ & $5-10$ & 0 & 0 & 0 & 0 & $1 / 64$ & $1 / 64$ & $1 / 64$ & $1 / 64$ & 0 & 0 & 0 & 0 & 0 & $1 / 64$ \\
\hline $\mathbf{5 4}$ & $10-13.8$ & 0 & 0 & 0 & 0 & $1 / 16$ & $1 / 16$ & $1 / 16$ & $1 / 16$ & 0 & 0 & 0 & 0 & 0 & $1 / 16$ \\
\hline $\mathbf{5 2}$ & $13.8+$ & 1 & 1 & 1 & 1 & 1 & 1 & 1 & 1 & 1 & 1 & 0 & 1 & 1 & 1 \\
\hline $\begin{array}{c}\text { Non- } \\
\text { leaker }\end{array}$ & & & & & & & & & & & & & & & \\
\hline $\mathbf{8 4}$ & $0-5$ & 0 & 0 & 0 & 0 & 0 & 0 & 0 & 0 & $1 / 64$ & $1 / 64$ & 0 & 0 & 0 & 0 \\
\hline $\mathbf{6 7}$ & $5-10$ & 0 & 0 & 0 & 0 & $1 / 64$ & $1 / 64$ & $1 / 64$ & $1 / 64$ & $1 / 64$ & $1 / 64$ & 0 & 0 & 0 & $1 / 64$ \\
\hline $\mathbf{6 8}$ & $10-13.8$ & 0 & 0 & 0 & 0 & $1 / 16$ & $1 / 16$ & $1 / 16$ & $1 / 16$ & $1 / 64$ & $1 / 64$ & 0 & 0 & 0 & $1 / 16$ \\
\hline $\mathbf{5 2}$ & $13.8+$ & 1 & 1 & 1 & 1 & 1 & 1 & 1 & 1 & 1 & 1 & 0 & 1 & 1 & 1 \\
\hline
\end{tabular}

a - (1) for max leakage; (1/16) for avg. leakage; (1/64) for min leakage; (0) for no leakage [sealed].

\subsubsection{Flux to Water Table}

The results from the vadose zone transport simulations are source terms to be employed in the aquifer transport analyses. The following are plots of the fractional flux to the water table for a few selected scenarios. Figure 3-10 shows the results for those H-3 scenarios in Table 3-14 for all four release model options and for both leaker and non-leaker heat exchangers. 
A significant reduction in this fractional flux occurs once the interim cover is placed $13.5 \mathrm{yr}$ after burial (i.e. 1/1/2016). As expected, in each of the four release option cases the fractional flux to the water table is greater for a "leaker" than for a "non-leaker" heat exchanger (i.e. one order of magnitude). For this particular leakage set (i.e. OptionT2 and NB3) the impact of release model follows the order II $\rightarrow$ DC_CE $\rightarrow$ DC_BE $\rightarrow$ DC_CE_Storage. The release option II always results in the highest peak fractional flux to the water table; however, the remaining options shift in impact depending on the other options considered.

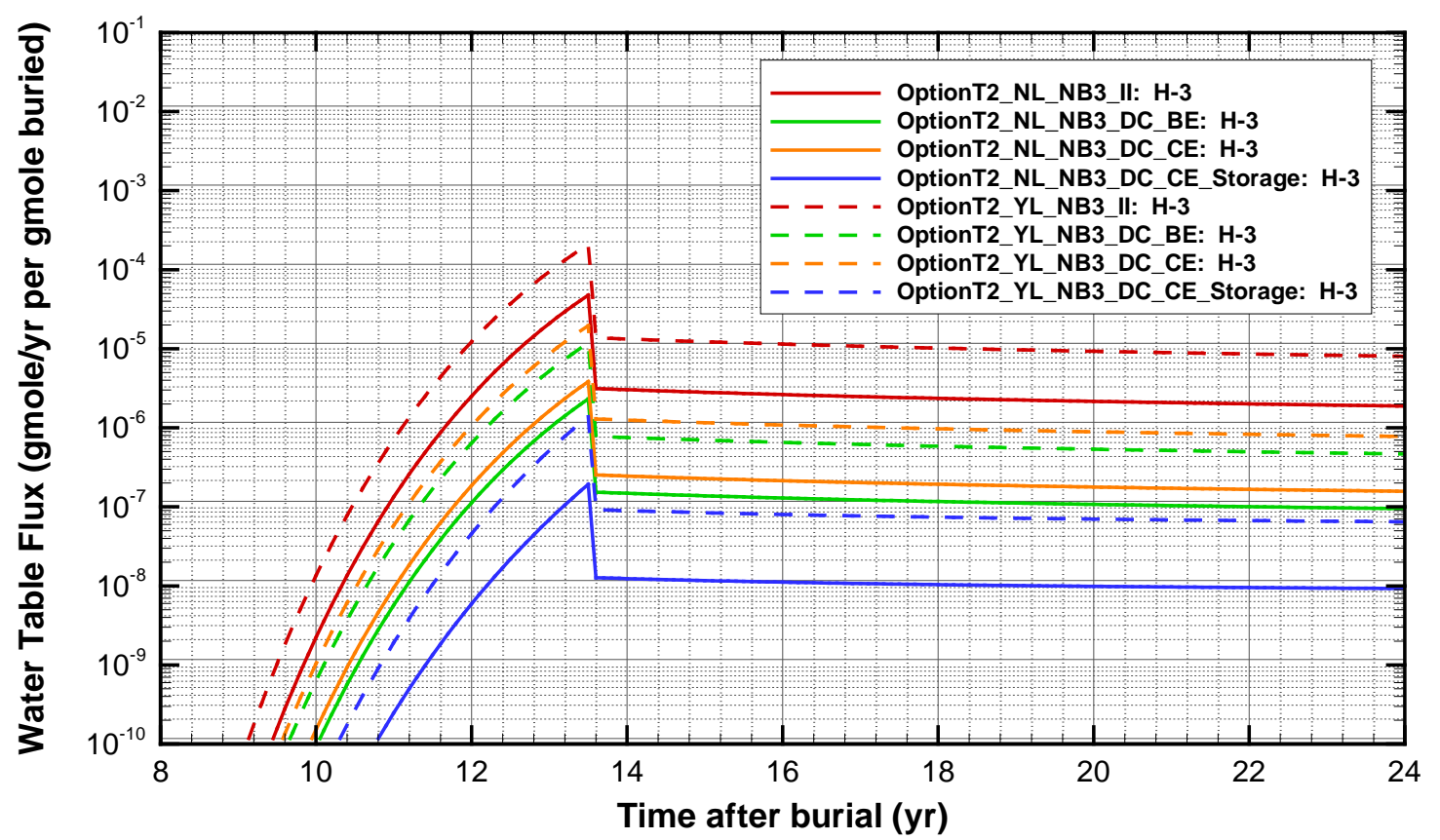

Figure 3-10 H-3 fractional flux to the water table for OptionT2_NL_NB3 and OptionT2_YL_NB3 specific transport scenarios (varying release model options) showing the intact results.

To see the impact associated with the variation in the leakage set (i.e. YB, NB, NB2, and NB3), Figure 3-11 shows H-3 fractional flux to the water table for the OptionT2 and release option DC_CE. For both types of heat exchangers (i.e. leakers and non-leakers) approximately two orders of magnitude reduction in peak fractional flux occurs when going from the line break case (LB) to the most sealed configuration (NB3). The impact follows the order:

- YB (a line break at burial, variation in leakage at burial up to cover placement [0-13.5 $\mathrm{yr}])$

- NB (lines remain intact, variation in leakage at burial up to cover placement [0-13.5 yr]

- NB2 (lines remain intact, no leakage for first $5 \mathrm{yr}$ [0-5 yr], then modest leakage for next 8.5 yr up to cover placement [5-13.5 yr])

- $\quad$ NB3 (lines remain intact, no leakage for first $5 \mathrm{yr}$ [0-5 yr], then slight leakage for next 5 $\mathrm{yr}$ [5-10 yr], then modest leakage for next $3.5 \mathrm{yr}$ up to cover placement [10-13.5 yr])

The majority of the H-3 fractional fluxes to water table follow this trend. 


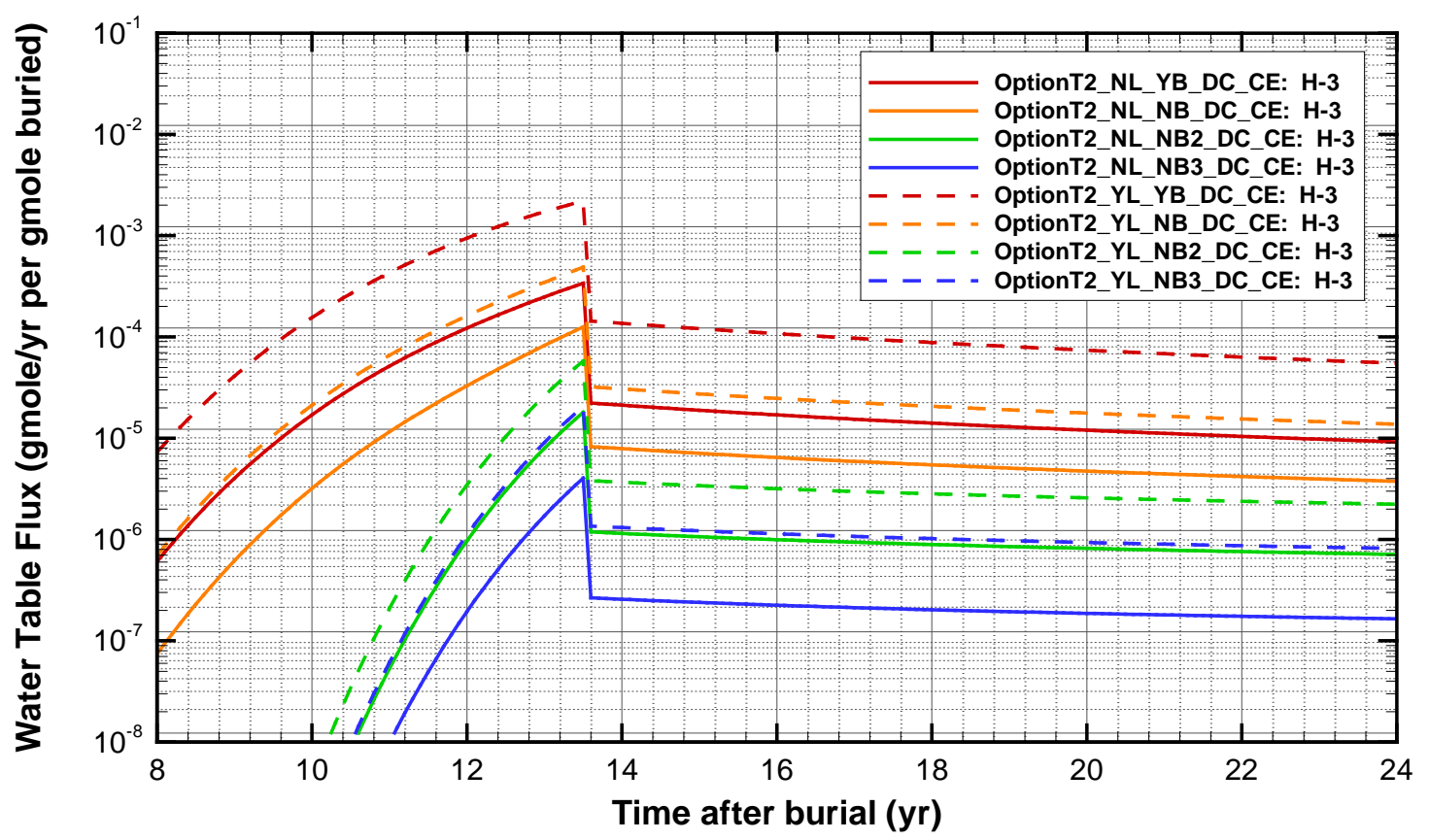

Figure 3-11 H-3 fractional flux to the water table for OptionT2 and release option DC_CE specific transport scenarios (varying the leakage set option) showing the intact results.

Figure 3-12 shows the H-3 fractional flux to the water table for OptionT3ab_YL_NB2 and each release mode.

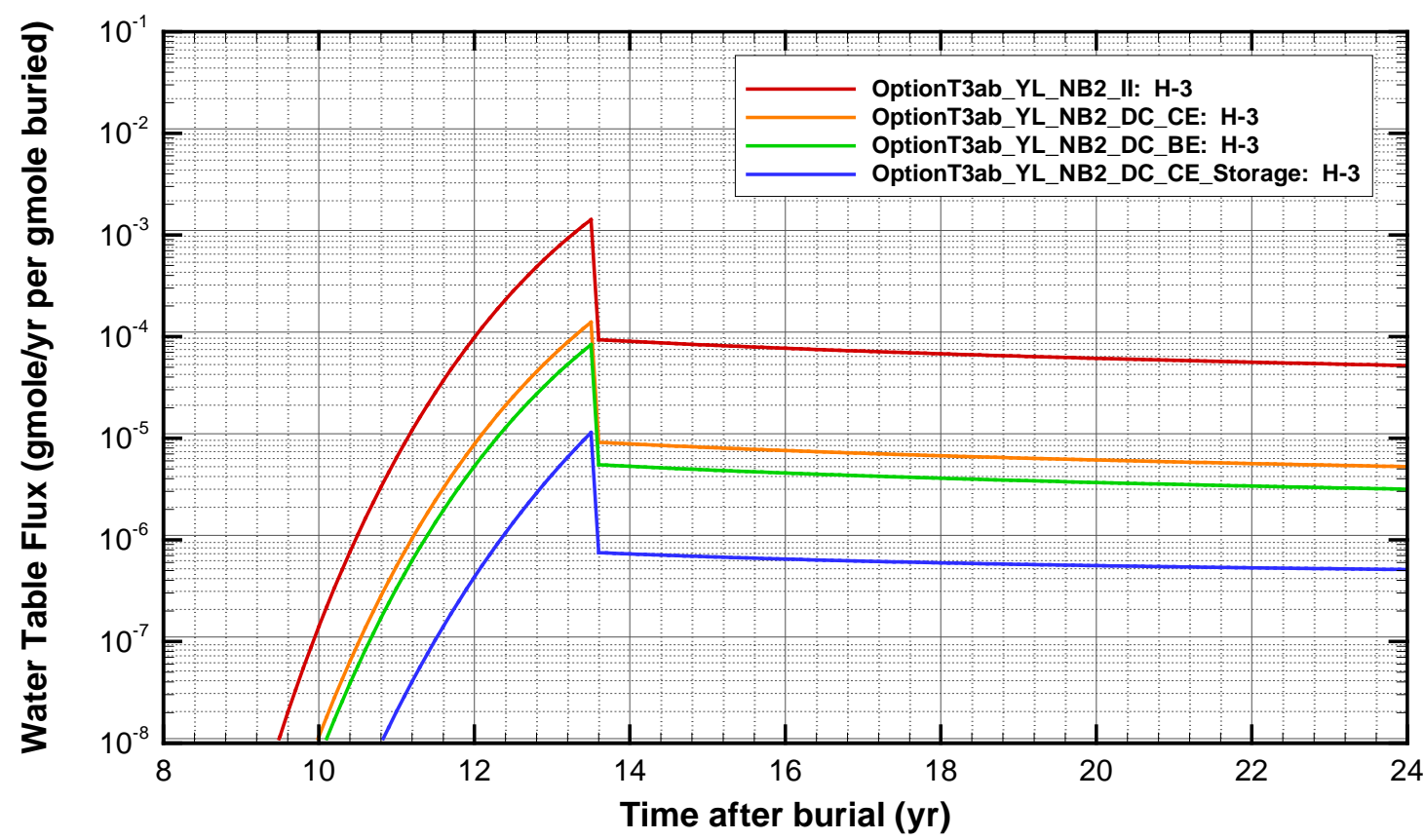

Figure 3-12 H-3 fractional flux to the water table for OptionT3ab_YL_NB2 and each release mode specific transport scenarios (varying release model options) showing the intact results.

For C-14 subsidence (i.e. Case11) was modeled as increased infiltration rates at the ground surface and by shifting of the tube bundle to the bottom of the heat exchanger shell. Because only a portion of the heat exchangers was assumed to collapse after dynamic compaction, the 
general case for aquifer analysis became a blend of intact-case fluxes and subsided-case fluxes. The blended case (i.e. Case01n11) was obtained by linear interpolation of the intact case (Case01) and the subsided case (Case11) fractional fluxes to the water table with a weighting factor of $14 / 19$ for the intact case and 5/19 for the subsided case. C-14 fractional flux to the water table is shown in Figure 3-13. The specific scenarios chosen are consistent with the results shown in Chapter 4 for C-14 aquifer transport.

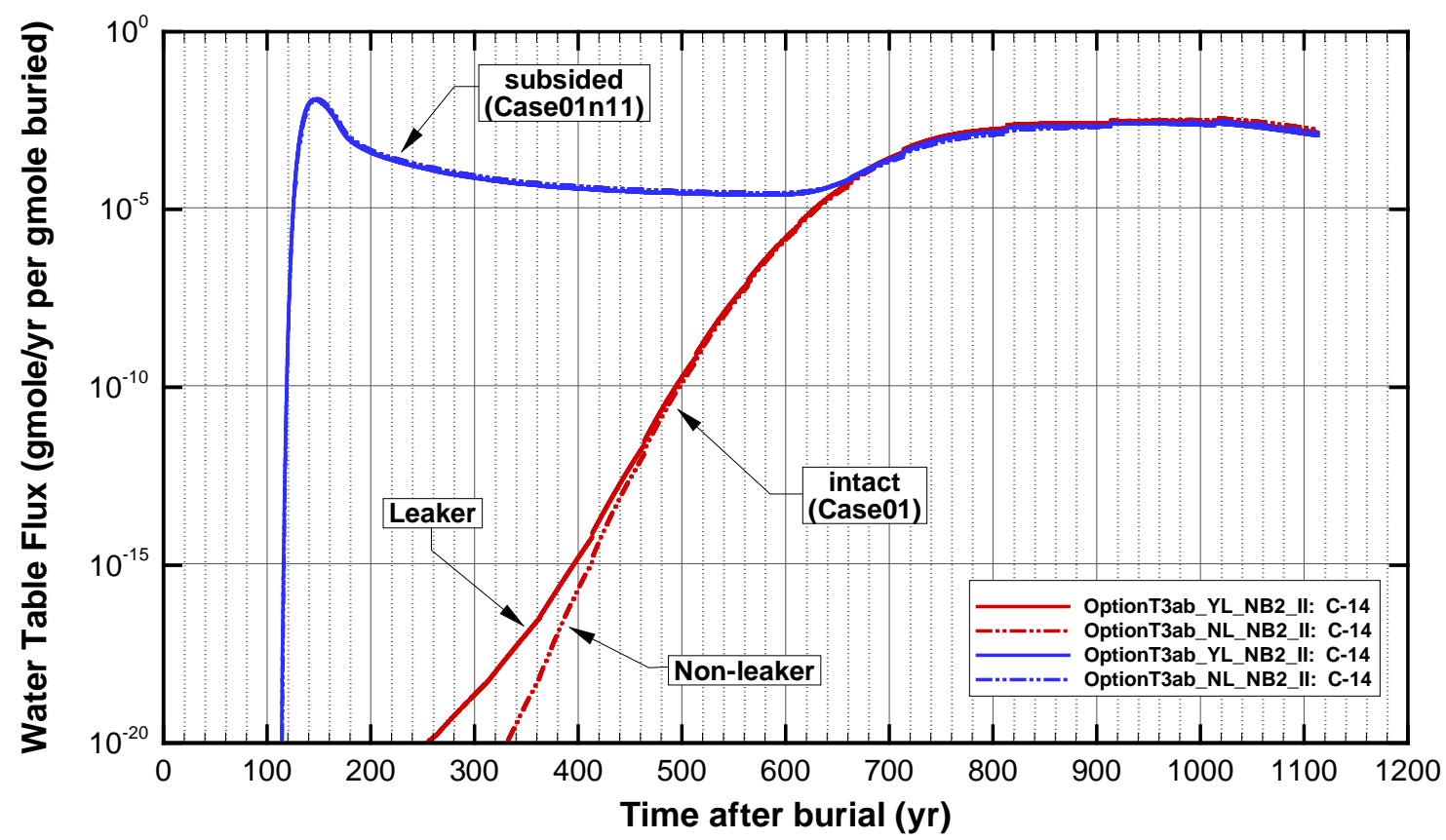

Figure 3-13 C-14 fractional flux to the water table for a specific transport scenario showing the intact, subsided (blended) results. Both leaker and non-leaker heat exchangers shown.

To maintain adequate mass balance residuals for these runs, time steps were kept very low throughout the entire simulation period:

- $\quad$ For H-3 - 0.01 yr for entire simulation period (0-113.5 yr); and

- For C-14 - $0.1 \mathrm{yr}$ for entire simulation period (0-1113.5 yr). 


\subsection{Aquifer Analysis}

The aquifer transport analysis for disposals in ST \#9 combined vadose zone fluxes at the water table, a steady-state aquifer flow field, and transport parameters to produce well concentrations. The maximum well concentration beyond the $100-\mathrm{m}$ buffer was recorded at regular time steps (typically at one-year intervals, although mobile contaminant recordings were often made at 0.1yr intervals). Subsequently, well concentrations were multiplied by well-concentration magnifiers to help calculate inventory limits for groundwater pathways.

\subsection{Conceptual Models}

The domain for all models was the same as that used for the ET \#3 down-selection [Collard and Hamm, 2012]. The conceptual model consisted of the PA (WSRC, 2008) model which was extended to include more territory, while keeping all cell footprint sizes identical (see Figure 4-1). Figure 4-1 shows streamtraces (from each corner of the disposal units) which indicate regions of potential plume interaction with ST \#9 (mainly ST \#8, ST \#10, and the ILV).

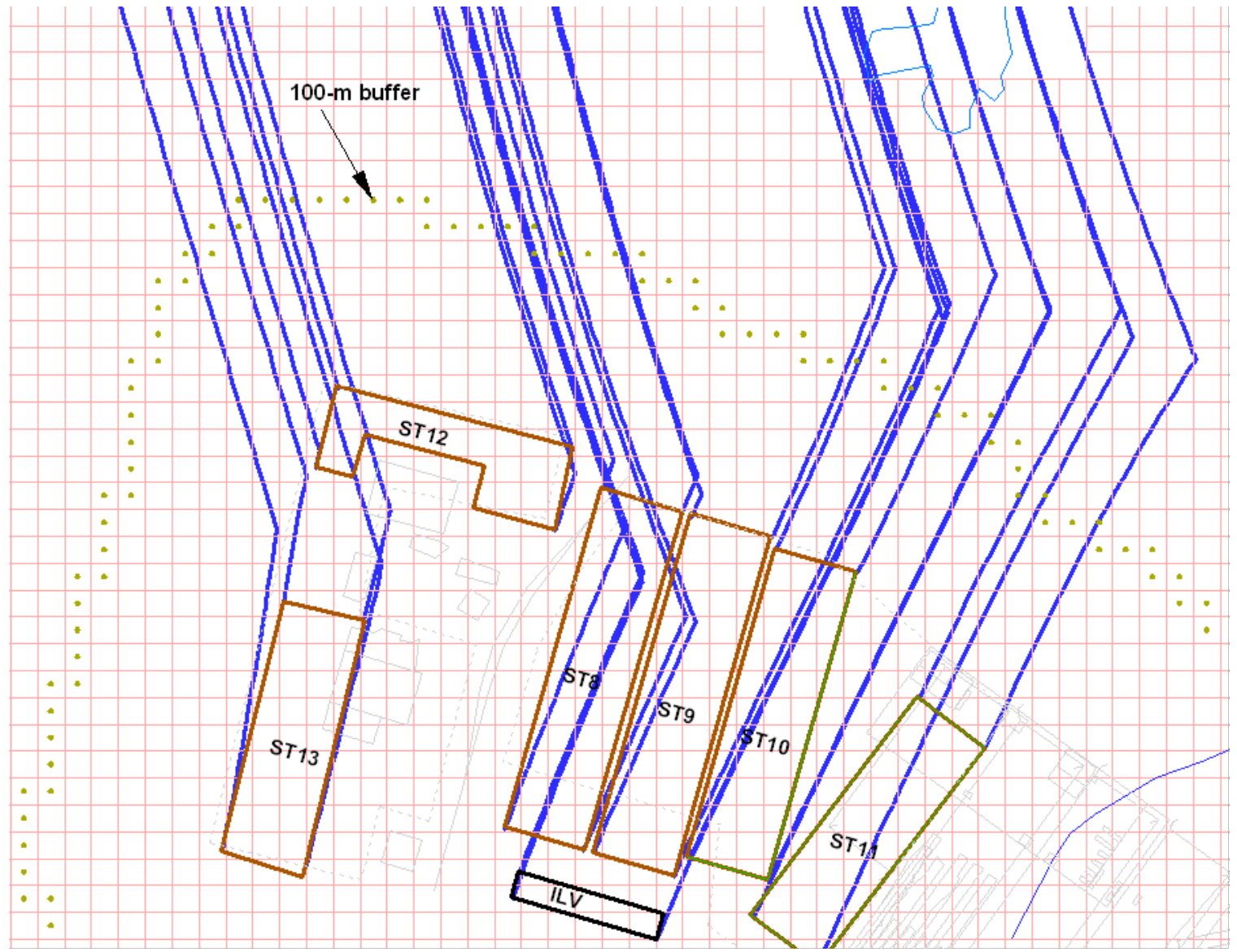

Figure 4-1. Aerial footprint of Slit West Group and ILV with 3D streamtraces

In the aquifer model, source fluxes from leakers and non-leakers were modeled simultaneously for the full set of 19 heat exchangers. Thus, a pair of scenarios from the vadose zone was combined to form a single aquifer scenario. 
Four conceptual models were developed for each scenario pair that was analyzed in the vadose zone. Models were developed with and without mechanical dispersion, although only models with mechanical dispersion were used subsequently to establish inventory limits. Models were also developed for two different spatial configurations of heat exchangers (because the exact configuration was unknown), which is discussed under Source Terms.

\subsection{Source Terms}

Source terms consisted of multiplying vadose zone fractional fluxes to the water table by an appropriate inventory. The heat exchanger inventories are presented in Table 4-1 (Walliser, 2012). Inventories from leakers were only multiplied by vadose zone fractional fluxes for leakers and a similar operation was performed for non-leakers.

Table 4-1. Inventories for leakers and non-leakers

\begin{tabular}{|c|c|c|c|c|}
\hline Number & ID & $\begin{array}{l}\mathrm{H}-3 \\
(\mathrm{Ci})\end{array}$ & $\begin{array}{c}\mathrm{C}-14 \\
(\mathrm{Ci})\end{array}$ & Possible leaker \\
\hline 1 & 4 & $4.62 \mathrm{E}+00$ & 2.92E-02 & $\mathrm{X}$ \\
\hline 2 & 7 & $7.37 \mathrm{E}+00$ & 4.66E-02 & $\mathrm{X}$ \\
\hline 3 & 10 & $1.09 \mathrm{E}+01$ & 4.28E-02 & \\
\hline 4 & 11 & $1.50 \mathrm{E}+01$ & 6.09E-02 & \\
\hline 5 & 12 & $9.65 E+00$ & 5.16E-02 & $\mathrm{X}$ \\
\hline 6 & 13 & $5.61 \mathrm{E}+00$ & 3.62E-02 & $\mathrm{X}$ \\
\hline 7 & 15 & $1.41 \mathrm{E}+01$ & $5.52 E-02$ & \\
\hline 8 & 16 & $6.53 \mathrm{E}+00$ & 4.25E-02 & $\mathrm{X}$ \\
\hline 9 & 18 & $1.54 \mathrm{E}+01$ & 6.23E-02 & \\
\hline 10 & 20 & $5.60 \mathrm{E}+00$ & 3.58E-02 & $\mathrm{X}$ \\
\hline 11 & 21 & $1.06 \mathrm{E}+01$ & 4.29E-02 & $\mathrm{X}$ \\
\hline 12 & 22 & $1.12 \mathrm{E}+01$ & $5.25 E-02$ & $\mathrm{X}$ \\
\hline 13 & 23 & $1.09 \mathrm{E}+01$ & 4.26E-02 & \\
\hline 14 & 25 & $1.48 \mathrm{E}+01$ & 5.80E-02 & \\
\hline 15 & 30 & $1.12 \mathrm{E}+01$ & 4.40E-02 & \\
\hline 16 & 32 & $7.37 \mathrm{E}+00$ & 3.94E-02 & $\mathrm{X}$ \\
\hline 17 & 33 & $1.35 E+01$ & 5.31E-02 & \\
\hline 18 & 36 & $3.24 \mathrm{E}+00$ & 1.98E-02 & $\mathrm{X}$ \\
\hline 19 & 37 & $7.27 \mathrm{E}+00$ & 4.69E-02 & $\mathrm{X}$ \\
\hline \multicolumn{2}{|c|}{ Sum leakers } & $7.91 \mathrm{E}+01$ & 4.43E-01 & \\
\hline \multicolumn{2}{|c|}{ Sum non-leakers } & $1.06 \mathrm{E}+02$ & 4.19E-01 & \\
\hline \multicolumn{2}{|c|}{ Total } & $1.85 \mathrm{E}+02$ & 8.62E-01 & \\
\hline
\end{tabular}

Heat exchanger source terms were assigned to aquifer source cells based on two configurations. Solid Waste stated that they would not dispose of any of the 19 heat exchangers closer than $200 \mathrm{ft}$ from the edge of ST \#9 that was closest to the hypothetical well. Therefore, a blue line was drawn at that location and two configurations were developed to investigate the sensitivity of results to the spatial distribution of heat exchangers. 
The first configuration (shown in Figure 4-2) was named the 4x5 configuration. Assuming two $\mathrm{ft}$ of spacing between heat exchangers, 19 of them (about $33 \mathrm{ft}-7$ in long by $7 \mathrm{ft}-4$ in wide) occupy about $6310 \mathrm{ft}^{2}$. Three aquifer source cells (each $50 \mathrm{ft}$ by $50 \mathrm{ft}$ ) occupy $7500 \mathrm{ft}^{2}$. An arrangement of heat exchanger slots four across by five deep (with one empty slot) was overlaid on the PORFLOW mesh. Three aquifer source cells were selected and heat exchanger slots were assigned to each cell. Seven cyan slots were assigned to cell A, eight purple slots were assigned to cell B and four pink slots were assigned to cell C.

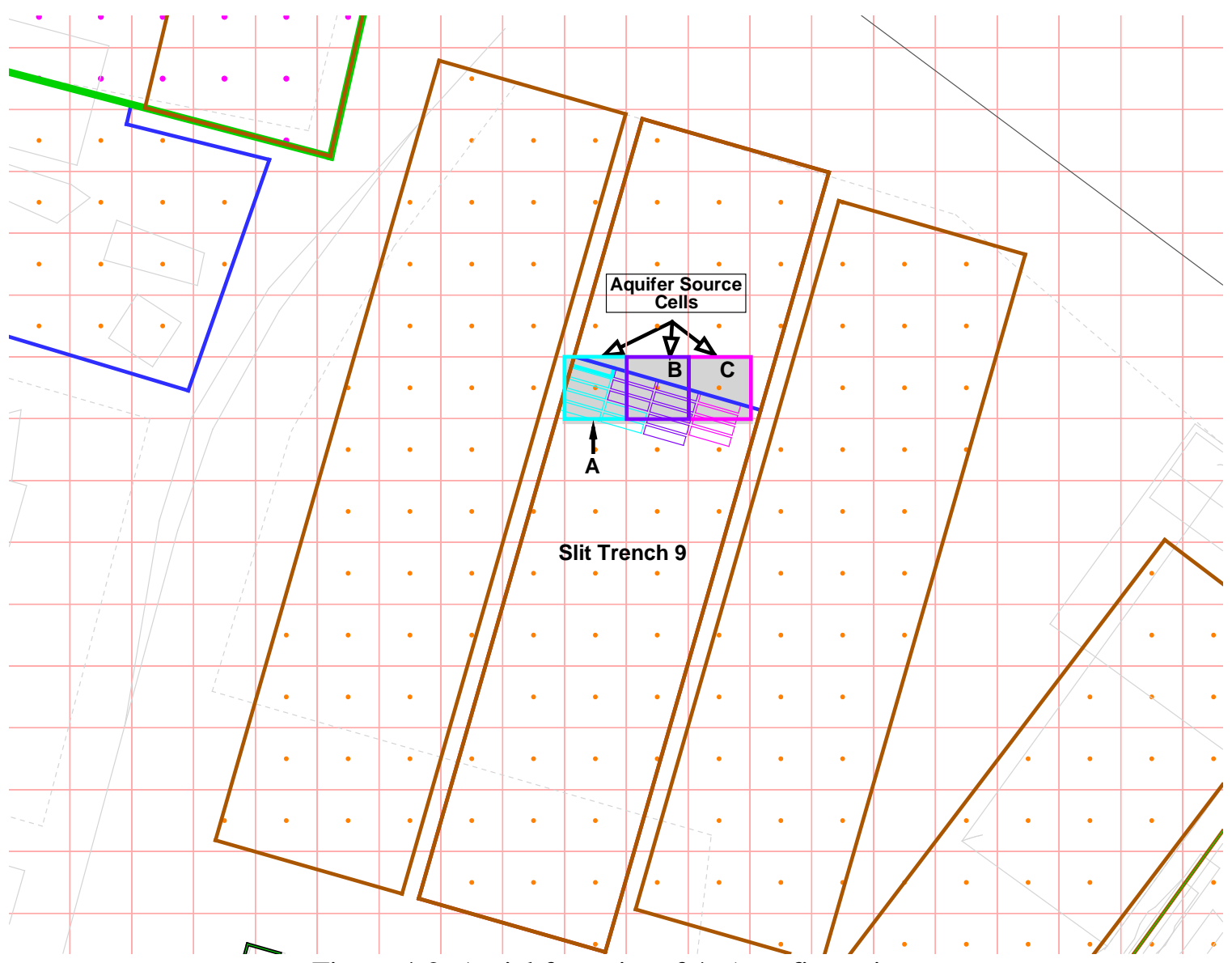

Figure 4-2 Aerial footprint of 4x5 configuration.

The second configuration (shown in Figure 4-3) was named the $3 \times 7$ configuration. An arrangement of heat exchanger slots three across by seven deep (with two empty slots) was overlaid on the PORFLOW mesh. Three aquifer source cells were selected and heat exchanger slots were assigned to each cell. Eight cyan slots were assigned to cell A, six purple slots were assigned to cell B and five green slots were assigned to cell D. 


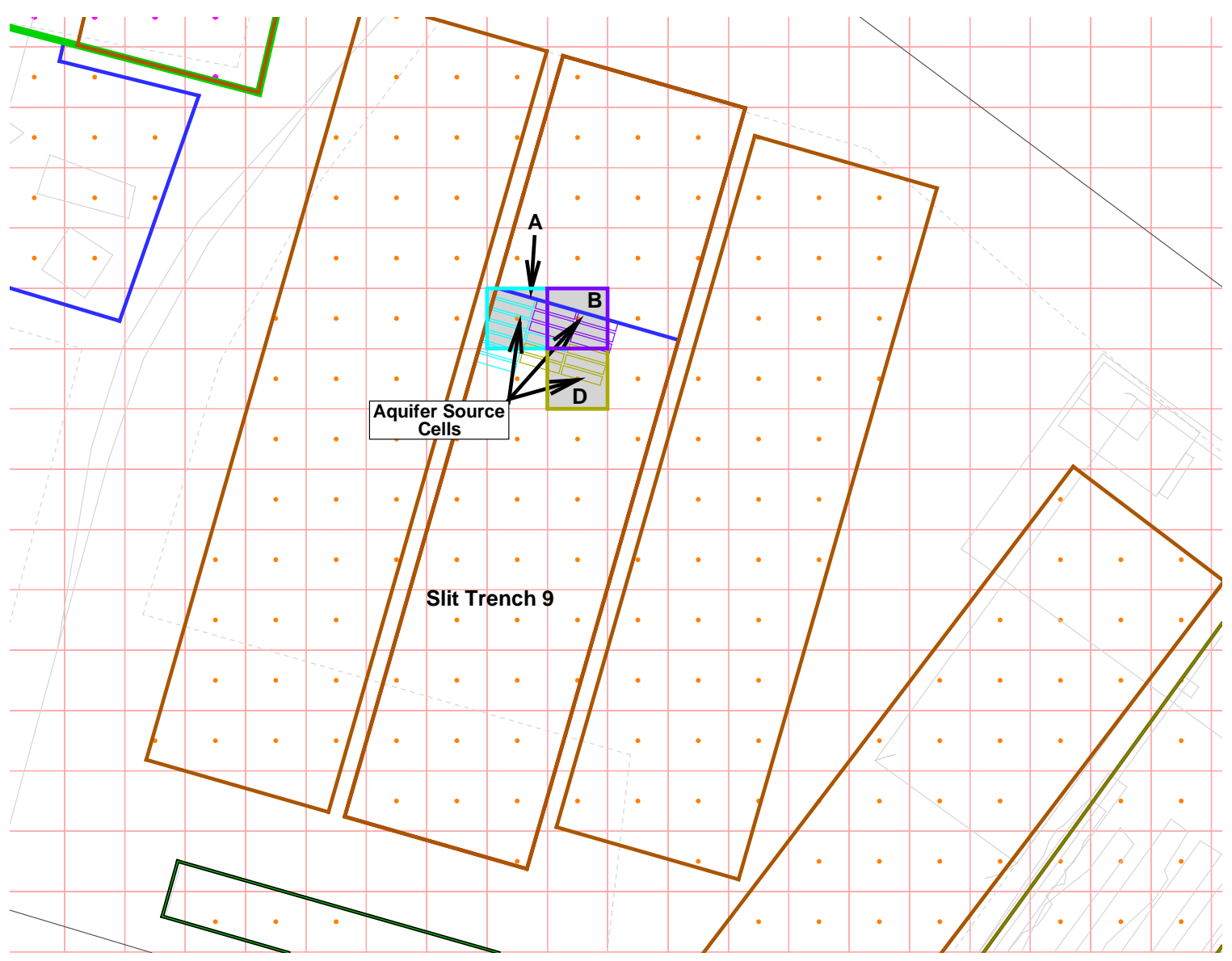

Figure 4-3 Aerial footprint of 3x7 configuration.

From the footprints, the $\mathrm{X}$ and $\mathrm{Y}$ (I and $\mathrm{J}$ ) indices were selected for each aquifer source cell used in the PORFLOW model. Then the uppermost saturated cell in that $\mathrm{X}, \mathrm{Y}$ vertical stack was selected yielding the $\mathrm{Z}(\mathrm{K})$ index for that aquifer source cell.

For each configuration an attempt was made to assign heat exchangers in a manner that would produce the highest well concentrations, in order to allow Solid Waste maximum flexibility in its disposal arrangement. Therefore, for each scenario the following steps were implemented:

6. The impact for each heat exchanger was calculated. The impact is the actual flux calculated by multiplying the heat exchanger's inventory peak fractional flux to the water table.

7. The highest impact heat exchangers were assigned to the aquifer source cell with the most heat exchanger slots (e.g. 8 to cell $\mathrm{B}$ for the $4 \times 5$ configuration).

8. The lowest impact heat exchangers were assigned to the aquifer source cell with the fewest heat exchanger slots (e.g. 4 to cell $\mathrm{C}$ for the $4 \times 5$ configuration)

9. All remaining heat exchangers were assigned to the remaining aquifer source cell (e.g. 7 to cell A for the $4 \times 5$ configuration).

10. All assigned leaker heat exchangers were grouped for each cell and their inventories were summed to provide a scaling factor that was applied to the leaker flux to the water table. 
11. All assigned non-leaker heat exchangers were grouped for each cell and their inventories were summed to provide a scaling factor that was applied to the non-leaker flux to the water table.

A simple hypothetical example for the $4 \times 5$ configuration is provided in Table $4-2$, where heat exchangers were sorted by their impacts. The four heat exchangers with the lowest impact (shaded in pink) would be assigned to cell $\mathrm{C}$ in Figure 4-2. The eight heat exchangers with the highest impact (shaded in purple) would be assigned to cell $\mathrm{B}$. The remaining seven heat exchangers (shaded in cyan) would be assigned to cell A.

Table 4-2 Hypothetical example of heat exchanger assignment for the $4 \times 5$ configuration

\begin{tabular}{|c|c|c|c|c|}
\hline Leaker peak flux & $\begin{array}{c}2 \mathrm{Ci} / \mathrm{yr} \text { per } \\
\text { Ci buried }\end{array}$ & & & \\
\hline Non-leaker peak flux & $\begin{array}{c}1 \mathrm{Ci} / \mathrm{yr} \text { per } \\
\mathrm{Ci} \text { buried }\end{array}$ & & & \\
\hline Heat Exchanger ID & Leaker? & $\begin{array}{c}\text { Inventory } \\
\text { (Ci) }\end{array}$ & $\begin{array}{l}\text { Peak flux } \\
\text { (Ci/yr per } \\
\text { Ci buried) }\end{array}$ & $\begin{array}{l}\text { Impact } \\
\text { (Ci/yr) }\end{array}$ \\
\hline 19 & $\mathrm{~N}$ & 1111117 & 1 & 1 \\
\hline 2 & $\mathrm{~N}$ & 1112111 & 1 & 2 \\
\hline 1 & $\mathrm{Y}$ & 1 & 2 & 2 \\
\hline 7 & $\mathrm{Y}$ & 1 & 2 & 2 \\
\hline 13 & $\mathrm{Y}$ & 1 & 2 & 2 \\
\hline 3 & $\mathrm{~N}$ & 3 & 1 & 3 \\
\hline 8 & $\mathrm{Y}$ & 2 & 2 & 4 \\
\hline 10 & $\mathrm{~N}$ & 4 & 1 & 4 \\
\hline 14 & $\mathrm{Y}$ & 2 & 2 & 4 \\
\hline 16 & $\mathrm{~N}$ & 4 & 1 & 4 \\
\hline 5 & $\mathrm{~N}$ & 5 & 1 & 5 \\
\hline 6 & $\mathrm{~N}$ & 6 & 1 & 6 \\
\hline 9 & $\mathrm{Y}$ & 3 & 2 & 6 \\
\hline 12 & $\mathrm{~N}$ & 6 & 1 & 6 \\
\hline 15 & $\mathrm{Y}$ & 3 & 2 & 6 \\
\hline 4 & $\mathrm{Y}$ & 4 & 2 & 8 \\
\hline 11 & $\mathrm{Y}$ & 5 & 2 & 10 \\
\hline 17 & $\mathrm{Y}$ & 5 & 2 & 10 \\
\hline 18 & $\mathrm{Y}$ & 6 & 2 & 12 \\
\hline
\end{tabular}

The inventories of all leaker heat exchangers assigned to an aquifer source cell were summed to produce that cell's leaker scaling factor (e.g. inventories for HX1 (1 Ci) and HX7 (1 Ci) for the pink set without cross-hatching in Table 4-2 were summed to produce $2 \mathrm{Ci}$ ). Non-leaker scaling factors were calculated similarly (e.g. inventories for HX19 (1 Ci) and HX2 (2 Ci) for the pink set with cross-hatching in Table 4-2 were summed to produce $3 \mathrm{Ci}$ ). Scaling factors depended on the impacts which could be different for:

- H-3 and C-14;

- Case01 and Case01n11 for C-14; and

- $4 \times 5$ configuration and 3x7 configuration.

Moving from a hypothetical case above to a real example, sample aquifer source scaling factors (inventories) are presented in Table 4-3 for C-14 Case01 in the $4 \times 5$ configuration. This table demonstrates how impacts are determined for each scenario based on the assignment of HXs ranked and grouped in source cells as illustrated in Table 4-2. In Table 4-3 the high impact cell contains eight heat exchangers with the greatest impact (inventory multiplied by peak flux to the 
water table for a nominal inventory of 1 g-mol). The low impact cell contains 4 heat exchangers with the smallest impact with the remaining seven HXs assigned to the Medium Impact Cell (A). The table shows the quantity of leakers and non-leakers for each cell and their respective inventories. Summing across each scenario for cells A, B and C in Table 4-3 will produce the total impact (Ci) at the 100-m well for all 19 HXs.

Table 4-3 Example aquifer source cell inventories for C-14 Case 01 in 4x5 configuration

\begin{tabular}{|c|c|c|c|c|c|c|c|c|c|c|c|}
\hline \multirow{3}{*}{ Scenario } & \multicolumn{3}{|c|}{ High Impact Cell (B) } & \multicolumn{4}{|c|}{ Medium Impact Cell (A) } & \multicolumn{4}{|c|}{ Low Impact Cell (C) } \\
\hline & Leaker & & $\begin{array}{l}\text { on- } \\
\text { aker }\end{array}$ & & aker & & $\begin{array}{l}\text { on- } \\
\text { aker }\end{array}$ & & aker & & on- \\
\hline & $\# \quad \mathrm{Ci}$ & \# & $\mathrm{Ci}$ & \# & $\mathrm{Ci}$ & \# & $\mathrm{Ci}$ & \# & $\mathrm{Ci}$ & \# & $\mathrm{Ci}$ \\
\hline DC_BE ${ }^{1}$ & 0.109 & 6 & 0.332 & 6 & 0.236 & 1 & 0.044 & 3 & 0.068 & 1 & 0.033 \\
\hline DC_CE & 0.109 & 6 & 0.332 & 5 & 0.201 & 2 & 0.077 & 4 & 0.102 & 0 & 0.000 \\
\hline DC_CE_Storage & 0.109 & 6 & 0.332 & 5 & 0.201 & 2 & 0.077 & 4 & 0.102 & 0 & 0.000 \\
\hline II & 0.109 & 6 & 0.332 & 5 & 0.201 & 2 & 0.077 & 4 & 0.102 & 0 & 0.000 \\
\hline
\end{tabular}

\subsection{Flow Results}

The aquifer flow result (see Figure 4-1) is a steady-state flow field that was extracted from the General Separations Area steady-state flow field. The mesh was further refined and velocities were interpolated within each refined cell. This refinement process is consistent with methods employed in prior $2008 \mathrm{PA}$ and subsequent SAs.

\subsection{Transport Results}

Aquifer transport results consisted of well concentrations, with those beyond the 100-m buffer being of interest. In this section, example results are discussed for profiles and concentration histories for a single scenario. Peak results over all scenarios are also discussed.

\subsubsection{Concentration Profiles}

Selected concentration contours from aquifer transport analyses are depicted in Figure 4-4 for H-3 in the T3ab_YL_NB2_II scenario (see for the naming convention) for the 4x5 configuration. The well-concentration magnifier of 2.08 (see Chapter 5) was applied before creating Figure 4-4. The peak concentration of 2,312 $\mathrm{pCi} / \mathrm{L}$ occurred at $15.2 \mathrm{yr}$ after burial. The figure is a snapshot at $15.0 \mathrm{yr}$ at the $8^{\text {th }}$ vertical layer of the grid (where the peak occurred). The 2,300 $\mathrm{pCi} / \mathrm{L}$ contour near the $100-\mathrm{m}$ well buffer indicates that the peak concentration occurred along the buffer. 


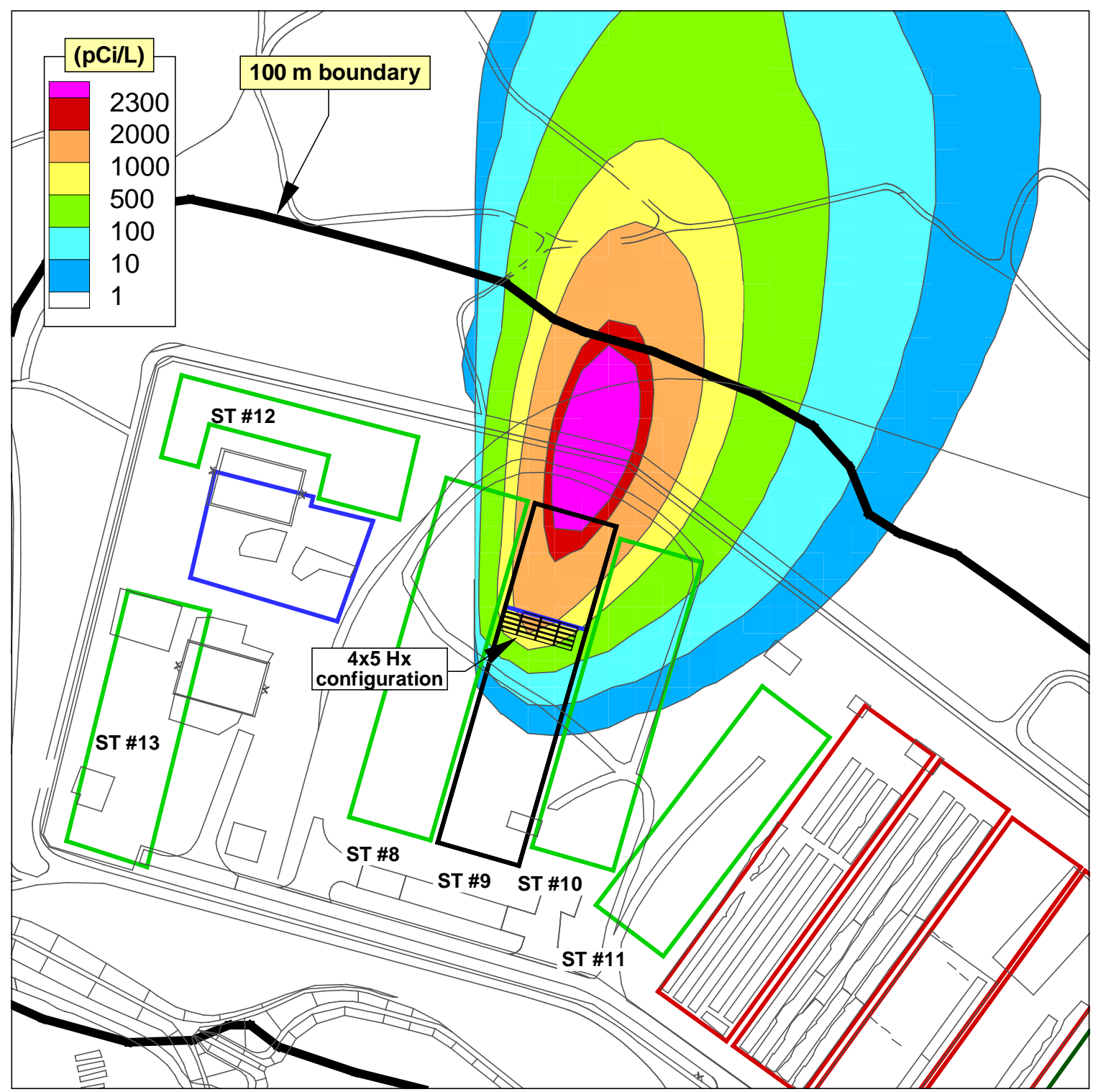

Figure 4-4. Aquifer concentration contours for H-3 on its key horizontal plane for Case01 near its time of peak maximum well concentration for the $4 \times 5$ configuration for scenario T3ab_YL_NB2_II

Selected concentration contours from aquifer transport analyses are depicted in Figure 4-5 for C-14 in the T3ab_YL_NB2_II scenario for the 4x5 configuration. The well-concentration magnifier of 4.29 (see Chapter 5) was applied before creating Figure 4-5. The peak concentration of $597 \mathrm{pCi} / \mathrm{L}$ occurred at $163.5 \mathrm{yr}$ after burial. The figure is a snapshot at $163.5 \mathrm{yr}$ at the $8^{\text {th }}$ vertical layer of the grid (where the peak occurred). The $600 \mathrm{pCi} / \mathrm{L}$ contour near the $100-\mathrm{m}$ well buffer indicates that the peak concentration occurred along the buffer. 


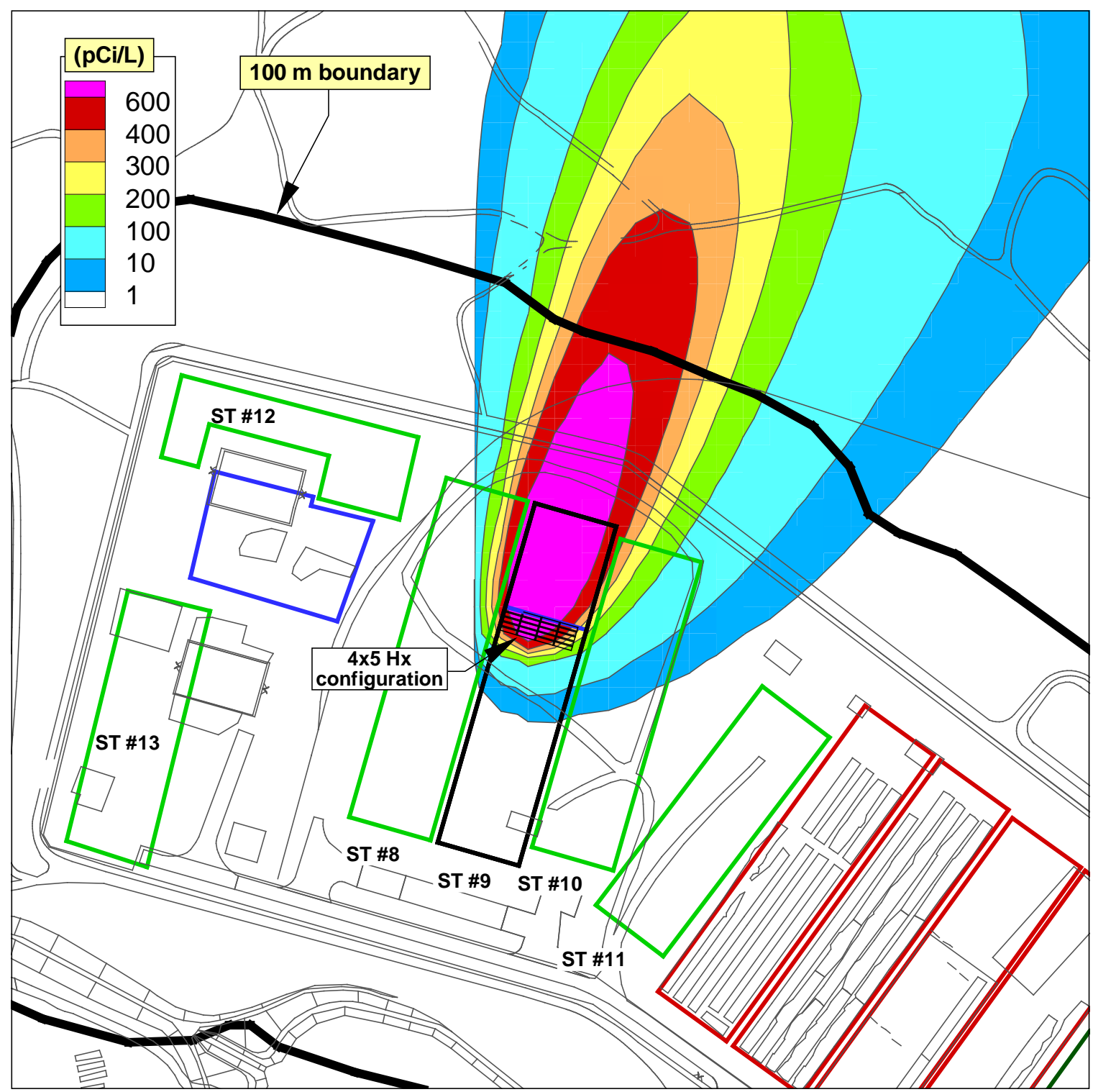

Figure 4-5. Aquifer concentration contours for C-14 on its key horizontal plane for Case01n11 near its time of peak maximum well concentration for the $4 \times 5$ configuration for scenario T3ab_YL_NB2_II

The concentration contours for H-3 show its transport path with significant spreading created by both mechanical and numerical dispersion. The center of the path is primarily along the centerline of ST \#9. The rapid movement of $\mathrm{H}-3$ is caused by its minimal $\mathrm{K}_{\mathrm{d}}$ of $0 \mathrm{ml} / \mathrm{g}$ (no retardation relative to the water movement). The magnitude of the peak is reduced by the rapid decay of $\mathrm{H}-3$ with its half-life of $12.32 \mathrm{yr}$.

The path for C-14 is identical to that of H-3. However, it moves much slower, thus the time of its peak is considerably delayed. While the $\mathrm{C}-14 \mathrm{~K}_{\mathrm{d}}$ is $0 \mathrm{ml} / \mathrm{g}$ inside the heat exchanger, it increases to $1 \mathrm{ml} / \mathrm{g}$ in sandy regions, which decreases its velocity by about a factor of five in the aquifer, i.e. 
SRNL-STI-2012-00321

Revision 0

where, 


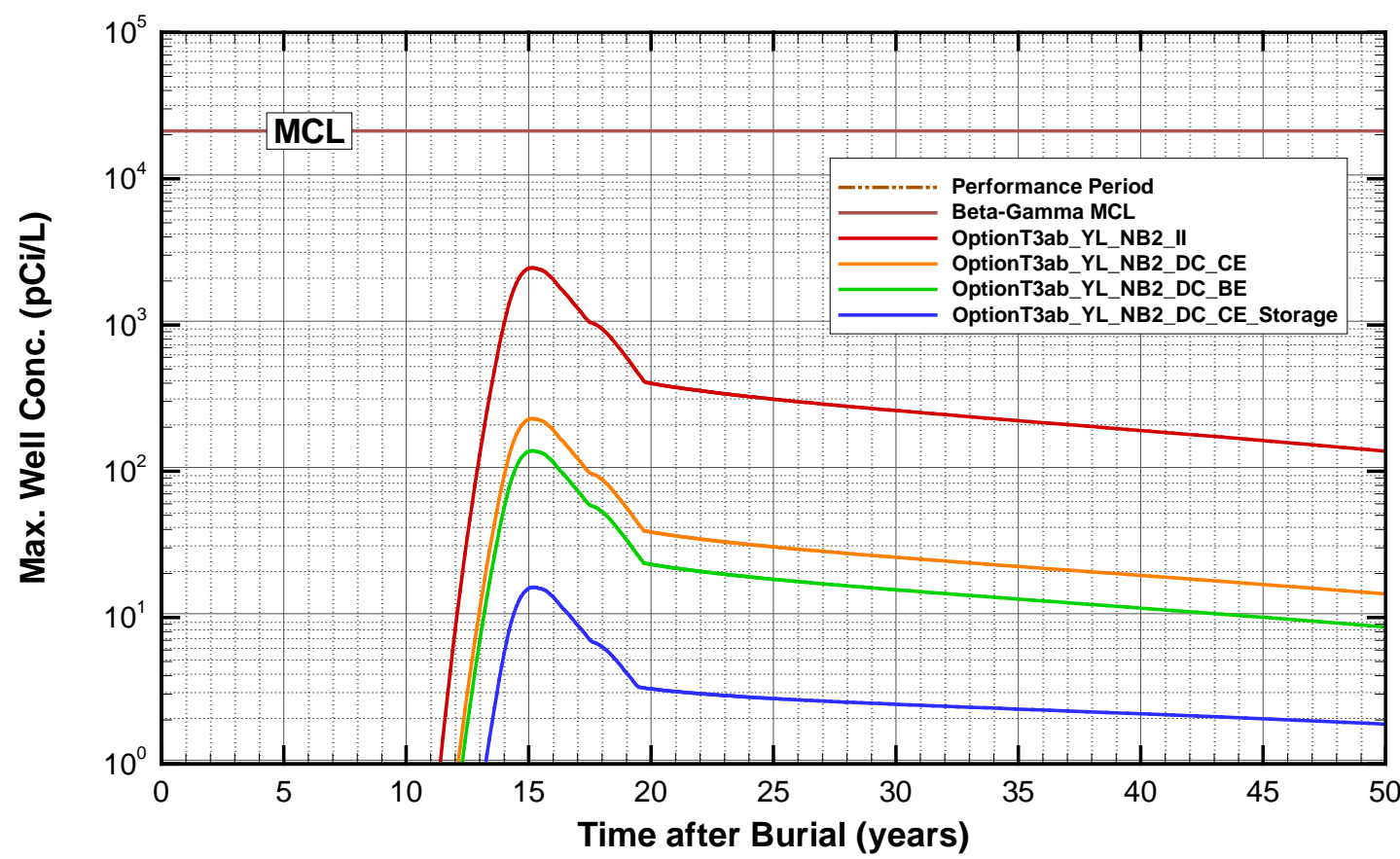

Figure 4-6. Concentration histories (including the well-concentration magnifier) for $\mathrm{H}-3$ for

Case01 and the 4x5 configuration for scenario T3ab_YL_NB2_II and related scenarios

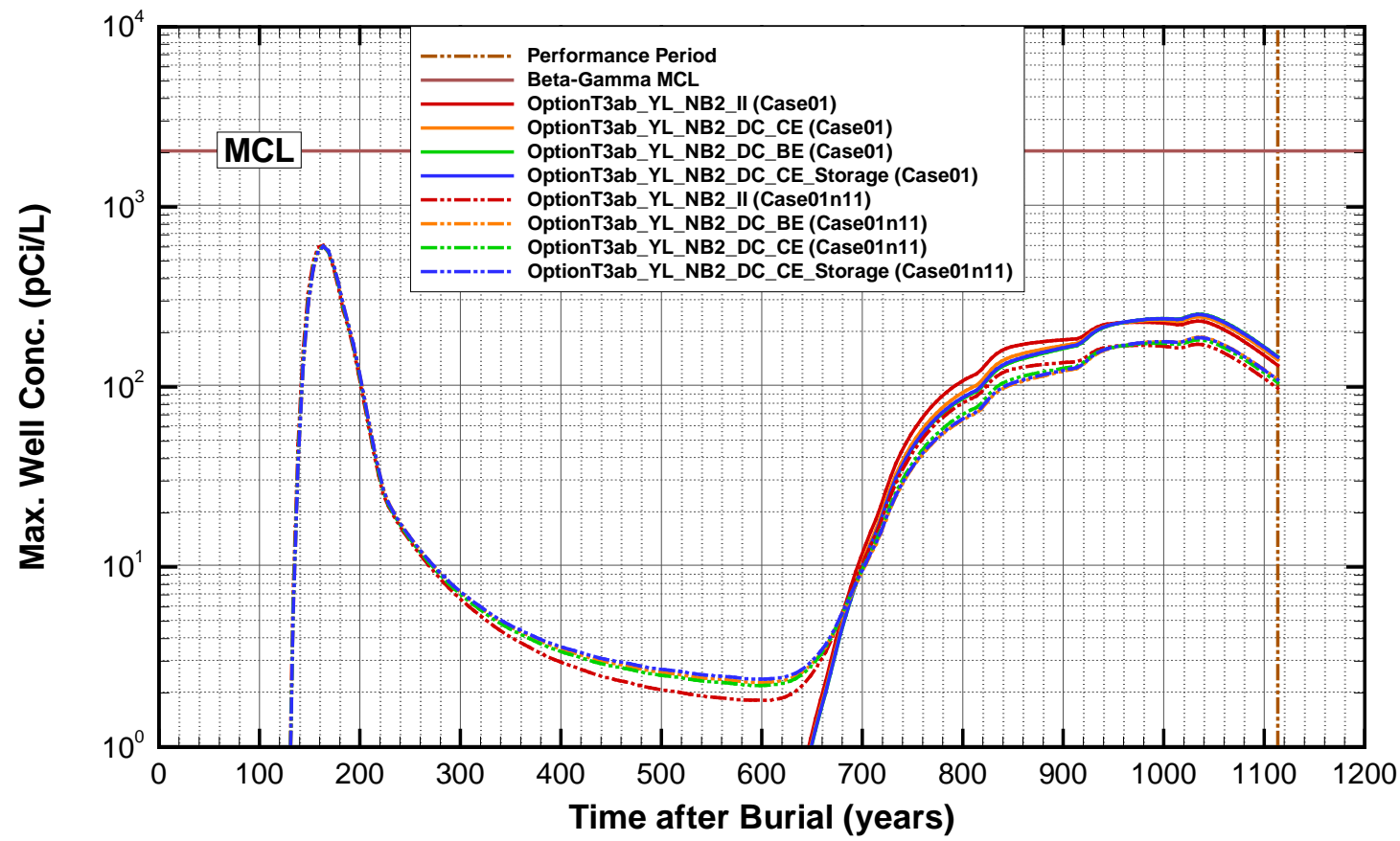

Figure 4-7. Concentration histories (including the well-concentration magnifier) for C-14 for Case01n11 and the 4x5 configuration for scenario T3ab_YL_NB2_II and related scenarios

\subsubsection{Concentration Histories over all Scenarios}

The peak concentration from each scenario for the $4 \times 5$ configuration (where the well-concentration magnifier has been included) is plotted in Figure 4-8 for H-3 and Figure 4-9 for $\mathrm{C}-14$. The companion results for the $3 \times 7$ configuration are not shown but consistently resulted in lower peak concentration values for both radionuclides. Because $\mathrm{H}-3$ peaks before the 
final cap would be placed the subsided case (i.e. Case01n11) has no significance and only Case01 concentrations were plotted for $\mathrm{H}-3$.

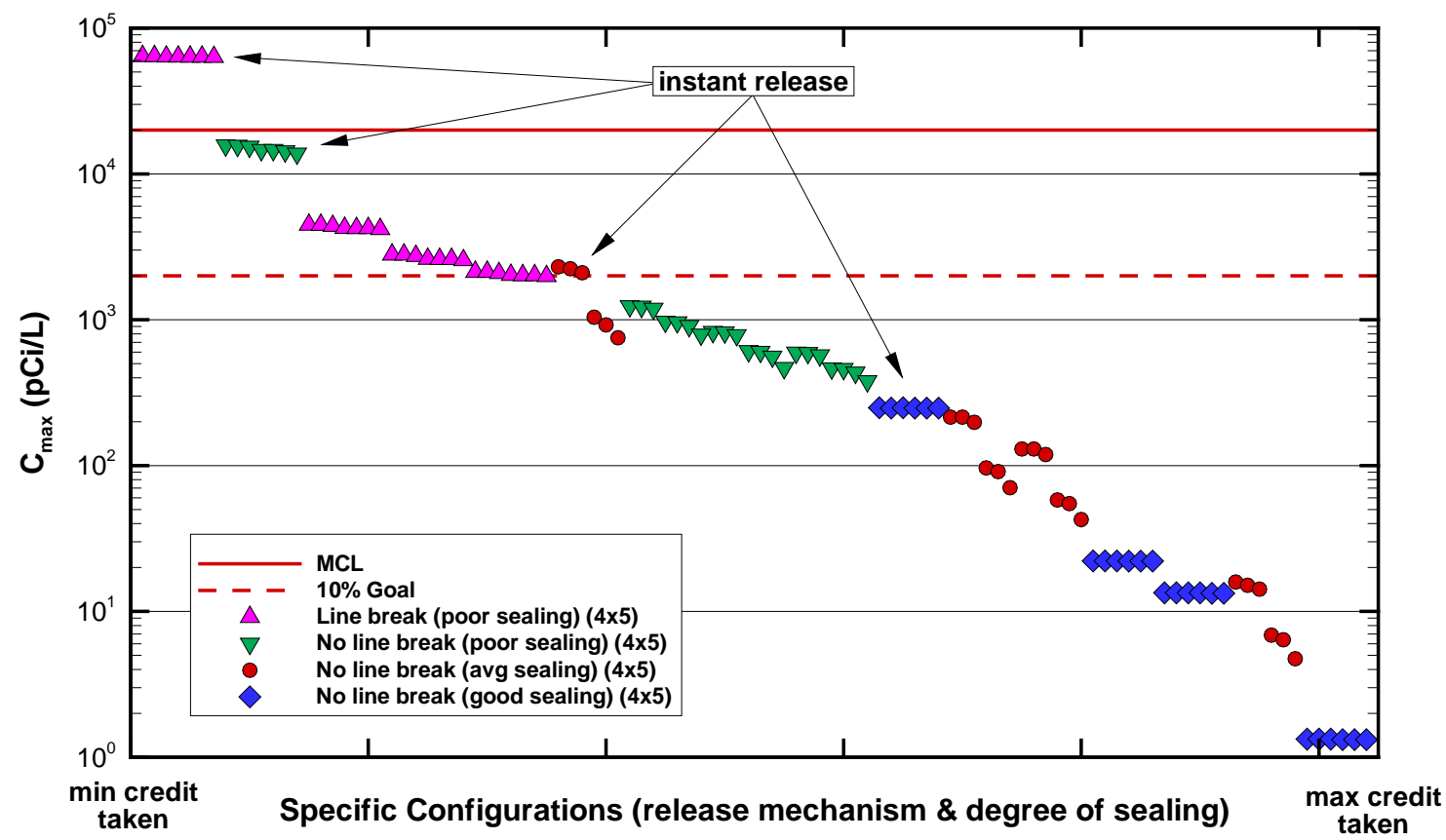

Figure 4-8. Summary of H-3 peak maximum well (Case01) concentrations in the aquifer for all scenarios in the $4 \times 5$ configuration.

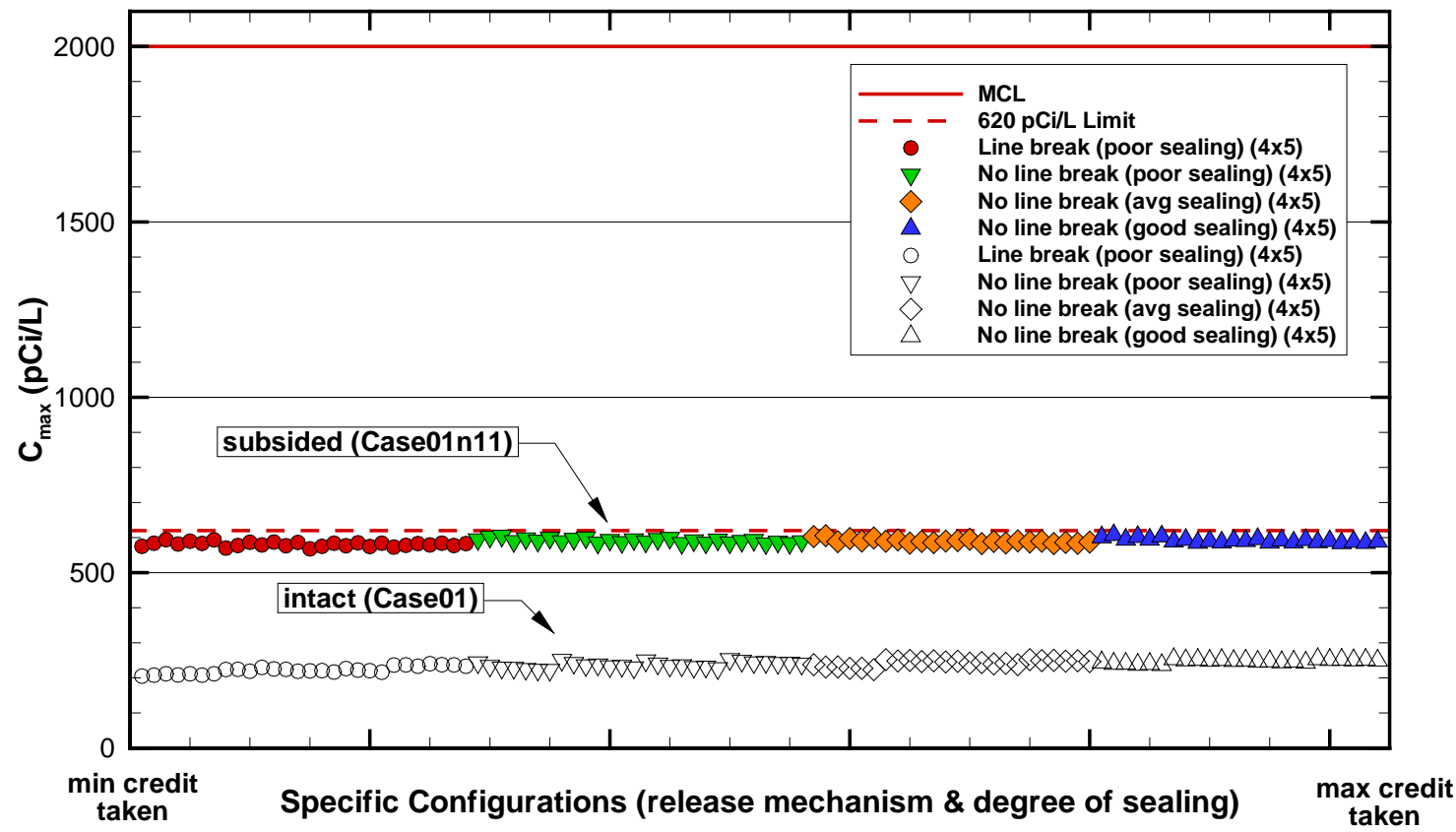

Figure 4-9. Summary of C-14 peak maximum well (Case01 and Case01n11) concentrations in the aquifer for all scenarios in the $4 \times 5$ configuration.

Results in Figure 4-8 and Figure 4-9 were sorted by scenario before plotting.

Figure 4-8 indicates that line breakage, poor sealing, and instant release would cause H-3 well concentrations for most scenarios to exceed the MCL. Scenarios with line breakage and poor 
sealing for other near-field release mechanisms produced unacceptably high well concentrations, which confirm that mitigating actions were required by ACP to prevent line breakage and to provide average to good sealing. Crediting those mitigating actions allow the line breakage and poor sealing scenarios to be excluded from consideration when establishing inventory limits.

Some scenarios with no line breakage but poor sealing and instantaneous release also produced H-3 well concentrations that were close to the MCL. These no line breakage, poor sealing and instantaneous release combination were considered to have very low probabilities and were not considered in establishing inventory limits. All of the remaining scenarios were selected as the set of base cases of interest and were considered in establishing limits.

Figure 4-9 indicates that all scenarios in the same case family for C-14 produced approximately the same peak well concentrations. Case $01 n 11$ C-14 peak concentrations were all higher than those for Case01. The $\mathrm{C}-14$ results indicate that the mitigating activities had little impact on $\mathrm{C}-14$ well concentrations.

Note that even if line breakage and poor sealing occur, the best release conditions would serve to mitigate those conditions, as shown by the pink triangles with peak concentrations slightly less than for the three red circles (see Figure 4-8). Also, line breakage means that all 19 heat exchangers suffer broken lines, which has a low probability of occurrence. 


\subsection{Plume Interaction}

Plume interaction factors in the 2008 PA (WSRC, 2008) were developed for the SlitWest group (i.e, STs \#8 through \#13). Because non-generic-waste heat exchangers will only be disposed in ST \#9, plume interaction factors were developed for ST \#9. Different factors were calculated for $\mathrm{H}-3$ and C-14 as discussed below.

\subsection{Method}

Plume interaction factors were estimated as well-concentration magnifiers that are time independent and that are incorporated via post-processing PORFLOW results. Plume interaction factors were calculated for ST \#9 because only its contents were modeled. By establishing plume interaction factors on a disposal unit basis, rather than on a disposal group basis, the spatial requirement for uniform distribution of waste is reduced from the group level to the disposal unit level. For this document, only the ILV and the SlitWest group disposal units were considered because other disposal units should have no (or very limited) interaction with ST \#9 (see Figure 4-1 showing streamtraces).

The first step was to calculate the peak well concentration when both the ILV and the SlitWest group were loaded at the same magnitude as was used in the 2008 PA plume interaction analysis. The second step was to load only ST \#9 such that it produced the same peak well concentration. The third step was to calculate the well concentration multiplier (plume interaction factor) by dividing the ST \#9 inventory from Step 2 by its inventory from Step 1 (i.e. its allowable inventory if it were the only disposal unit in the E-Area is divided by its allowable inventory when the EArea is fully considered).

For the first two steps a constant-rate tracer was modeled, so the inventory was actually a source with a fixed strength or magnitude. The magnitudes that were applied were the magnitudes from the 2008 PA when the E-Area was simultaneously modeled, namely:

- 0.739 g-mol for the SlitWest group; and

- 0.345 g-mol for the ILV.

These factors were applied to protect the 2008 PA limits for all other disposal units in the SlitWest group and the ILV.

The concentration magnifier calculated via the above method was applied only to C-14. The release of all radionuclides from the ILV is delayed substantially (see Figure 5-1 for the interaction of $\mathrm{H}-3$ from the ILV). Therefore, the peak concentrations for mobiles (such as $\mathrm{H}-3$ ) released from the SlitWest group which is down-gradient from the ILV are not materially affected by any ILV releases. Thus the ILV was excluded from the set of disposal units that could interact with ST \#9 for H-3. This change matches that which was done for I-129 in the 2008 PA and could be applied to all mobile radionuclides. 
SRNL-STI-2012-00321

Revision 0

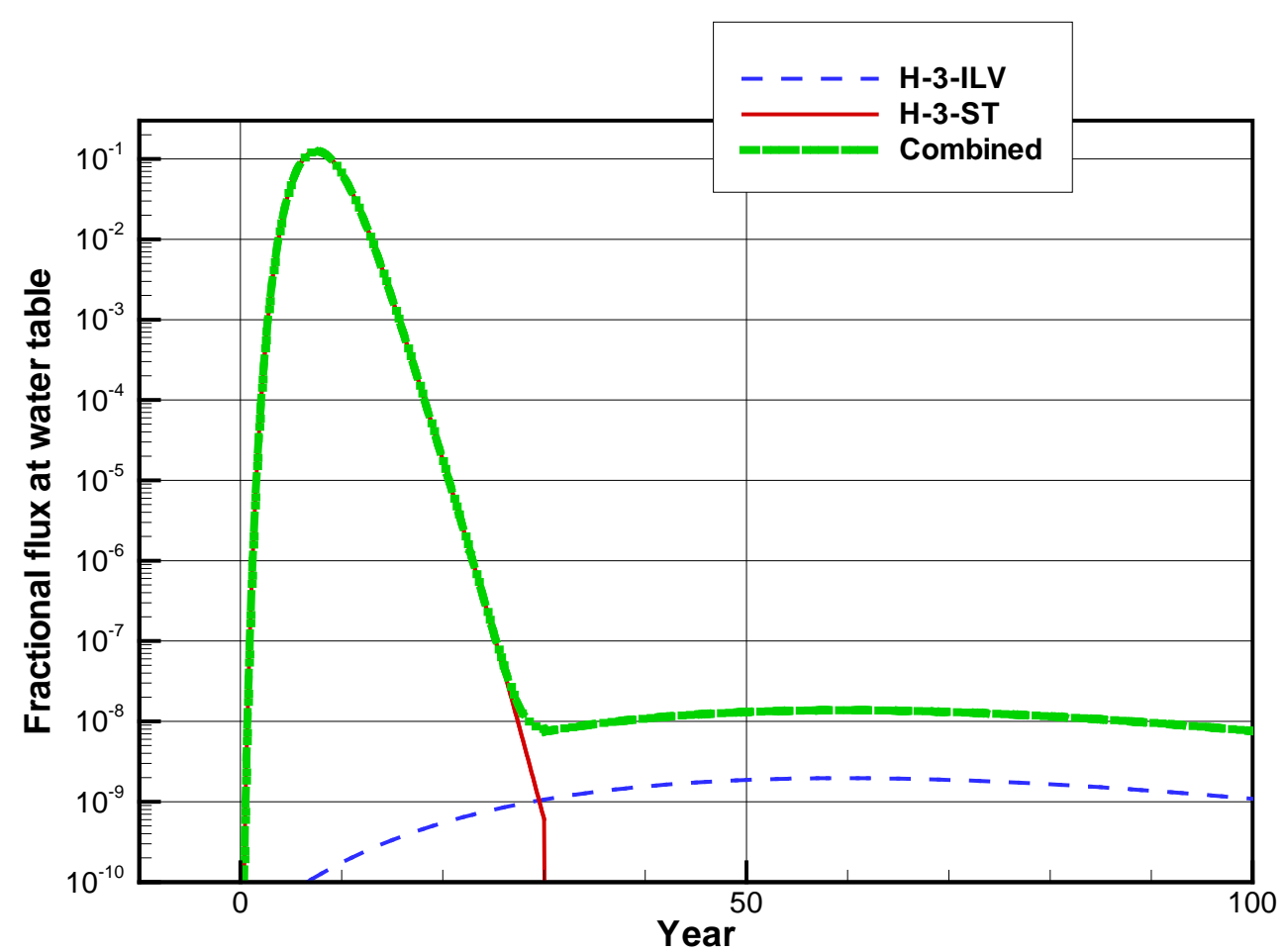

Figure 5-1. Plot of H-3 release from a Slit Trench vs. from the ILV

\subsection{Results}

Approximate values for the inventory source magnitudes for each disposal unit in the SlitWest group for the first two steps are shown in Table 5-1 (for C-14) where the ILV is included. Magnitudes were applied in the PA so that each aquifer source cell would have the same initial concentration, thus they were a function of the footprint area and the thickness of the aquifer source cells. The concentration magnifier for C-14 in ST \#9 is 4.29, because of the heavy influence of the ILV.

Table 5-1. Plume interaction inventory source magnitudes (g-mol) and the concentration magnifier for C-14.

\begin{tabular}{cccc} 
Disposal Unit & Step1 & Step2 & $\begin{array}{c}\text { Concentration } \\
\text { Magnifier }\end{array}$ \\
\hline ILV & 0.345 & 0 & \\
ST \#8 & 0.116 & 0 & \\
ST \#9 & 0.118 & 0.499 & 4.29 \\
ST \#10 & 0.096 & 0 & \\
ST \#11 & 0.173 & 0 & \\
ST \#12 & 0.119 & 0 & \\
ST \#13 & 0.116 & 0 &
\end{tabular}

The peak well concentration for the tracer from Step 1 (matched in Step 2) was $3.11 \times 10^{-7} \mathrm{~g}$ $\mathrm{mol} / \mathrm{ft}^{3}$.

Figure 5-2 displays concentrations on a horizontal slice (the $6^{\text {th }}$ K-plane) of the aquifer model where the peak concentrations appeared when the ILV is included. This figure is from Step 1. 
The location of the peak concentration is directly down-gradient from ST \#9 indicating significant interaction with its nearest neighbors (ST \#8, ST \#10, and the ILV).

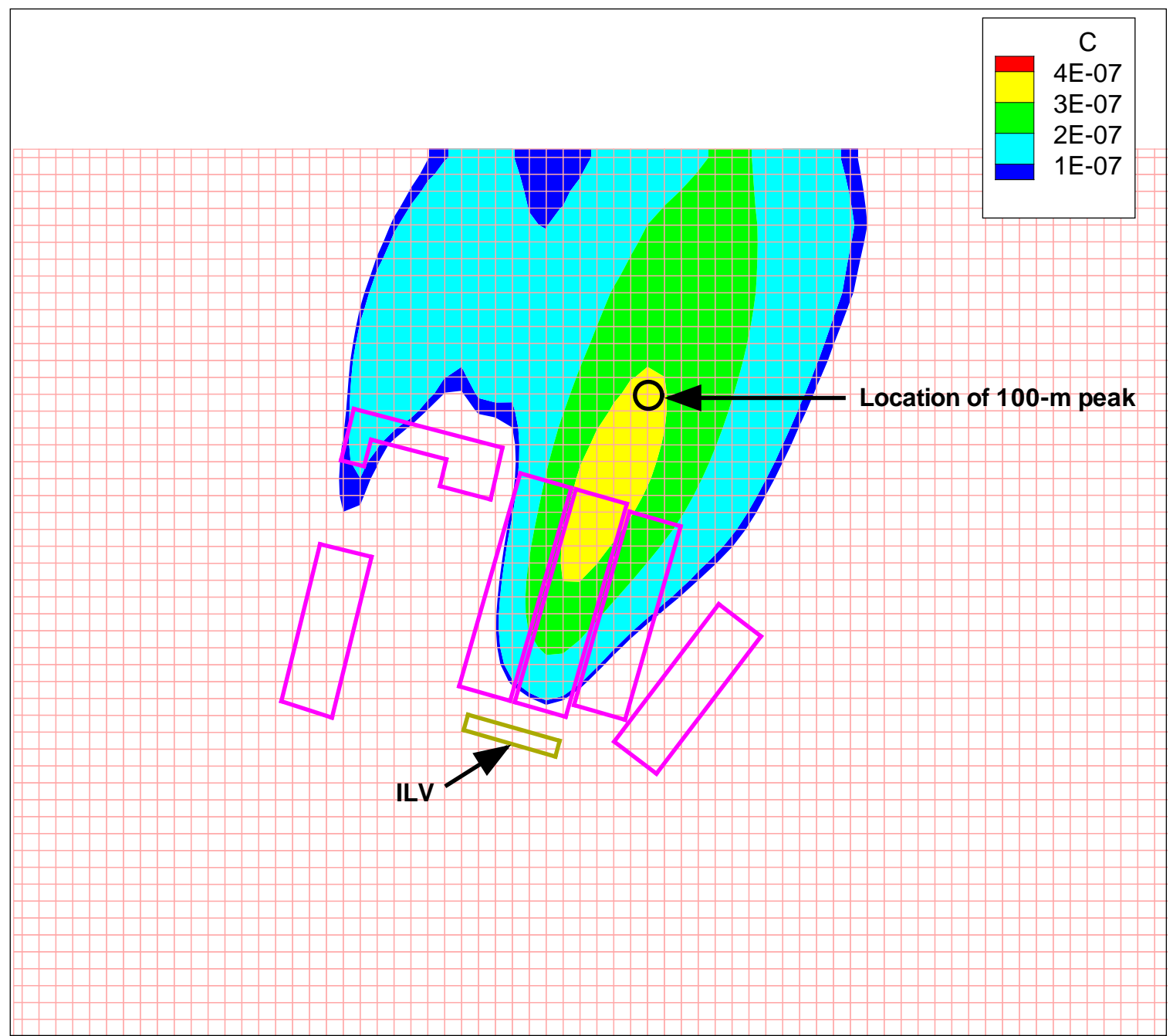

Figure 5-2. Plume interaction for peak horizontal plane with ILV used to compute plume interaction factor for C-14.

Approximate values for the inventory source magnitudes for each disposal unit in the SlitWest group for the first two steps are shown in Table 5-2 (for H-3) where the ILV is excluded. The concentration magnifier for C-14 in ST \#9 is 2.08, where the influence of the ILV was removed.

Table 5-2. Plume interaction inventory source magnitudes (g-mol) and the concentration magnifier for $\mathrm{H}-3$.

\begin{tabular}{cccc} 
Disposal Unit & Step1 & Step2 & $\begin{array}{c}\text { Concentration } \\
\text { Magnifier }\end{array}$ \\
\hline ILV & 0 & 0 & \\
ST \#8 & 0.116 & 0 & \\
ST \#9 & 0.118 & 0.242 & 2.08 \\
ST \#10 & 0.096 & 0 & \\
ST \#11 & 0.173 & 0 & \\
ST \#12 & 0.119 & 0 & \\
ST \#13 & 0.116 & 0 &
\end{tabular}


The peak well concentration for the tracer from Step 1 (matched in Step 2) was $1.51 \times 10^{-7} \mathrm{~g}$ $\mathrm{mol} / \mathrm{ft}^{3}$.

Figure 5-3 displays concentrations on a horizontal slice (the $6^{\text {th }}$ K-plane) of the aquifer model where the peak concentrations appeared when the ILV was not included. This figure is from Step 1. The location of the peak concentration is directly down-gradient from ST \#9 indicating significant interaction with its nearest neighbors (ST \#8 and ST \#10). The peak concentration was reduced by about a factor of two after the ILV was removed (from $3.11 \times 10^{-7}$ to $1.51 \times 10^{-7}$ ) indicating that the ILV more than doubled the total concentration for the analysis for C-14.

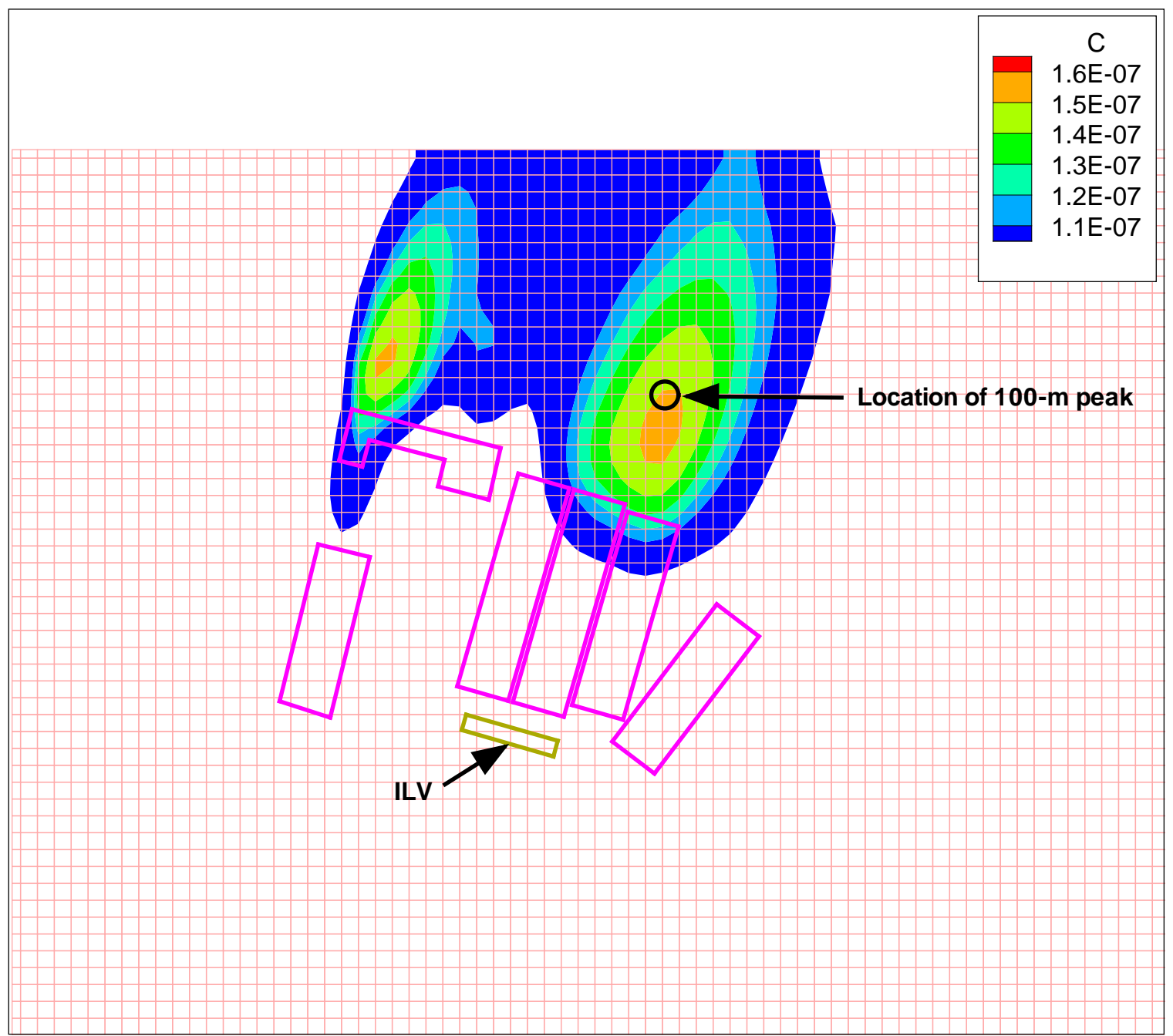

Figure 5-3. Plume interaction for peak horizontal plane without ILV used to compute plume interaction factor for $\mathrm{H}-3$.

As a confirmation, only ST \#9 was loaded with generic H-3 at a newly calculated allowable inventory, which was calculated as follows:

1. In the 2008 PA an inventory limit calculated for the entire SlitWest group was then divided by the number of standard-sized Slit-Trench footprints (4.95) occupied by the group to obtain a nominal preliminary limit. That step was reversed by multiplying the 2008 PA H-3 limit of 3.6 Ci by 4.95 to recover the limit for the SlitWest group of $17.82 \mathrm{Ci}$. 
2. The PORFLOW analysis uniformly distributed the mass of the contaminant based on the volume of aquifer source cells for each disposal unit. Therefore, the SlitWest group inventory limit was distributed similarly. ST \#9 occupies 0.158 of the group volume, so it was assigned a limit of $17.82 \mathrm{Ci} * 0.158=2.81 \mathrm{Ci}$.

3. Because the ILV was no longer considered as a plume interaction contributor, its effect was canceled by multiplying by 1.9 (the 2008 PA-SlitWest-group plume interaction factor), or $2.81 \mathrm{Ci} * 1.90=5.33 \mathrm{Ci}$.

The $5.33 \mathrm{Ci}$ was then input into a PORFLOW run that produced a well concentration of $10,119 \mathrm{pCi} / \mathrm{L}$. The PORFLOW result multiplied by the ST \#9 concentration magnifier of 2.08 produced a well concentration of $21,049 \mathrm{pCi} / \mathrm{L}$ that is very close to the MCL of 20,000 $\mathrm{pCi} / \mathrm{L}$. Differences likely are due to multiple round-off errors. Reproducing the MCL for ST \#9 confirms the ST \#9 well concentration magnifier of 2.08 . 


\subsection{Inventory Limits}

Inventory limits were developed for H-3 and C-14 in the 19 heat exchangers, where the special waste forms were designated $\mathrm{H}-3 \mathrm{X}$ and $\mathrm{C}-14 \mathrm{X}$, respectively. Chapter 4 contains a discussion of the selection of scenarios for inventory limit calculations. Figure 6-1 annotates Figure 4-8 to identify the scenarios used, where all scenarios to the right of the vertical dashed line were selected. Those scenarios to the left of this line were considered to have a very low probability of occurrence from a leakage perspective and/or from a release mechanism perspective. The top two groups of data in the upper left corner of Figure 6-1 (pink and green triangles) assume instantaneous release, taking no credit for diffusion and corrosion in holdup of tritium. Tritium diffusion into and out of the stainless steel tubes and corrosion of the surface oxide layer are known to occur. The remaining two groups of data (pink triangles) to the left of the dashed line assume both a line break and poor sealing of the potential leak paths, also considered a very low probability based on the precautions being taken by ACP in sealing the openings and by SWM in protecting the drain lines during burial. Figure 6-1 only shows the $4 \times 5$ disposal configuration. In performing the limits analyses both the $4 \times 5$ and $3 \times 7$ scenario sets were considered.

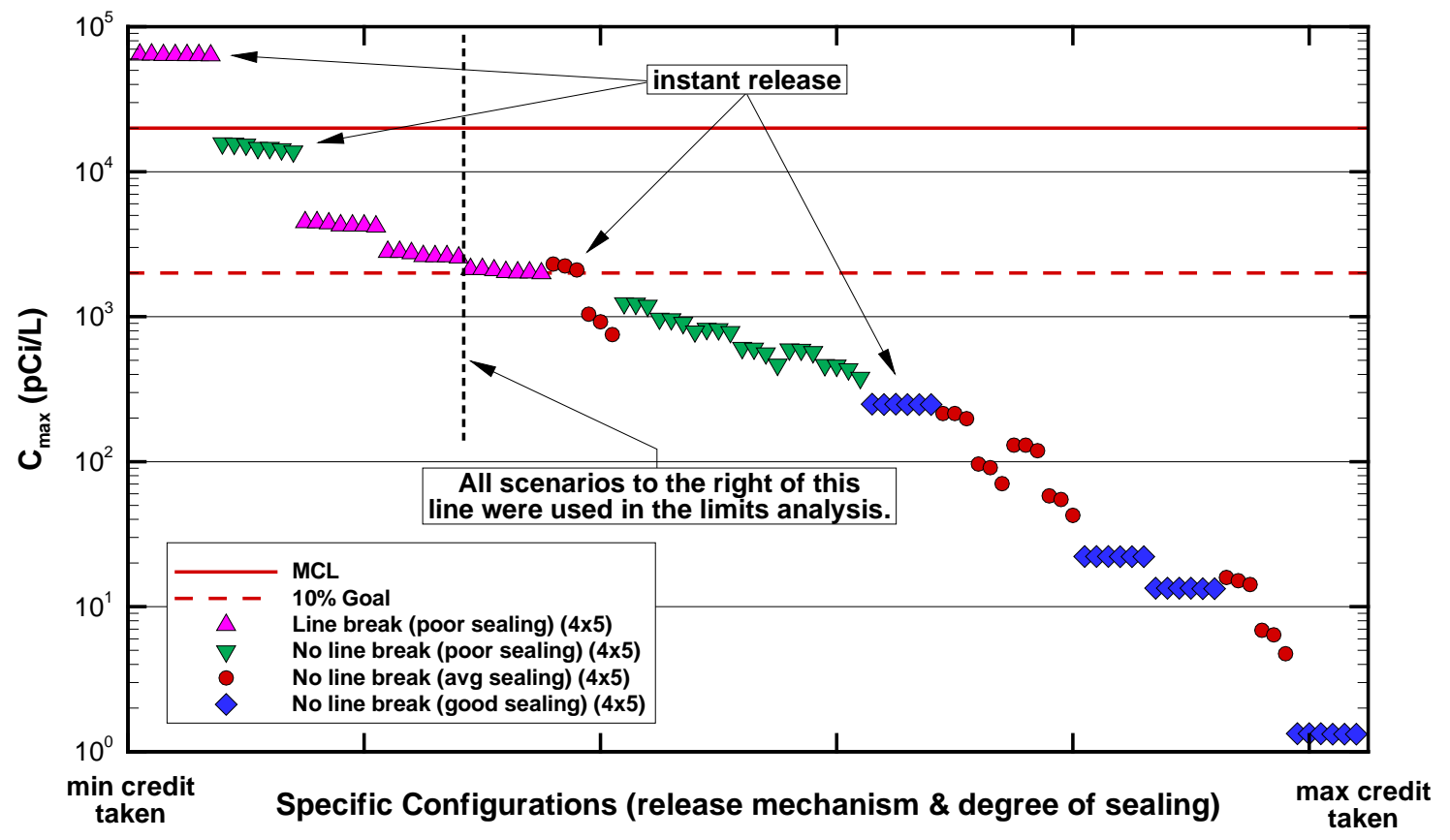

Figure 6-1. Selection of $\mathrm{H}-3$ scenarios (Case01) in the $4 \mathrm{x} 5$ configuration for limits calculations.

To cover all "credible" disposal scenarios and to allow Solid Waste the maximum flexibility from a burial perspective (i.e. burial configuration), the largest PORFLOW well concentration value from the entire chosen subset from each burial configuration was selected at each time step. Data from the largest set of values (that were multiplied by the well-concentration magnifier) were used as input to the software that calculates inventory limits.

\subsection{Groundwater Beta-Gamma Pathway Concentration Results}

The performance of $\mathrm{H}-3 \mathrm{X}$ and $\mathrm{C}-14 \mathrm{X}$ in terms of peak well concentrations were presented and discussed in the Chapter 4 Aquifer Analysis section. Those concentrations were compared with the MCL, which is the EPA allowable value for the Beta-Gamma pathway. Inventory limits are provided below for both the Beta-Gamma pathway and the groundwater All-Pathways. 


\subsection{Inventory Limits Results}

Inventory limits results for C-14X are provided for each of the cases and configurations in Table 6-1. The minimum limit for each pathway was selected as the final limit. The dashes indicate that there is no limit or the limit is greater than $1 \mathrm{E} 20 \mathrm{Ci}$. The first PA beta-gamma pathway window from 0 to $12 \mathrm{yr}$ is not applicable because it started at the end of 1995 and stopped at the end of 2007 before the first of these heat exchangers could be buried.

All cases and configurations contributed a minimum except for Case 01 for the $3 \times 7$ configuration. Case 01 has the lower limit in the last $130 \mathrm{yr}$ likely because more contaminant was leached out in Case01n11 when subsidence occurred, thus there was less contamination remaining to affect later peaks.

\begin{tabular}{|c|c|c|c|c|c|c|c|c|c|c|}
\hline \multirow[b]{2}{*}{ Radionuclide } & \multicolumn{2}{|c|}{ Beta-Gamma } & \multirow{2}{*}{$\begin{array}{l}\text { Alpha } \\
\text { all }\end{array}$} & \multirow{2}{*}{$\begin{array}{c}\text { Radium } \\
\text { all }\end{array}$} & \multirow{2}{*}{$\begin{array}{c}\text { Uranium } \\
\text { all }\end{array}$} & \multicolumn{3}{|c|}{ All-Pathways } & \multirow[t]{2}{*}{ Case } & \multirow[t]{2}{*}{ Config } \\
\hline & $\begin{array}{c}\text { to } \\
100 \\
\mathrm{yr}\end{array}$ & $\begin{array}{l}100 \text { to } \\
1130 \mathrm{yr}\end{array}$ & & & & $\begin{array}{c}130 \text { to } 200 \\
y r\end{array}$ & $\begin{array}{l}200 \text { to } \\
1000 \mathrm{yr}\end{array}$ & $\begin{array}{l}1000 \text { to } \\
1130 \mathrm{yr}\end{array}$ & & \\
\hline C-14X & --- & $2.7 \mathrm{E}+00$ & --- & --- & --- & $2.7 \mathrm{E}+00$ & $5.8 \mathrm{E}+00$ & $8.8 \mathrm{E}+00$ & $01 n 11$ & $4 \times 5$ \\
\hline$C-14 X$ & --- & $6.5 \mathrm{E}+00$ & --- & --- & --- & $1.4 \mathrm{E}+18$ & $7.0 \mathrm{E}+00$ & $6.5 E+00$ & 01 & $4 \times 5$ \\
\hline$C-14 X$ & --- & $2.8 \mathrm{E}+00$ & --- & --- & --- & $2.8 \mathrm{E}+00$ & $5.7 \mathrm{E}+00$ & $9.0 \mathrm{E}+00$ & 01n11 & $3 \times 7$ \\
\hline$C-14 X$ & --- & $6.6 \mathrm{E}+00$ & --- & --- & --- & $1.3 \mathrm{E}+18$ & $7.2 \mathrm{E}+00$ & $6.7 E+00$ & 01 & $3 \times 7$ \\
\hline Min & --- & $2.7 \mathrm{E}+00$ & --- & --- & --- & $2.7 \mathrm{E}+00$ & $5.7 \mathrm{E}+00$ & $6.5 \mathrm{E}+00$ & & \\
\hline
\end{tabular}

Limits results for H-3X are provided for each of the cases and configurations in Table 6-2. H-3 decays rapidly, thus Case01n11 is not applicable because it starts deviating from Case01 only after 113.5 yr (more than nine half-lives). The minimum limit for each pathway was selected as the final limit. The minimum always occurred for the $4 \times 5$ configuration, although all the differences between the configurations were small.

Table 6-2. H-3X inventory limit matrix (Ci)

\begin{tabular}{|c|c|c|c|c|c|c|c|c|c|c|}
\hline \multirow[b]{2}{*}{ Radionuclide } & \multicolumn{2}{|c|}{ Beta-Gamma } & \multirow{2}{*}{$\begin{array}{c}\text { Alpha } \\
\text { all }\end{array}$} & \multirow{2}{*}{$\begin{array}{c}\text { Radium } \\
\text { all }\end{array}$} & \multirow{2}{*}{$\begin{array}{c}\text { Uranium } \\
\text { all }\end{array}$} & \multicolumn{3}{|c|}{ All-Pathways } & \multirow[t]{2}{*}{ Case } & \multirow[t]{2}{*}{ Config } \\
\hline & $\begin{array}{c}12 \text { to } \\
100 \mathrm{yr}\end{array}$ & $\begin{array}{l}100 \text { to } \\
1130 \mathrm{yr}\end{array}$ & & & & $\begin{array}{l}130 \text { to } \\
200 \mathrm{yr}\end{array}$ & $\begin{array}{l}200 \text { to } \\
1000 \mathrm{yr}\end{array}$ & $\begin{array}{l}1000 \text { to } \\
1130 \mathrm{yr}\end{array}$ & & \\
\hline$H-3 X$ & $1.7 \mathrm{E}+03$ & $1.0 \mathrm{E}+05$ & --- & --- & --- & $9.5 \mathrm{E}+06$ & $9.6 \mathrm{E}+06$ & $1.2 \mathrm{E}+07$ & 01 & $4 \times 5$ \\
\hline$H-3 X$ & $1.7 \mathrm{E}+03$ & $1.0 \mathrm{E}+05$ & --- & --- & --- & $9.6 \mathrm{E}+06$ & $9.8 \mathrm{E}+06$ & $1.2 \mathrm{E}+07$ & 01 & $3 \times 7$ \\
\hline Min & $1.7 \mathrm{E}+03$ & $1.0 \mathrm{E}+05$ & --- & --- & --- & $9.5 \mathrm{E}+06$ & $9.6 \mathrm{E}+06$ & $1.2 \mathrm{E}+07$ & & \\
\hline
\end{tabular}

Final inventory limits for C-14X and H-3X are presented in Table 6-3. Inventory limits for generic waste in the West Slit Trenches, which apply to Slit Trench 9, are also provided in Table 6-3 for comparison.

The lowest inventory limit for $\mathrm{C}-14 \mathrm{X}$ is $2.7 \mathrm{E} 0 \mathrm{Ci}$ versus the lowest limit for generic $\mathrm{C}-14$ of $1.9 \mathrm{E}-1 \mathrm{Ci}$, representing an increase of $1321 \%$ for C-14X. Figure $6-2$ shows the performance of generic waste C-14 from the PA (2008) analysis to the behavior of C-14X for a sample scenario. The time windows from the PA are shown by vertical dashed lines. The first time window for the PA ends before the heat exchangers are disposed, so there is no limit for the heat exchangers during this time window. The generic C-14 peaked during this time window. During the second time window, the generic C-14 concentration is rapidly decreasing but is significantly higher than the $\mathrm{C}-14 \mathrm{X}$ concentration for this scenario, thus the inventory limit for generic C-14 is still at least an order of magnitude less than the limit for C-14X. For the third time window, the C-14 analysis was stopped early, because with its zero $K_{d}$ it was rapidly decreasing. However, the third time 
window is where all the action for C-14X occurred because its higher $\mathrm{K}_{\mathrm{d}}$ caused it to travel much slower. Therefore, during the third time window, the inventory limit for C-14X was much smaller than the inventory limit for generic C-14.

Because the C-14 moves faster (with its $\mathrm{K}_{\mathrm{d}}$ of $0 \mathrm{ml} / \mathrm{g}$ ) at later times the bulk of C-14 moves beyond the 100-m buffer and outside the modeling domain, so it displays very low well concentrations at those later times. However, C-14X moves slower (with its $\mathrm{K}_{\mathrm{d}}$ of $1 \mathrm{ml} / \mathrm{g}$ in sand and $30 \mathrm{ml} / \mathrm{g}$ in clay), therefore at later times it reaches the $100-\mathrm{m}$ buffer and is still inside the modeling domain where it displays relatively higher well concentrations (although they are much lower than those for C-14). Because time windows are employed to establish inventory limits, C-14X exhibits relatively lower limits at later times, although they are extremely lower than the minimum limits for C-14.

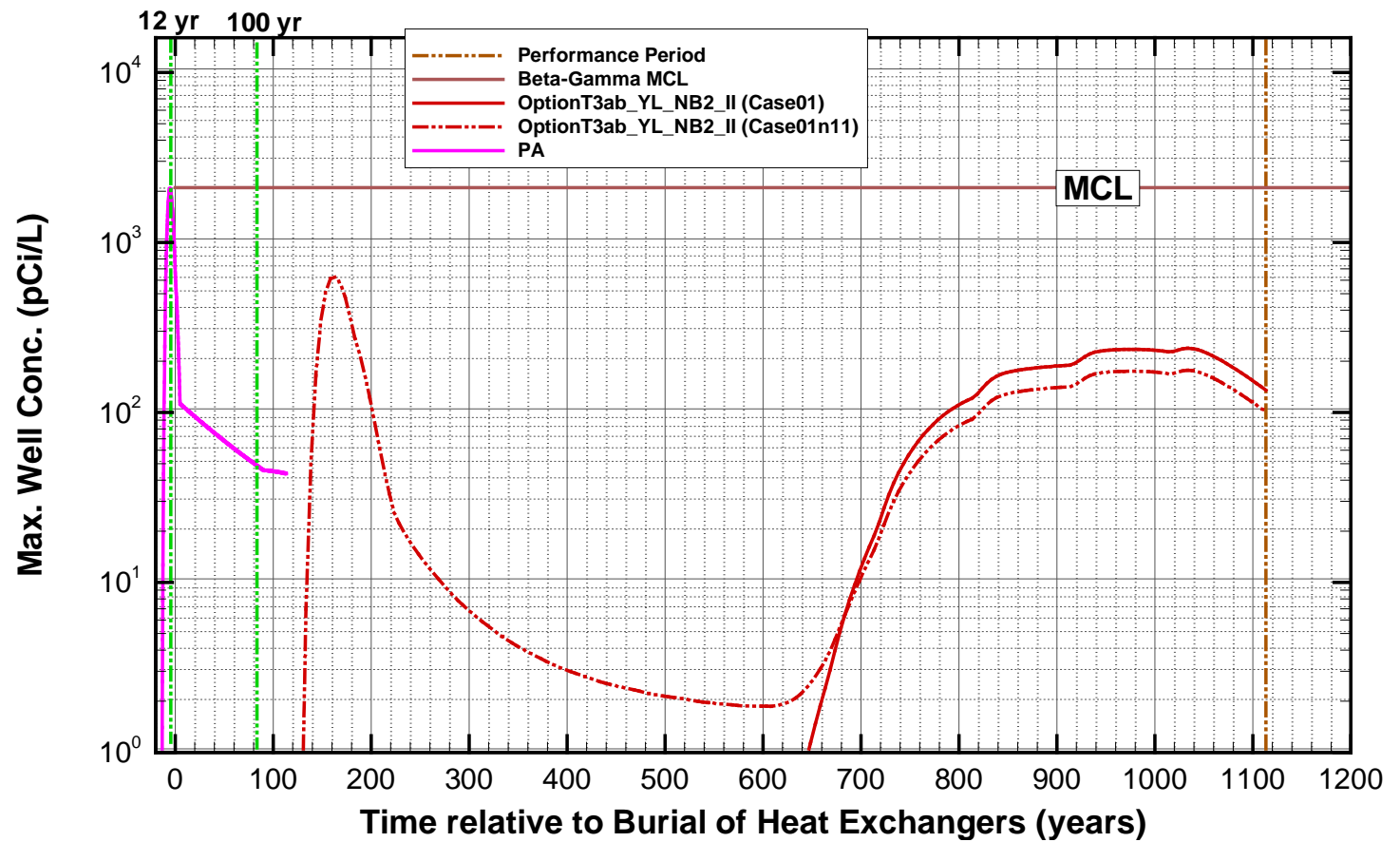

Figure 6-2. Comparison of PA well concentration for C-14 with a sample C-14X scenario.

The lowest inventory limit for $\mathrm{H}-3 \mathrm{X}$ is $1.7 \mathrm{E} 3 \mathrm{Ci}$ versus the lowest limit for generic $\mathrm{H}-3$ of 3.6E0 $\mathrm{Ci}$, representing an increase of $47,122 \%$ for $\mathrm{H}-3 \mathrm{X}$. Because the $\mathrm{K}_{\mathrm{d}}$ is the same for $\mathrm{H}-3 \mathrm{X}$ and $\mathrm{H}-3$ window timing has little effect, the inventory limits for $\mathrm{H}-3 \mathrm{X}$ are always higher than those for H-3.

\begin{tabular}{|c|c|c|c|c|c|c|c|c|c|}
\hline \multirow[b]{2}{*}{ Radionuclide } & \multicolumn{3}{|c|}{ Beta-Gamma } & \multirow{2}{*}{$\begin{array}{c}\text { Alpha } \\
\text { all }\end{array}$} & \multirow{2}{*}{$\begin{array}{c}\text { Radium } \\
\text { all }\end{array}$} & \multirow{2}{*}{$\begin{array}{c}\text { Uranium } \\
\text { all }\end{array}$} & \multicolumn{3}{|c|}{ All-Pathways } \\
\hline & $\begin{array}{c}0 \text { to } 12 \\
y r\end{array}$ & $\begin{array}{l}12 \text { to } \\
100 \mathrm{yr}\end{array}$ & $\begin{array}{l}100 \text { to } \\
1130 \mathrm{yr}\end{array}$ & & & & $\begin{array}{l}130 \text { to } \\
200 \mathrm{yr}\end{array}$ & $\begin{array}{l}200 \text { to } \\
1000 \mathrm{yr}\end{array}$ & $\begin{array}{l}1000 \text { to } \\
1130 \mathrm{yr}\end{array}$ \\
\hline$C-14 X$ & --- & --- & $2.7 E+00$ & --- & --- & --- & 2.7E+00 & $5.7 \mathrm{E}+00$ & $6.5 \mathrm{E}+00$ \\
\hline$H-3 X$ & --- & $1.7 \mathrm{E}+03$ & $1.0 \mathrm{E}+05$ & --- & --- & --- & $9.5 E+06$ & $9.6 \mathrm{E}+06$ & $1.2 \mathrm{E}+07$ \\
\hline $\begin{array}{l}\text { C-14 (West Slit } \\
\text { Trenches) }\end{array}$ & $1.9 \mathrm{E}-01$ & $2.0 \mathrm{E}-01$ & $8.3 E+00$ & --- & --- & --- & $9.6 \mathrm{E}+00$ & $9.6 \mathrm{E}+00$ & $9.6 \mathrm{E}+00$ \\
\hline $\begin{array}{l}\text { H-3 (West Slit } \\
\text { Trenches) }\end{array}$ & $3.6 \mathrm{E}+00$ & $3.9 E+00$ & $2.2 \mathrm{E}+04$ & --- & --- & --- & $3.5 E+06$ & $3.5 E+06$ & $3.5 \mathrm{E}+06$ \\
\hline
\end{tabular}


The C-14X and H-3X inventory limits include the appropriate plume interaction factors (well concentration magnifiers) for ST \#9 therefore no other limit adjustments or adjustments for the allowable SOF need be applied. Changes listed in Butcher and Hiergesell (2012) do not apply to C-14X and H-3X.

\subsection{Sum-of-Fraction Results}

The heat-exchanger special-waste-form inventories and their fraction of the inventory consumed for each pathway are presented in Table 6-4. The current WITS SOFs (adjusted for Interim Measures changes (Butcher and Hiergesell, 2012)) and the combined SOFs are also presented in Table 6-4 for Slit Trench 9.

\begin{tabular}{|c|c|c|c|c|c|c|c|}
\hline \multirow[b]{2}{*}{ Radionuclide } & & \multicolumn{5}{|c|}{ Table 6-4. Sums-of-fractions } & \\
\hline & $\begin{array}{c}\text { Inventory }^{2} \\
\text { (Ci) }\end{array}$ & $\begin{array}{c}0 \text { to } 12 \\
\text { yr }\end{array}$ & $\begin{array}{c}12 \text { to } 100 \\
\mathrm{yr}\end{array}$ & $\begin{array}{c}100 \text { to } 1130 \\
\text { yr }\end{array}$ & $\begin{array}{c}130 \text { to } 200 \\
\text { yr }\end{array}$ & $\begin{array}{c}200 \text { to } 1000 \\
\text { yr }\end{array}$ & 1000 to $1130 \mathrm{yr}$ \\
\hline Current $^{3}$ & & 3.3E-01 & $3.5 \mathrm{E}-01$ & $2.4 \mathrm{E}-01$ & 2.2E-01 & 2.9E-01 & 2.2E-01 \\
\hline C-14X & $8.62 \mathrm{E}-01$ & --- & --- & 3.19E-01 & $3.19 E-01$ & $1.51 \mathrm{E}-01$ & $1.33 \mathrm{E}-01$ \\
\hline H-3X & $1.85 \mathrm{E}+02$ & --- & $1.09 \mathrm{E}-01$ & $1.85 \mathrm{E}-03$ & $1.95 \mathrm{E}-05$ & $1.93 \mathrm{E}-05$ & $1.54 \mathrm{E}-05$ \\
\hline Combined & & 3.3E-01 & 4.6E-01 & 5.6E-01 & $5.4 \mathrm{E}-01$ & 4.5E-01 & 3.5E-01 \\
\hline
\end{tabular}

The current volume consumption is approximately 36\%. The approximate area that will be occupied by the 19 heat exchangers is $6310 \mathrm{ft}^{2}$ or about $6 \%$ of a standard-sized trench disposal unit (656 ft long by $157 \mathrm{ft}$ wide). If no waste were placed on top of the heat exchangers, the combined volume would be about $42 \%$ of a disposal unit. If intermixed waste and soil are not considered (i.e., only the physical volume $\left(1400 \mathrm{ft}^{3}\right)$ of each heat exchanger is used), the combined volume would be about $41 \%$.

\subsection{Non-Groundwater Pathways}

Radionuclide inventory from the 19 reactor heat exchangers (Walliser, 2012) was compared with the West Slit Trench group non-groundwater pathway limits for Air, Radon, Resident Intruder, and Post-Drilling Intruder (Swingle, 2011). All fractions for individual radionuclides were well below one percent and the SOF impact for each pathway was below one percent as well. Therefore, the inventory from the heat exchangers falls well within non-groundwater pathways limits and no special waste form limits are needed. 
SRNL-STI-2012-00321

Revision 0

\subsection{References}

Abraham, P.M., D. Chandra, J.M. Mintz, T.S . Elleman, and K. Verghese, 1976. "Final Report On Diffusion of Gases in Solids; Rare Gas Diffusion in Solids, Tritium Diffusion in Fission and Fusion Reactor Metals,” US ERDA Report No. ORO-3508-10, North Carolina State University, Raleigh, NC 27607.

Butcher, B. T. 2012a, "Memo to File: Identification of Reactor Heat Exchangers that are Leakers”, SRNL-L3200-2012-00019, Savannah River Nuclear Solutions, Savannah River Site, Aiken, SC 29808, June 14, 2012.

Butcher, B. T., 2012b. "Memo to File: SRNL Guidance to ACP for Addressing Leak Paths on 19 Reactor Process Heat Exchangers," SRNL-L3200-2012-00018, Savannah River Nuclear Solutions, Savannah River Site, Aiken, SC 29808, June 7, 2012.

Butcher, B. T. and R. A. Hiergesell, 2012. "Performance Assessment Interim Measures for Returning E-Area Low-Level Waste Facility Trenches to Operation,” SRNL-STI-201200320, Revision 0, May 2012, Savannah River National Laboratory, Savannah River Site, Aiken, SC 29808.

Collard, L.B. and L.L. Hamm, 2008, "Special Analysis of Operational Stormwater Runoff Covers Over Slit Trenches,” SRNL-STI-2008-00397 (Rev. 0), December 2008, Savannah River National Laboratory, Savannah River Site, Aiken, SC 29808.

Collard, L. B. and L. L. Hamm, 2012. “Alternatives Analysis for Selecting ET \#3 Site,” SRNLSTI-2012-0047, Revision 0, February 2012.

DOE, 1999. “Radioactive Waste Management,” Order 435.1, U.S. Department of Energy.

Elleman, T.S. and K. Verghese, 1974. "Surface Effects on Tritium Diffusion in Niobium, Zirconium and Stainless Steel,” Journal of Nuclear Materials, 53, 299-306, (1974).

Estochen, E. G., 2010. "HWCTR Burial Failure Evaluations (U),” M-CLC-E-00048 (Revision 0), Savannah River Nuclear Solutions, July 2010.

Hamm, L. L. and F. G. Smith, III, 2010. "Special Analysis for Slit Trench Disposal of the Heavy Water Components Test Reactor," SRNL-STI-2010-00574, Savannah River Nuclear Solutions, Savannah River Site, Aiken, SC 29808, October 29, 2010.

Kaplan, D. I., 2010. "Geochemical Data Package For Performance Assessment Calculations Related To The Savannah River Site,” SRNL-STI-2009-00473, Savannah River Nuclear Solutions, Savannah River Site, Aiken, SC 29808, March 15, 2010.

Ketcham, D. R. (1993). "Heat Exchangers - Status," WSRC Inter-office Memorandum, to H.F. Allen, RRD-RED-93-0101, January 29, 1993.

PA, 2008. "E-Area Low Level Waste Facility DOE 435.1 Performance Assessment," WSRC-STI-2007-00306, Revision 0, Washington Savannah River Company, LLC, Aiken, SC, March 2008.

Phifer, M. A., M. R. Millings, and G. P. Flach, 2006. "Hydraulic Property Data Package for the E-Area and Z-Area Soils, Cementitious Materials and Waste Zones," WSRC-STI-200600198, Rev.0, Washington Savannah River Company, September 2006.

Swingle, R. F., 2011. "Revision of the ELLWF Disposal Limits Database Incorporating the Air Pathway Special Analysis (Revision 2011-2)”, SRNL-L3200-2011-00004, Savannah River Nuclear Solutions, Savannah River Site, Aiken, SC 29808, October 4, 2011.

UDQ, 2011. Attachment 1 of Unreviewed Disposal Question (U), SW-ENG-0601, Rev. 8. "Need for Development of PA Disposal Limits for Engineered Trench \#3.” May 29, 2011.

Walliser, S. A., 2012. N-Area Non-Decontaminated Reactor Process Water heat Exchangers Radiological Characterization, Q-CLC-N-00019, Revision 1, Savannah River Nuclear Solutions, Savannah River Site, Aiken, SC 29808, June 5, 2012. 
WSRC, 2008. "E-Area Low Level Waste Facility DOE 435.1 Performance Assessment," WSRC-STI-2007-00306, Revision 0, Washington Savannah River Company, LLC, Aiken, SC, March 2008. 
SRNL-STI-2012-00321

Revision 0

\section{Appendix A. Heat Exchanger Diffusion Source Terms for H-3X and C-14X}

The derivation of the source terms for tritium (H-3X) and carbon-14 (C-14X) is described below. Tritium is released into groundwater from the heat exchangers (HXs) via two mechanisms: 1) by diffusion from the bulk metal into which it had been absorbed during reactor operations, and 2) by corrosion of the tritium-containing metal and consequent release. Carbon-14 does not diffuse through bulk metal like tritium, so the only mechanism for its release into groundwater is corrosion of the surfaces on which it has been deposited. The diffusion source term is derived in this appendix, and the corrosion source term in Appendix B.

\section{A.1 Diffusion Coefficients for Tritium in Type 304 Stainless Steel}

The HXs absorbed tritium from the heavy water moderator during their yr of operation at SRS. Since the shutdown of the reactors, their tritium inventory has been steadily declining due to radioactive decay as well as diffusion out of the bulk metal. In order to establish credible estimates of the rate at which tritium will continue to diffuse out of the bulk metal in the future, a clear understanding of the diffusion mechanism is needed.

The diffusion of tritium in Type 304L stainless steel (as well as two other metals used in reactor systems) was characterized in a paper by Elleman and Verghese (1974). Measuring concentration profiles as well as surface release rates, they found that tritium accumulated in a narrow layer at the surface of metal specimens, while exhibiting classical diffusion behavior in the bulk material at depths greater than five $\mu \mathrm{m}$. A two-region diffusion model was successfully fitted to the data to account for this effect, resulting in diffusion coefficient estimates in the surface film that were two orders of magnitude smaller than those in the bulk material for stainless steel. Much larger differences (eight to ten orders of magnitude) were seen for niobium and Zircaloy-2. This apparent tritium trapping ability of the metal surface layer was attributed to the presence of oxide films that form on metal surfaces.

Figure A-1 shows tritium profiles measured by Elleman and Verghese (1974) for Type 304 stainless steel and Zircaloy-2 samples immediately after exposure to tritium. 


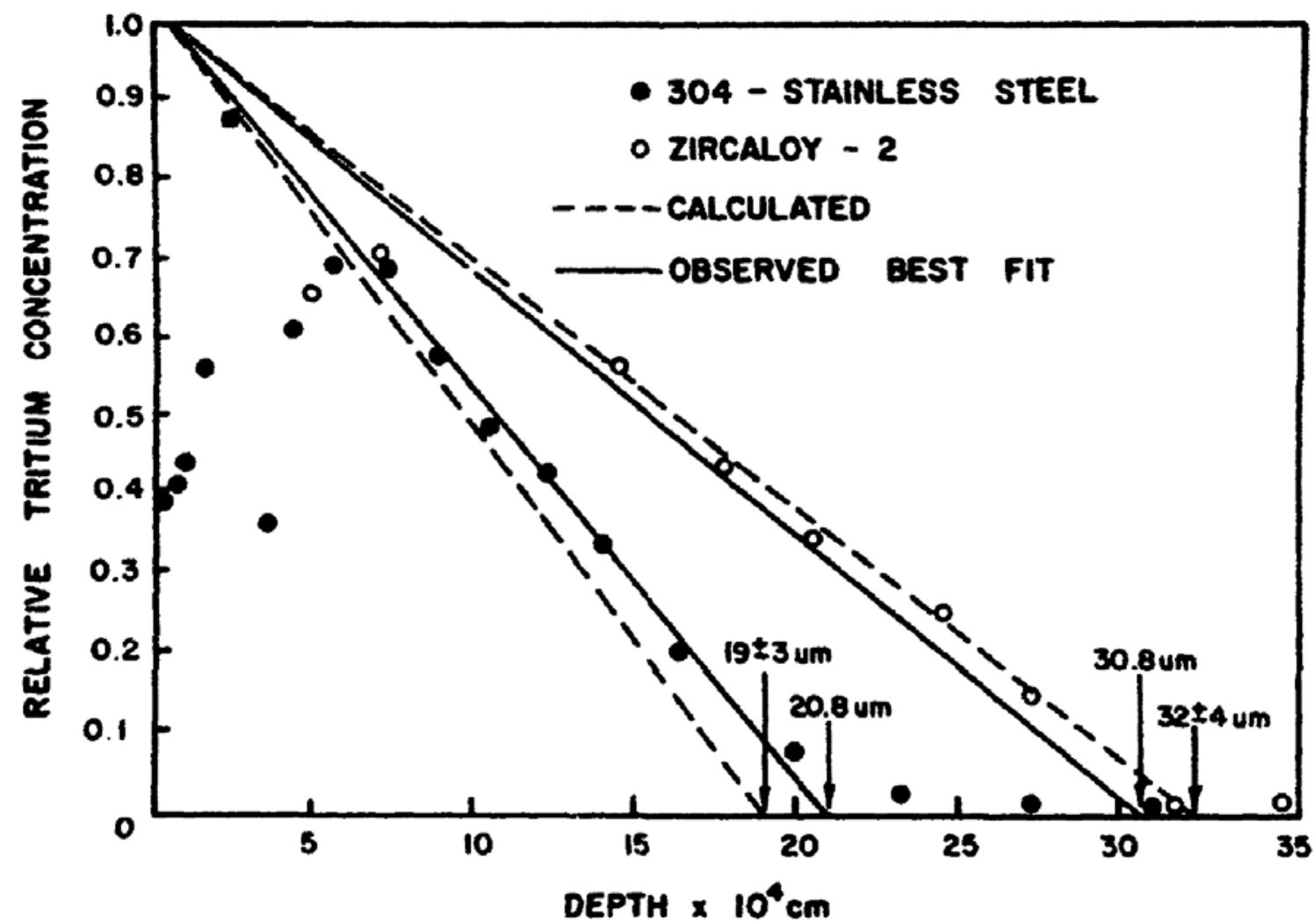

Figure A-1 Initial tritium concentration profile in Type 304 stainless steel and Zircaloy-2

(Elleman and Verghese, 1974).

Figure A-2 illustrates tritium concentration profiles for the three metals that were measured by Elleman and Verghese after annealing at the conditions stated on the chart. Three distinct regions were identified. Region I, which was several $\mu \mathrm{m}$ thick, was at the surface and had the highest concentrations. Region II was characterized by bulk diffusion behavior. They also saw a third region of low and nearly uniform concentration that they attributed to rapid grain boundary diffusion, but this phenomenon did not need to be included in the simple model they posited due to the limiting nature of the surface layer. 

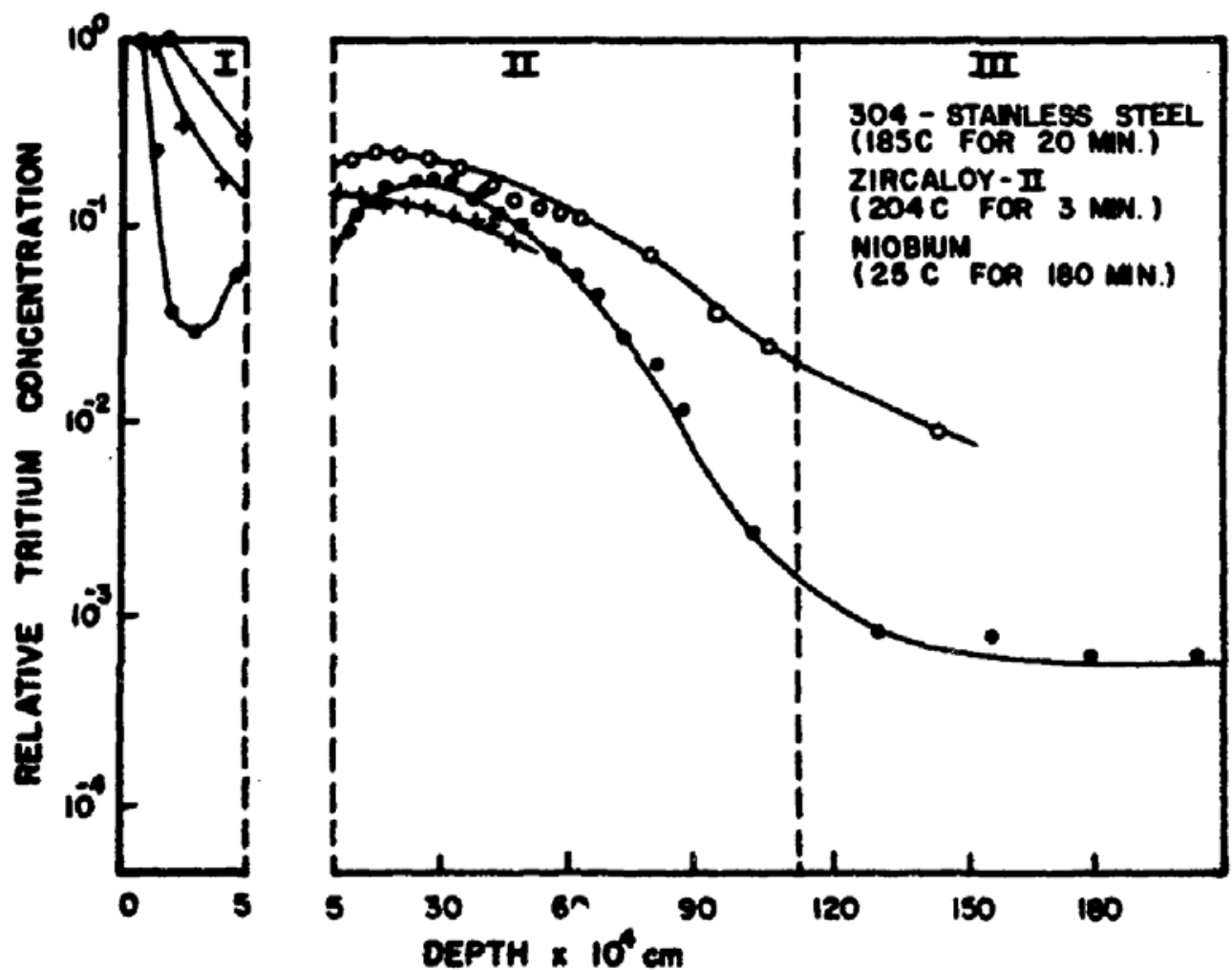

Figure A-2 Tritium distributions after annealing in Type 304 stainless steel, Zircaloy-2, and niobium measured by Elleman and Verghese (1974).

Diffusion coefficients for the three metals were determined over a range of temperatures and are plotted on a logarithmic scale against the inverse absolute temperature in Figure A-3. As expected, the logarithm of each diffusion coefficient appears to have a linear dependence on the inverse temperature.

Elleman and Verghese did not provide equations for the diffusion coefficients as functions of temperature. However, their work was part of a multiyear research project funded by the Energy Research and Development Agency (ERDA), for which a Final Report that contains this information was prepared (Abraham et al., 1976). The bulk diffusion coefficient for Type 304 stainless steel was found to fit the Arrhenius expression,

$$
D_{\text {bulk }}=0.018 \mathrm{e}^{-(14 \mathrm{kcal}) / \mathrm{RT}} \mathrm{cm}^{2} / \mathrm{s}
$$

at temperatures between 25 and $222^{\circ} \mathrm{C}$, while the diffusion coefficient for the surface region was represented by another Arrhenius expression,

$$
D_{\text {surface }}=0.0003 \mathrm{e}^{-(15.4 \mathrm{kcal}) / R T} \mathrm{~cm}^{2} / \mathrm{s}
$$

at temperatures between 25 and $184^{\circ} \mathrm{C}$. Figure A-4 compares data from Elleman and Verghese's (1974) paper (obtained by digitizing their Figure 4) with the Arrhenius formulae reported by Abraham et al. (1976). Considering the likely errors introduced by digitizing a small, scanned graph with a logarithmic scale, the match is good. 
SRNL-STI-2012-00321

Revision 0

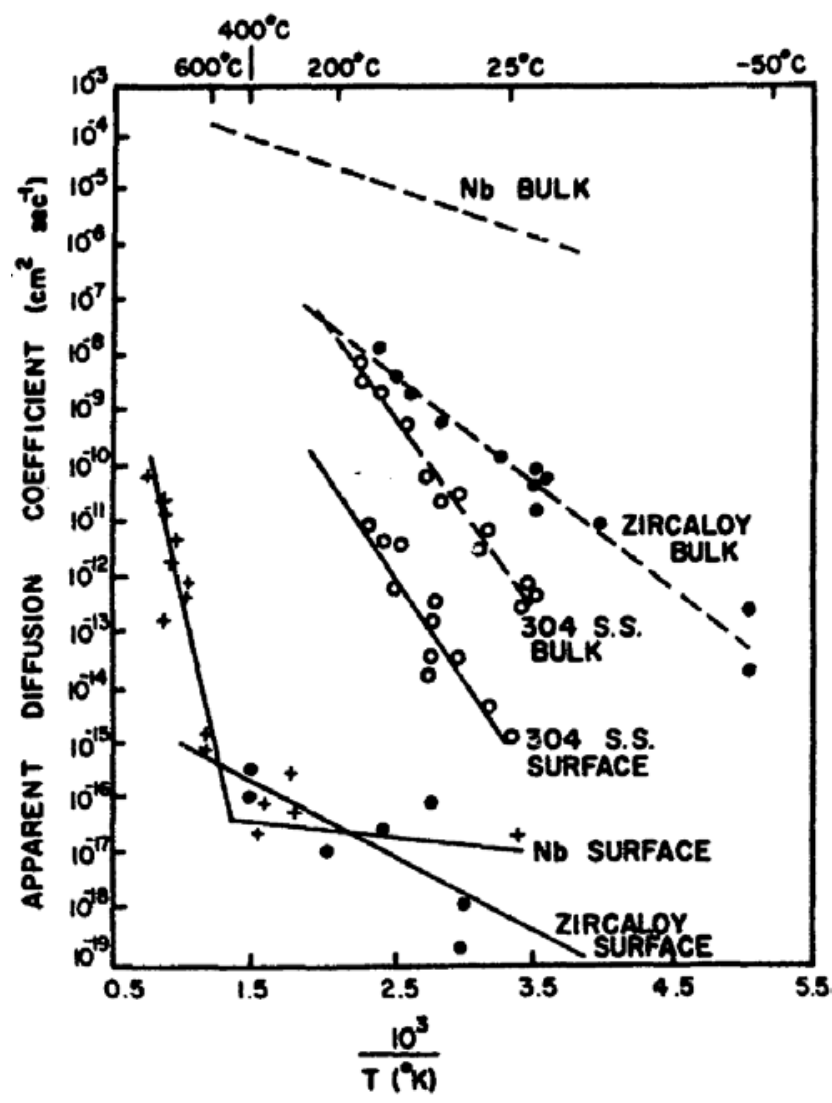

Figure A-3 Surface layer and bulk diffusion coefficients for Type 304 stainless steel, niobium, and Zircaloy-2 measured by Elleman and Verghese (1974).

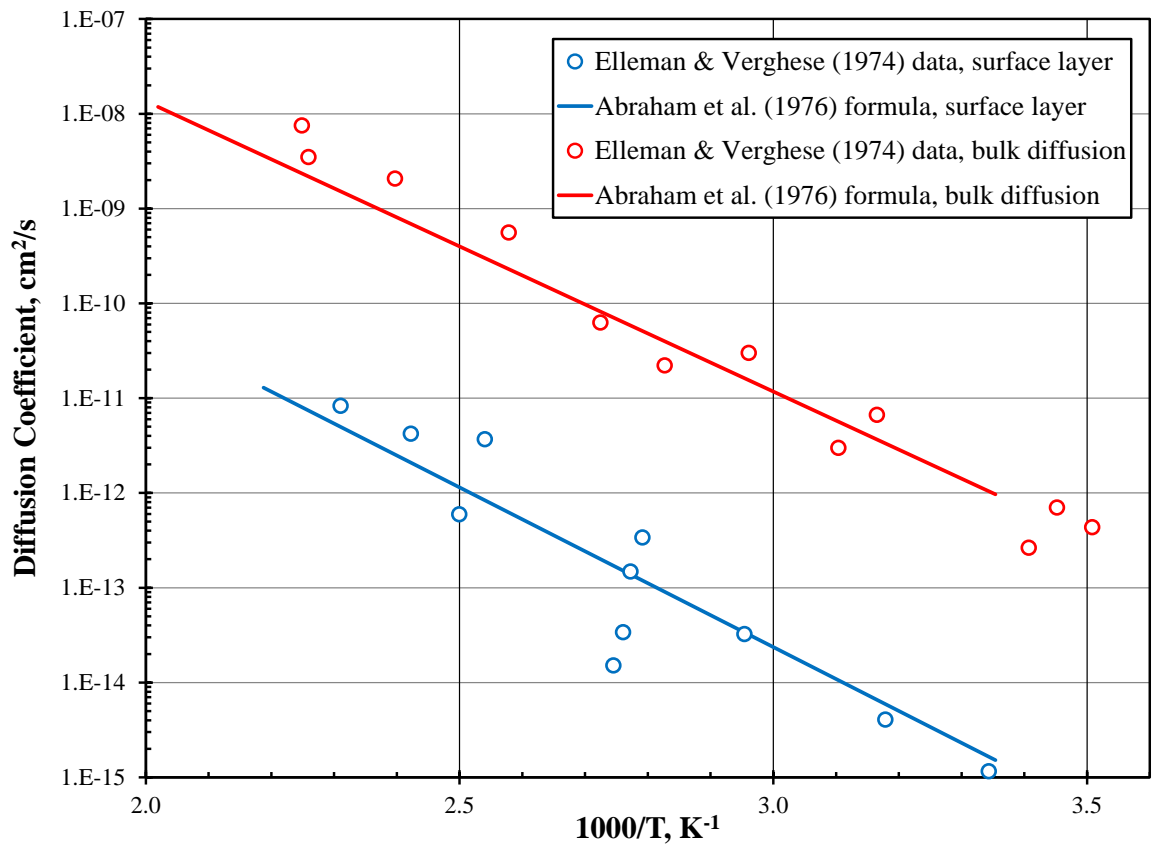

Figure A-4 Comparison between Elleman and Verghese (1974) data (digitized) and Abraham et al. (1976) formulae for tritium diffusion coefficients in Type 304 stainless steel. 
Diffusion coefficients in the bulk phase and in the surface layer for Type 304 stainless steel at the two temperatures of interest for modeling the behavior of tritium in the $\mathrm{HXs}\left(43.8^{\circ} \mathrm{C}\right.$ average temperature during operation and $20^{\circ} \mathrm{C}$ average temperature during storage and burial) are listed in Table A-1 below. These values were calculated using the Arrhenius expressions from Abraham et al. (1976) and converted to units compatible with the PORFLOW time scale ( $\left.\mathrm{cm}^{2} / \mathrm{yr}\right)$.

Table A-1 Diffusion coefficients for tritium in Type 304 stainless steel at temperatures needed for SA calculation

\begin{tabular}{|c|c|c|c|c|}
\hline \multirow{2}{*}{$\begin{array}{c}\text { Temperature, } \\
{ }^{\circ} \mathbf{C}\end{array}$} & \multicolumn{2}{|c|}{$\mathbf{c m}^{2} / \mathbf{s}$} & \multicolumn{2}{c|}{$\mathbf{c m}^{2} / \mathbf{y r}$} \\
\cline { 2 - 5 } & Surface & Bulk & Surface & Bulk \\
\hline 20 & $9.74 \times 10^{-16}$ & $6.47 \times 10^{-13}$ & $3.07 \times 10^{-8}$ & $2.04 \times 10^{-5}$ \\
\hline 43.8 & $7.10 \times 10^{-15}$ & $3.94 \times 10^{-12}$ & $2.24 \times 10^{-7}$ & $1.24 \times 10^{-4}$ \\
\hline
\end{tabular}

PORFLOW was used to simulate the loading with tritium of a Type 304 stainless steel coupon (representing a sample of a HX tube wall) at typical reactor operating conditions and the subsequent release of tritium over time after exposure. The behavior of all $19 \mathrm{HXs}$ was averaged into a single calculation representative of the typical history of an individual HX unit. This assumed that the HX had been placed in service 53 yr prior to burial, operating at an average temperature of $43.8^{\circ} \mathrm{C}$ for $30 \mathrm{yr}$ before being taken out of service. It was then assumed that the $\mathrm{HX}$ sat out in the open environment at an average temperature of $20^{\circ} \mathrm{C}$ for $23 \mathrm{yr}$, after which it was buried at $20^{\circ} \mathrm{C}$ for $200 \mathrm{yr}$. Consequently, the PORFLOW calculation was set up to maintain a constant tritium concentration at the coupon surface representing the interior tube wall for $30 \mathrm{yr}$, followed by a 223-yr period at zero tritium concentration. The tritium concentration at that surface during the exposure period was adjusted to achieve a total 0.5 g-mol tritium inventory in the coupon at the 53-yr point, essentially corresponding to the February 28, 2012 smear test date. (Another $0.5 \mathrm{~g}$-mol was assumed to be contained in the oxide layer at the surface that is subject to corrosion. This gave a total coupon tritium inventory of $1 \mathrm{~g}$-mol, evenly split between the oxide later and the bulk metal, which allowed for easy scaling to actual smear test data thanks to the linearity of the diffusion calculation.) Figure A-5 below plots the tritium inventory as a function of time calculated by the PORFLOW simulation. 


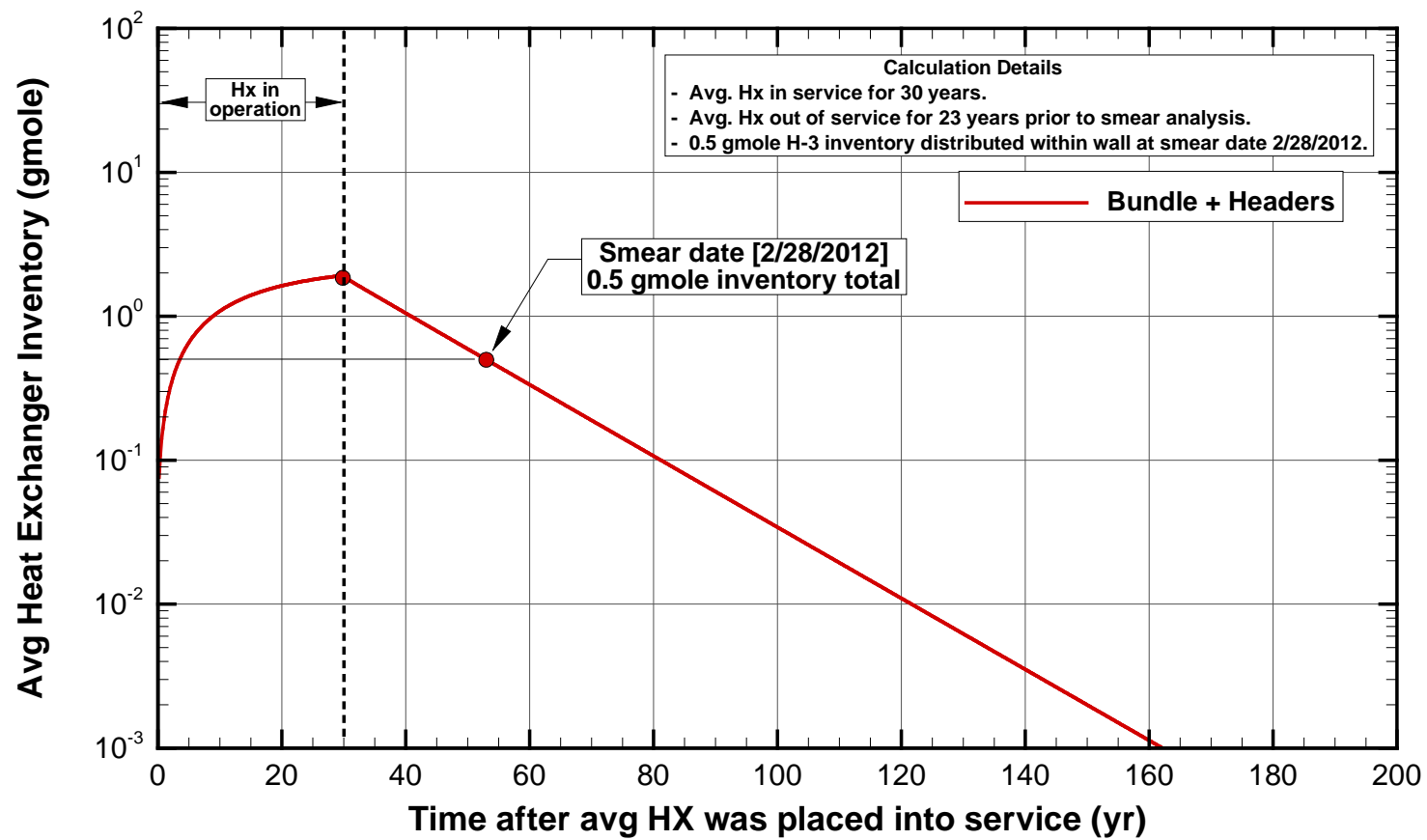

Figure A-5 Predicted tritium inventory in HX walls over time based on diffusion and decay.

Figure A-5 shows the inventory versus time in an average heat exchanger. Two key points in time are highlighted: (1) time when the avg. HX was taken out of service (30 yr) and (2) the time when the smear analysis was performed ( $23 \mathrm{yr}$ later). The analysis was adjusted such that a $0.5 \mathrm{~g}$ mol of $\mathrm{H}-3$ was present at the $53-y r$ point in time.

The flux release versus time was allocated between two different surfaces, representing the HX tube bundle surfaces and those in the HX headers. A bulk metal tritium inventory of 0.5 g-mol was assumed to be present at time 0 (corresponding to the time of burial). The relative proportions of the two different types of surfaces to the total active surface in a typical HX was calculated from the HX geometry (99.679\% tube bundle, $0.321 \%$ header) and applied to the total flux. The result is plotted in Figure A-6 below 


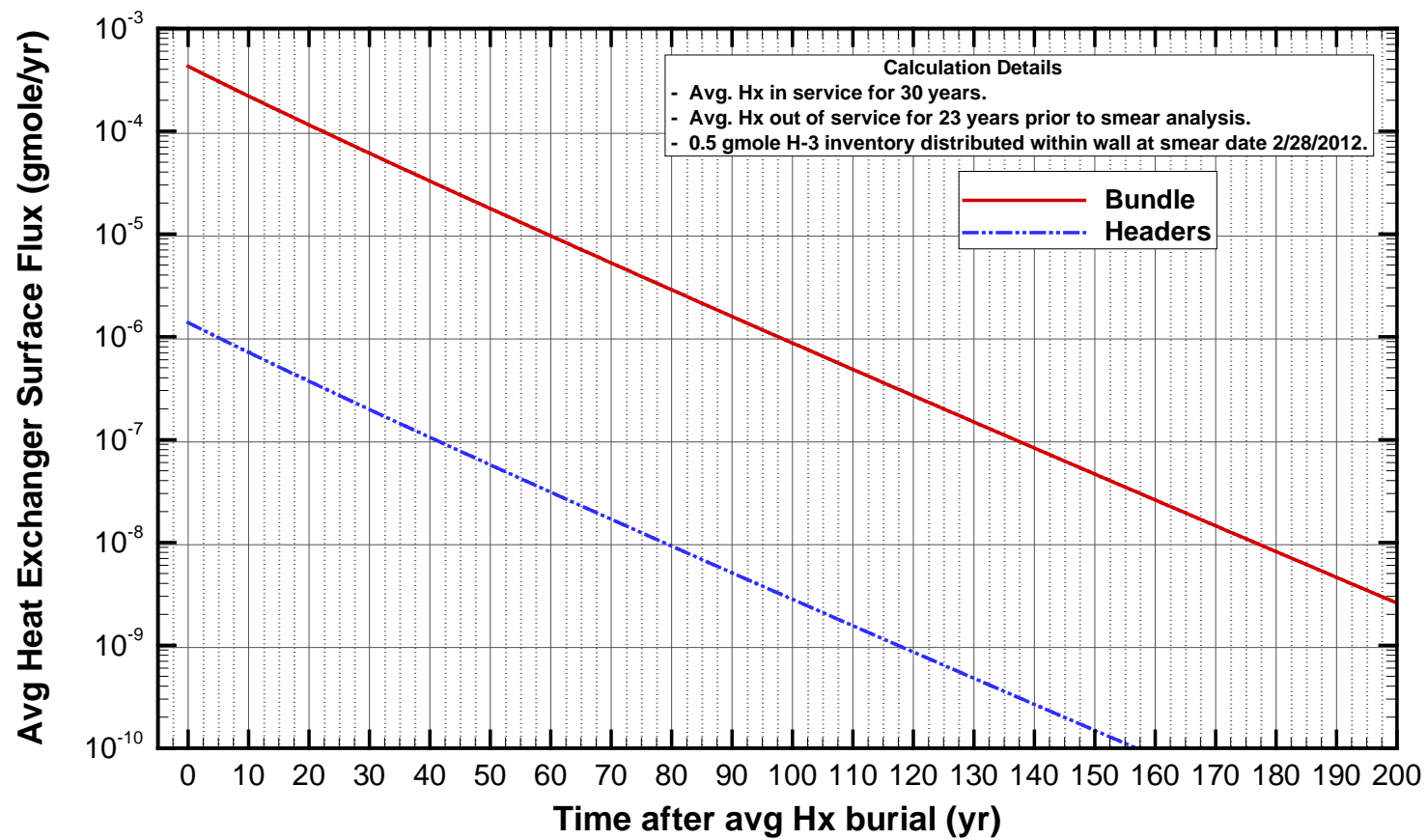

Figure A-6 Predicted tritium fluxes from HX tube bundle and headers as functions of time for the first $200 \mathrm{yr}$ following burial.

The diffusional process of tritium in 304 stainless steel is a very slow process where significant amounts of tritium will decay along its migration path into and ultimately out of a metal wall. The $50 \%$ allocation to the metal and $50 \%$ to its oxide layer was established by the inventory analyses presented by Walliser (2012). In Walliser (2012) an estimate was made as to the tritium content in the oxide layer and then based on safety factor arguments an equal amount of tritium was assumed to have migrated into the metal. Since diffusion of tritium out of this metal is slow, and tritium has a short half-life, the actual amount that may have migrated into the metal plays a minor role in setting the inventory limits presented in Chapter 6. The dominant release is by the corrosion mechanism as discussed in Appendix B. 


\section{Appendix B. Heat Exchanger Corrosion Source Term for H-3X and $\mathrm{C}-14 \mathrm{X}$}

The nineteen Savannah River Site reactor heat exchangers under consideration in this SA were in service on average for $30 \mathrm{yr}$ and out of service for about $23 \mathrm{yr}$ prior to being smeared for tritium and carbon-14. The tube side of each heat exchanger working fluid was heavy water and the shell side fluid was river water. Over the years of operation, oxide films developed in the 304L stainless steel metal comprising the heat exchanger tubes and headers.

Heavy water circulated through the SRS reactor core as primary coolant and moderator. During reactor operation, tritium and carbon-14 were released into the heavy water, and then diffused into the heat exchanger tubes and headers at their oxide layers during service. During operations tritium is present in the heavy water due to neutron absorption into the large amount of deuterium nuclides present, while the source of carbon-14 is primarily from the neutron absorption of $\mathrm{N}-14$ nuclides.

The tritium deposited in the $304 \mathrm{~L}$ stainless steel is assumed to be $50 \%$ bound, and immobile, in the oxide layer and $50 \%$ in the non-oxidized metal. The carbon-14 is assumed to reside completely within the oxide layer in each tube and header. This Appendix describes and models the release mechanism of tritium and carbon-14 from the oxide layer due to corrosion from contact with moist air and groundwater.

The best estimate and conservative estimate of the thickness of the oxide layer are assumed to be five microns and three microns, respectively. The initial inventory of tritium and carbon-14 in the oxide layers is set at $0.5 \mathrm{~g}$-mol and $1.0 \mathrm{~g}$-mol, respectively. The actual inventories, derived from smears of each heat exchanger, are then used to scale the modeled inventories in the aquifer transport simulations. Based on surface area, the heat exchanger tube bundle contains $99.679 \%$ of the respective inventories. The remaining $0.321 \%$ of the inventories reside in the heat exchanger headers. These surface fractions are assumed fixed in all nineteen heat exchangers.

The initial state of each heat exchanger is empty but in contact with moist air. As groundwater percolates into the buried heat exchanger, the heat exchanger is assumed to fill with water at a constant flow rate without any leakage. The best estimate and conservative estimate of the fill times are 20 and $10 \mathrm{yr}$, respectively. The basis for these minimum fill times is provided in Chapter 3. The heat exchanger is assumed to start filling with water at the time of burial, otherwise it is delayed for five years to account for a coating protecting the aluminum blind flanges from corrosion.

The best estimate and conservative estimate models for corrosion release of tritium and carbon-14 from the 304 stainless steel oxide layer utilizes two release mechanisms. The first mechanism models the instantaneous corrosion release of tritium and carbon-14 in contact with moist air and groundwater. The second mechanism stores the corrosion release of tritium and carbon-14 in contact with moist air until the water level reaches that section of the heat exchanger. The corrosion rates of 304L stainless steel in moist air and groundwater are provided in a calculation note by Estochen (2010) as 0.005 mils/yr and 0.04 mils/yr respectively. Table B-1 shows the best estimate (BE) and conservative estimate (CE) corrosion scenarios modeled. 
SRNL-STI-2012-00321

Revision 0

Table B-1. Best Estimate and Conservative Estimate Corrosion Scenarios

\begin{tabular}{|c|c|c|c|c|}
\hline Scenario & State & $\begin{array}{c}\text { Oxide } \\
\text { Thickness } \\
\text { (microns) }\end{array}$ & $\begin{array}{c}\text { Start of } \\
\text { Fill } \\
\mathbf{( y r )}\end{array}$ & $\begin{array}{c}\text { Duration of } \\
\text { Fill } \\
\text { (yr) }\end{array}$ \\
\hline \hline $3-00-10$ & DC_CE & 3 & 0 & 10 \\
\hline $3-05-10$ & DC_CE & 3 & 5 & 10 \\
\hline $5-00-20$ & DC_BE & 5 & 0 & 20 \\
\hline $5-05-20$ & DC_BE & 5 & 5 & 20 \\
\hline 3-00-10S & DC_CE_Storage & 3 & 0 & 10 \\
\hline $3-05-10 S$ & DC_CE_Storage & 3 & 5 & 10 \\
\hline 5-00-20S & DC_BE_Storage & 5 & 0 & 20 \\
\hline 5-05-20S & DC_BE_Storage & 5 & 5 & 20 \\
\hline
\end{tabular}

$\mathrm{BE}$ and $\mathrm{CE}$ are the best estimate and conservative estimate states, respectively, with instantaneous corrosion release. BE_Storage and CE_Storage are the best estimate and conservative estimate states, respectively, with the storage of corrosion products released in moist air. The last two scenarios were not incorporated in any of the vadose zone transport simulations

The reactor heat exchanger fill space was modeled as a series of equal volume layers because the flow rate of water into the heat exchanger was assumed to be constant. The number of layers was computed as the time to fill divided by the time step. The time step chosen was $0.005 \mathrm{yr}$. The initial concentration of the oxide layer is computed as the initial inventory divided by the oxide thickness and the number of layers. The units of concentration are g-mol/micron/layer. Because tritium and carbon-14 are non-conservative tracers, their respective radioactive decay must be incorporated. The transient concentration of the oxide layer in each volume layer is computed as: 
Figures B-1 and B-2 show the $\mathrm{H}-3 \mathrm{X}$ bundle and header source term flux, respectively, for the eight scenarios described in Table B-1. The solid lines represent instantaneous corrosion flux releases with and without storage in moist air. Scenarios 3-00-10 and 5-00-20 all have layers contributing to the source term from time zero. Their counterparts, scenarios 3-00-10S and 5-0020S, have corrosion flux releases only from wet layers which include storage. The dash-dotted lines are the scenarios with a five-year delay to start of fill. Two of the scenarios have all layers fluxing in moist air for the first five years, while the other two scenarios store the fluxes in moist air for five years. In all scenarios, the peak flux occurs at time:

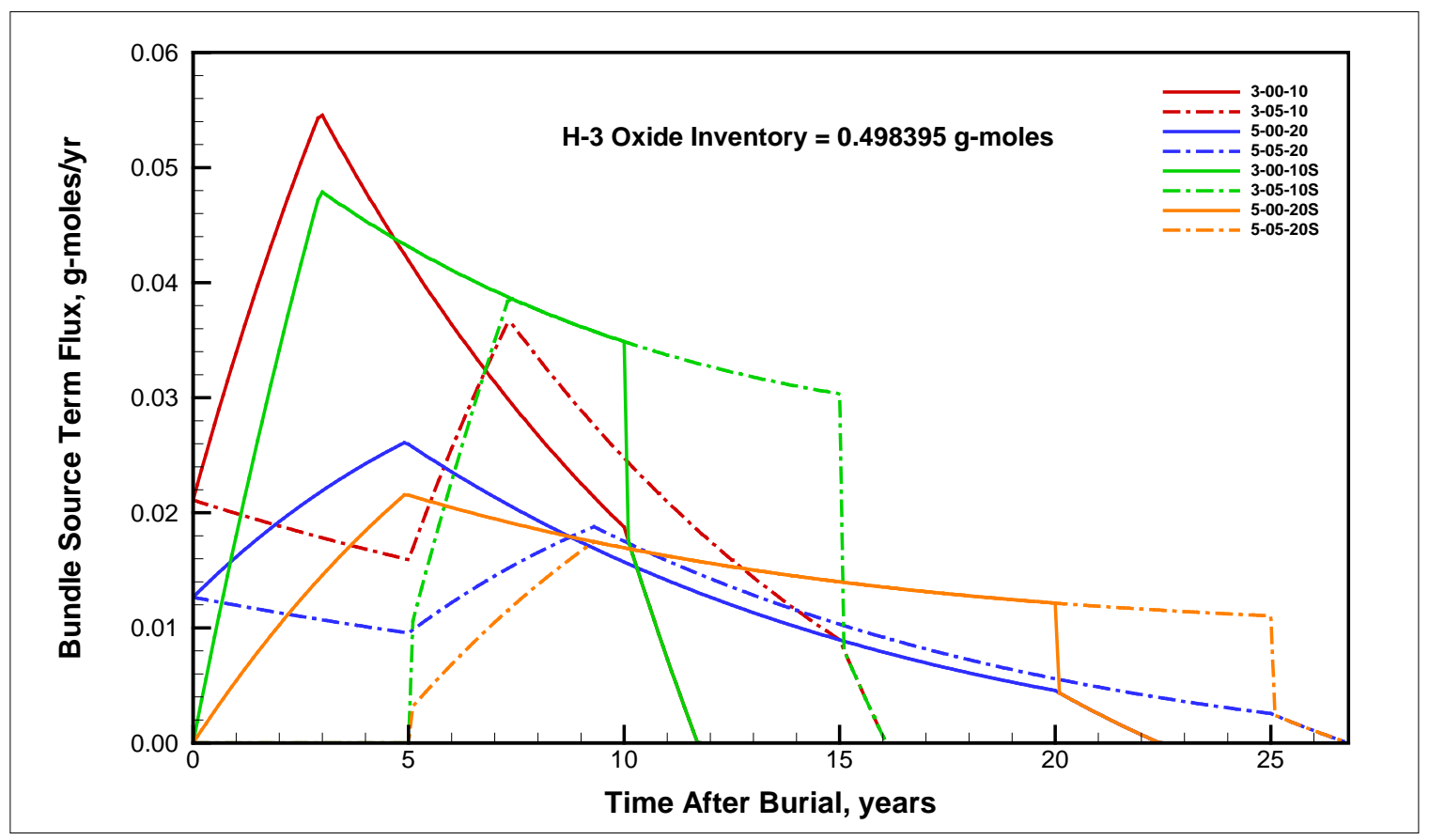


SRNL-STI-2012-00321

Revision 0

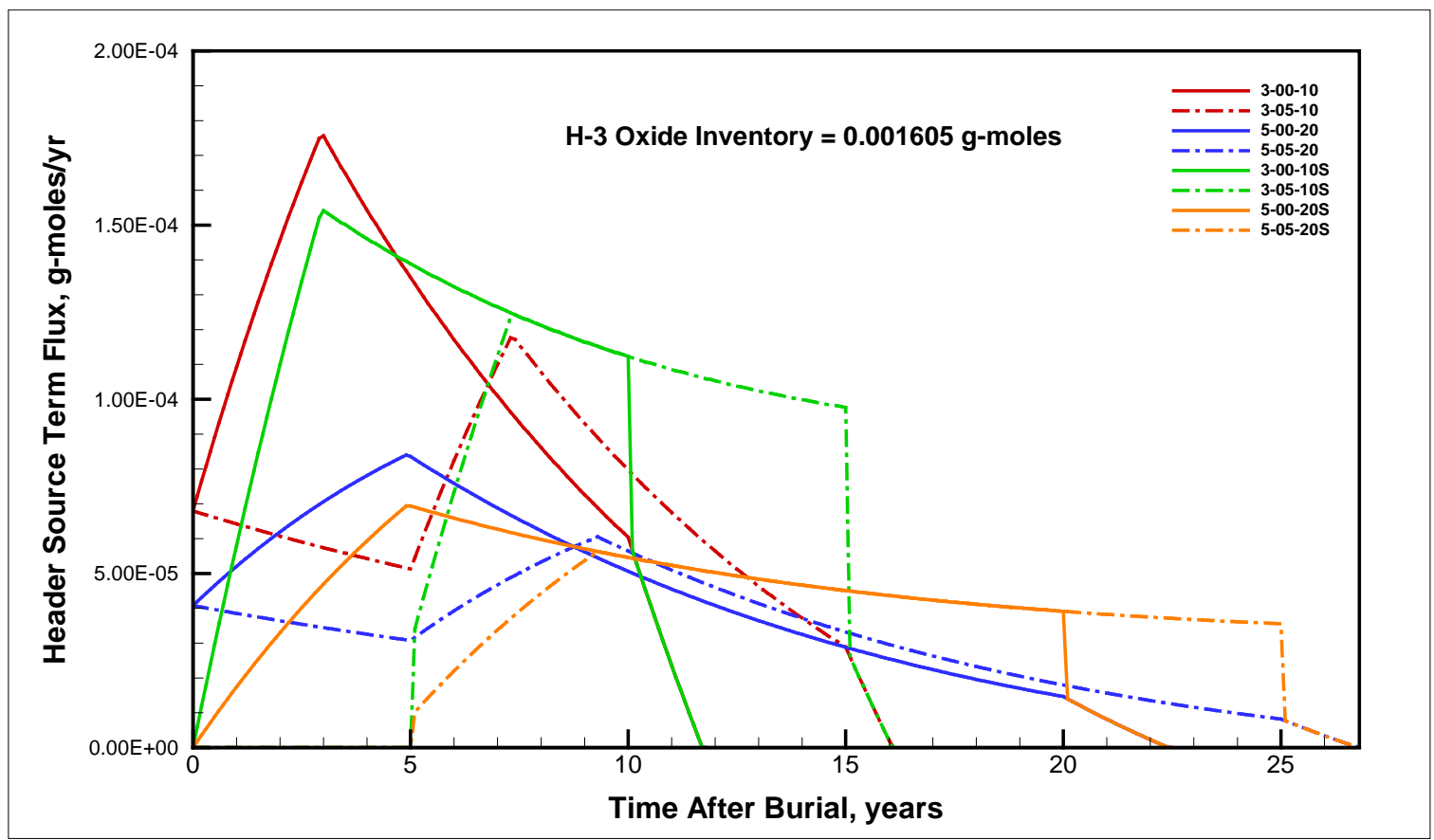

Figure B-2 H-3X Header Source Term Flux for Various Scenarios

Figures B-3 and B-4 show the C-14X bundle and header source term flux, respectively for the eight scenarios described in Table B-1. The C-14X source term fluxes show very similar shapes to those of H-3X but higher fluxes due to a higher initial inventory of C-14X. The scenarios with instantaneous corrosion flux releases with delayed time to start fill have constant fluxes for the first five years due to little radioactive decay occurring.

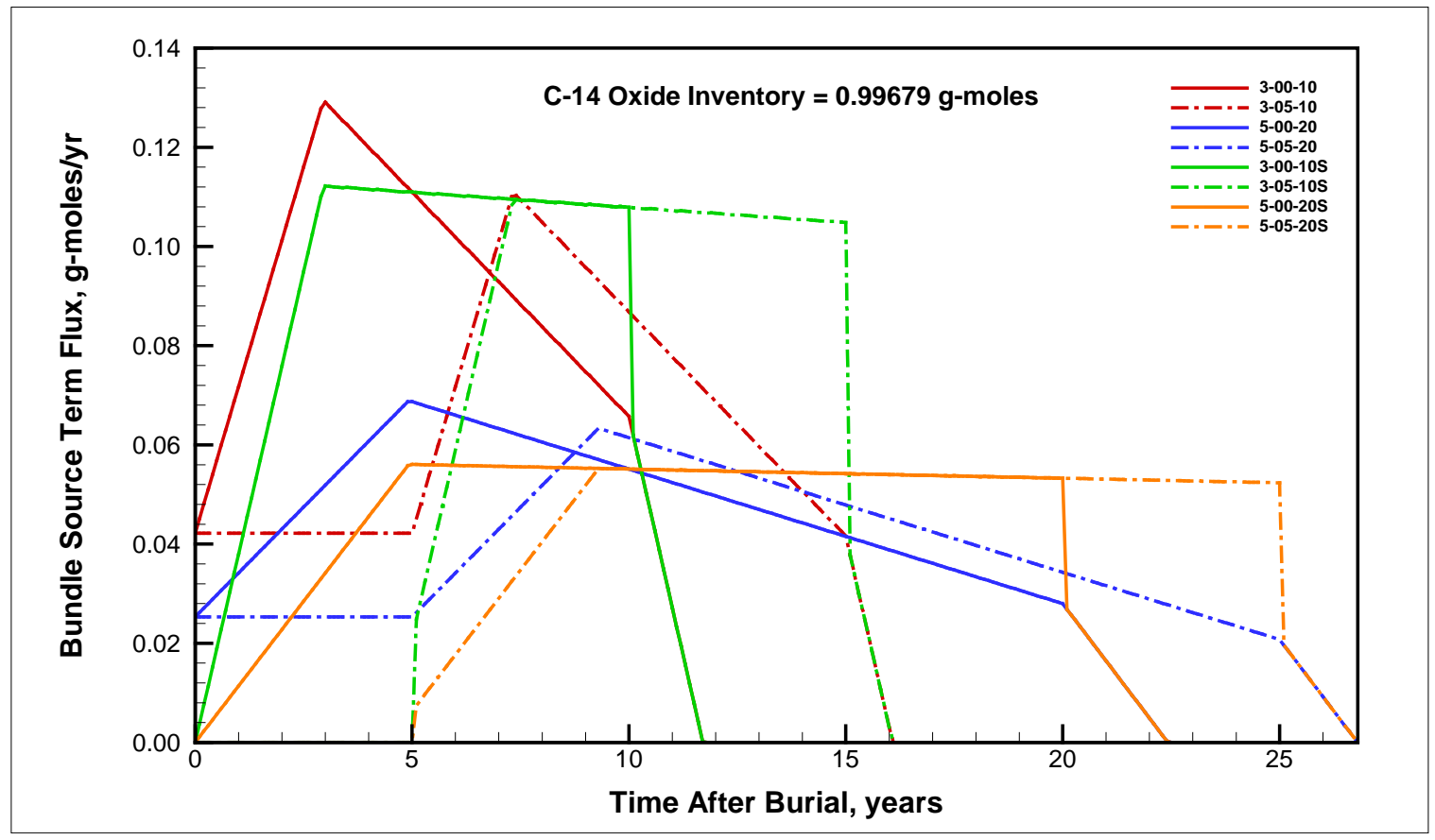

Figure B-3 C-14X Bundle Source Term Flux for Various Scenarios 
SRNL-STI-2012-00321

Revision 0

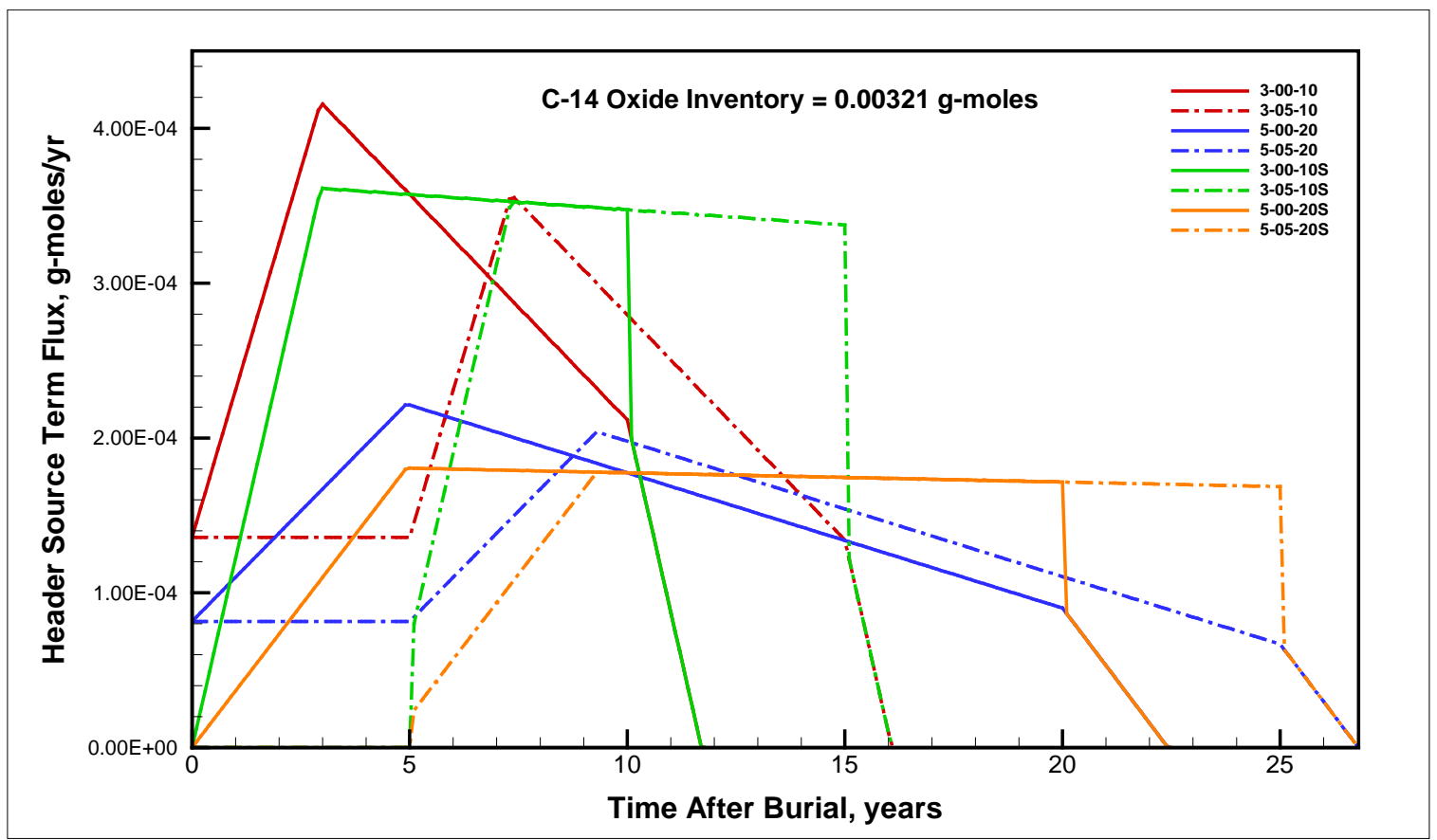

Figure B-4 C-14X Header Source Term Flux for Various Scenarios 


\section{Appendix C. Sealing and protecting mitigation activities}

\begin{tabular}{|c|c|}
\hline \multicolumn{2}{|c|}{ HEAT EXCHANGER FLANGE WORK PROCESS 5/09/12 - FINAL } \\
\hline Flange Category & Work Process \\
\hline Aluminum Blind Flanges & $\begin{array}{l}\text { - Remove adhesive film residue with light scraping and solvent or } \\
\text { adhesive remover (where applicable). } \\
\text { - Thoroughly clean aluminum surfaces that are to be coated (inhibited } \\
\text { alkaline cleaner or similar for aluminum surfaces). } \\
\text { - Roughen surfaces that are to be coated with } 7447 \text { grade or coarser } \\
\text { Scotch-Brite pads to the extent practicable (hand tools, wire brush or } \\
\text { other tools for surface roughening may also be used) } \\
\text { - Apply Macropoxy 920 Pre-Prime to prepared surfaces per } \\
\text { manufacturer instructions } \\
\text { - Apply } 2 \text { coats of Macropoxy 646 Fast Cure Epoxy (Mill White or } \\
\text { Black suitable for immersion) at 5-10 mils dry per coat per } \\
\text { manufacturer instructions. }\end{array}$ \\
\hline $\begin{array}{l}\text { Gaps Between Bolted Flanges } \\
\text { Containing a Gasket } \\
\text { Note: The gap between the raised- } \\
\text { face flanges (as shown in photo } \\
\text { below) is a normal condition that } \\
\text { exists between this type of flange } \\
\text { connection and does not imply a } \\
\text { failed or missing gasket. }\end{array}$ & $\begin{array}{l}\text { HEAT EXCHANGERS (Designated as Leakers) } \\
\text { - For flanges with gaskets on bottom or ends of Heat Exchanger - Use } \\
\text { Work Practices 3,4 } \\
\text { - For flanges with gaskets on top of Heat Exchanger - Use Work } \\
\text { Practices 1,2, and } 4 \\
\text { HEAT EXCHANGERS (Designated as NON-Leakers) } \\
\text { - For flanges with gaskets on bottom or top of Heat Exchanger - NO } \\
\text { WORK required (secondary side) } \\
\text { For Flanges with gaskets on ends of Heat Exchanger - Use Work } \\
\text { Practices 3,4 (primary side) }\end{array}$ \\
\hline Ee & $\begin{array}{l}\text { WORK PRACTICE } \\
\text { 1. Inspect bolted flange connections for gaps in gasket. If no } \\
\text { gaps are found. STOP } \\
\text { 2. If gaps in a gasket are found, seal the space between the } \\
\text { flanges with Sikaflex } 1 \mathrm{~A} \text {.(per instructions in SRNL email } \\
\text { dated 4/30/12). }\end{array}$ \\
\hline & $\begin{array}{l}\text { 3. Seal the space between the flanges with Sikaflex 1A.(per } \\
\text { instructions in SRNL email dated 4/30/12) }\end{array}$ \\
\hline & $\begin{array}{l}\text { 4. Apply pipeline tape such as Tapecoat H35 around flange } \\
\text { over Sikaflex (per instruction in SRNL email dated 4/30/12) }\end{array}$ \\
\hline Valves on Drain Ports & $\begin{array}{l}\text { - Valve handles will not be cut off } \\
\text { - Apply a water-activated polyurethane fiberglass wrap product such } \\
\text { as Syntho-Glass Fiberglass Composite (NRI Neptune Research), } \\
\text { Pipe Wrap, Pow-R-Wrap or similar around the valve, including the } \\
\text { valve handle. (per instructions in SRNL email dated 4/30/12) } \\
\text { - Wrap several layers with 50\% overlap as practical until the valve } \\
\text { body and stem/handle joint is completely covered. }\end{array}$ \\
\hline
\end{tabular}


SRNL-STI-2012-00321

Revision 0

\section{Appendix D. Unreviewed Disposal Question Evaluation}

\begin{tabular}{llr}
\hline \multirow{2}{*}{ Unreviewed Disposal Question (U) } & Procedure: & SW-ENG-0601 \\
& Revision: & 8 \\
& Page: & 7 of 12 \\
\hline
\end{tabular}

\section{ATTACHMENT 1}

Page 1 of 2

UNREVIEWED DISPOSAL QUESTION (UDQ) SCREENING CRITERIA

Proposed Activity: SLit Trench disposal of 19 Reactor Cooling Water Heat $E x$ changers with Tritium and Carbon-14 concentrations That exceed current Trench disposal linits.

REVIEW the following questions against the Proposed Activity:
1. Yes
No $\square$
N/A

Does the proposed disposal activity or new information involve a change to the disposal facility from what has been previously described or analyzed in the most recent Performance Assessment, Composite Analysis, approved Special Analyses, or approved UDQ Evaluations?
2. Yes
No $X$
N/A

Does the proposed disposal activity or new information involve a change to the disposal process or procedures from what has been previously described or analyzed in the most recent Performance Assessment, Composite Analysis, approved Special Analyses, or approved UDQ Evaluations?

\section{* 3. Yes $\bigotimes$ No $\square$ N/A}

Does the proposed disposal activity or new information involve a change to the radionuclide disposal limits from what has been previously described or analyzed in the most recent Performance Assessment, Composite Analysis, approved Special Analyses, or approved UDQ Evaluations?

4. Yes $\square$ No $X$ N/A

Does the proposed disposal activity or new information involve a change to the Waste Acceptance Criteria from what has been previously described or analyzed in the most recent Performance Assessment, Composite Analysis, approved Special Analyses, or approved UDQ Evaluations?

5. Yes $\square$ No $\square$ N/A

Does the proposed disposal activity or new information involve a change to what has been previously described or analyzed in the PA / Composite Analysis Inputs and Assumptions (I\&A) Database? 
SRNL-STI-2012-00321

Revision 0

\begin{tabular}{llr}
\hline & Procedure: & SW-ENG-0601 \\
Unreviewed Disposal Question (U) & Revision: & 8 \\
& Page: & 8 of 12 \\
\hline
\end{tabular}

ATTACHMENT 1

Page 2 of 2

UNREVIEWED DISPOSAL QUESTION (UDQ) SCREENING CRITERIA

6. Yes $\square$ No $\square$ N/A

Does the proposed disposal activity or new information involve a change to the facility closure design or criteria from what has been previously described or analyzed in the most recent Performance Assessment, Composite Analysis, approved Special Analyses, approved UDQ Evaluations or associated Closure Plan?

7. Yes $\square \quad$ No $\square \quad$ N/A

Does the proposed disposal activity or new information involve a test or experiment not described or analyzed in the most recent Performance Assessment, Composite Analysis, approved Special Analyses, approved UDQ Evaluations or associated Closure Plan?

8. Yes $\square$ No $\square$ N/A

Does the proposed disposal activity or new information involve any analytical errors, omissions or deficiencies in the most recent Performance Assessment, Composite Analysis, approved Special Analyses, approved UDQ Evaluations or associated Closure Plan?

If all questions above are answered "No" or "N/A" (defined by a in the box provided), then implement Proposed Activity in Performance Assessment space. If any of the questions above answered "Yes" (defined by a $\boldsymbol{\nu}$ in the box provided), then forward to SRNL for development of an UDQ Evaluation or Special Analysis.

Provide Explanation / Justification for all "Yes" answers: A Performanes Assessment Speclal Analysis will be necessary
To analyze This special waste form and develop increased
Tritium and carbon 14 disposal Limits.

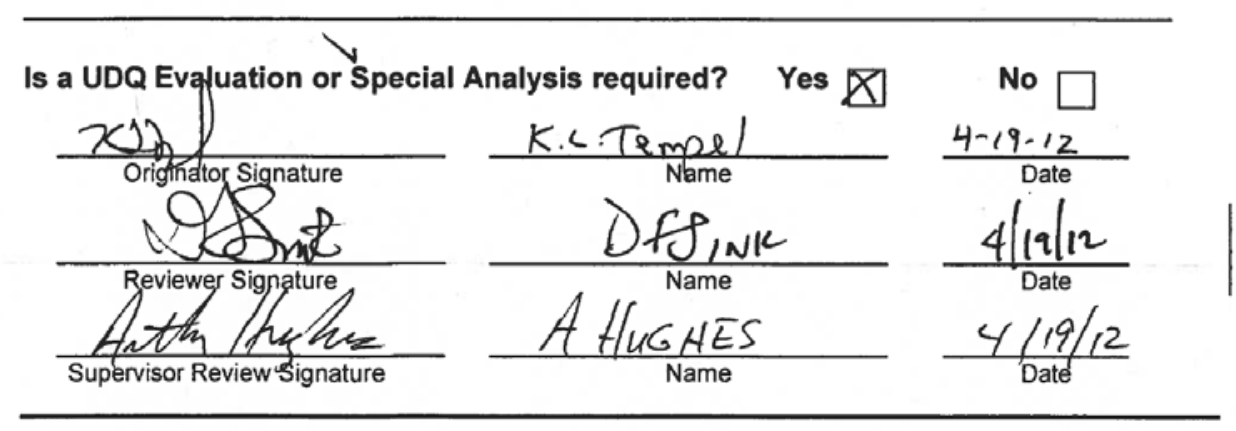




\section{Distribution:}

S. E. Aleman, 735-A

R. S. Aylward, 773-42A

L. A. Bagwell, 773-42A

C. L. Bergren, 730-4B

H. H. Burns, 773-41A

B. T. Butcher, 773-43A

L. B. Collard, 773-43A

D. A. Crowley, 773-43A

G. P. Flach, 773-42A

F. L. Fox, 704-59E

G. L. Friday, Jr., 730-4B

J. C. Gilmour, 704-59E

M.B. Gorensek, 703-41A

J. C. Griffin, 773-A

L. L. Hamm,703-41A

S. J. Hensel, 703-41A

R. A. Hiergesell, 773-43A

A. R. Hughes, 704-56E

G. K. Humphries, 730-4B

J. M. Jordan, 703-41A

T. F. Kmetz, 730-4B

M. A. Kokovich, 704-60E

K. M. Kostelnik, 730-4B

D. I. Kaplan, 773-43A

D. Li, 773-43A

A. L. Lioi, 703-H

T. J. Long, 730-4B

M. G. Looper, 704-36E

M. R. Millings, 773-42A

P. Molnar, 730-4B

P. A. Northington, 730-4B

T. O. Oliver, 773-42A

M. A. Phifer, 773-42A

K. A. Roberts, 773-43A

R. R. Seitz, 773-43A

D. F. Sink, 704-56E

F. G. Smith, 703-41A

R. F. Swingle, 773-43A

G. A. Taylor, 773-43A

K. L. Tempel, 704-56E

C. Wilson (1 file copy and 1 electronic copy), 773-43A - Rm. 213 